$$
\text { UNIVERSIDADE DE SÃO PAULO }
$$

FACULDADE DE ECONOMIA, ADMINISTRAÇÃO E CONTABILIDADE DEPARTAMENTO DE ADMINISTRAÇÃO PROGRAMA DE PÓS-GRADUAÇÃO EM ADMINISTRAÇÃo

CURSO DE MESTRADO EM ADMINISTRAÇÃO

\author{
MARCELO NOTOMI KANAZAWA
}

\title{
AVALIAÇÃO DE EMPRESAS POR MÚLTIPLOS APLICADO AO MERCADO BRASILEIRO
}

Orientadora: Prof. . . Dr. a Alessandra de Ávila Montini Orientando: Marcelo Notomi Kanazawa

São Paulo

2019 
Prof. Dr. Vahan Agopyan

Reitor da Universidade de São Paulo

Prof. Dr. Adalberto Américo Fischmann

Diretor da Faculdade de Economia, Administração e Contabilidade

Prof. Dr. Moacir de Miranda Oliveira Júnior

Chefe do Departamento de Administração

Prof. Dr. Eduardo Kazuo Kayo

Coordenador do Programa de Pós-Graduação em Administração 


\title{
AVALIAÇÃO DE EMPRESAS POR MÚLTIPLOS APLICADO AO MERCADO BRASILEIRO
}

\begin{abstract}
Dissertação apresentada ao Programa de Pós Graduação em Administração do Departamento de Administração da Faculdade de Economia, Administração e Contabilidade da Universidade de São Paulo como requisito parcial para a obtenção do título de Mestre em Ciências.
\end{abstract}

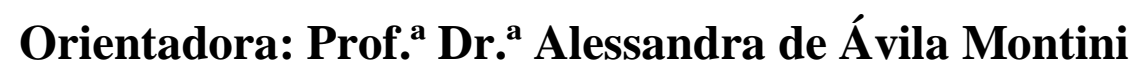

Versão Corrigida

SÃO PAULO

2019 
Catalogação na Publicação (CIP)

Ficha Catalográfica com dados inseridos pelo autor

Kanazawa, Marcelo.

AVALIAÇÃO DE EMPRESAS POR MÚLTIPLOS APLICADO AO

MERCADO BRASILEIRO / Marcelo Kanazawa. - São Paulo, 2019.

$115 \mathrm{p}$.

Dissertação (Mestrado) - Universidade de São Paulo, 2019.

Orientador: Alessandra de Ávila Montini.

1. Avaliação de empresas. 2. Avaliação por múltiplos. 3. Avaliação relativa. 4. Determinantes dos múltiplos. I. Universidade de São Paulo. Faculdade de Economia, Administração e Contabilidade. II. Título. 


\section{AGRADECIMENTOS}

Agradeço aos meus pais, que sempre me apoiam e foram essenciais para a concretização desta etapa.

À Professora Dr. ${ }^{a}$ Alessandra Ávila Montini, pela dedicação em me orientar, por me transmitir a paixão por ensinar, e pelos crescimentos pessoal e profissional proporcionados. À Professora Dr. ${ }^{a}$ Liliam Sanchez Carrete, por ter participado da banca de qualificação, apresentando importantes comentários e direcionado o andamento da presente pesquisa.

Sou muito grato às pessoas que trabalham comigo, à minha superintendente Selma Lima, e ao meu gerente Fernando Lanci pela confiança e suporte fundamentais desde o início da jornada do Mestrado.

Aos professores da FEA pelo nível de excelência e que, surpreendentemente, sempre superaram minhas expectativas. Aos amigos da FEA que tive a oportunidade de conhecer, pelo aprendizado e apoio. E, de forma geral, ao espírito de cooperação que presenciei entre os alunos e professores da USP pois, apesar da limitação de tempo, sempre que solicitados encontraram uma maneira para escutar as minhas dúvidas e me darem algum valioso comentário.

Por fim, aos amigos que me acompanharam e incentivaram nesta caminhada, sabendo da importância dessa etapa na minha vida. 



\section{RESUMO}

O objeto deste estudo é a metodologia de avaliação de empresas conhecida como avaliação relativa ou por múltiplos, com os objetivos de identificar: quais características melhor explicam as diferenças do preço relativo das empresas listadas na bolsa de valores brasileira; e quais modelos estimados apresentam melhores resultados. A pesquisa contribui para uma melhor compreensão da metodologia de avaliação de empresas por múltiplos, agregando maior grau de confiabilidade na utilização da técnica. A forma tradicional de estimação de valor de empresas por múltiplos utiliza uma média dos valores dos múltiplos das empresas consideradas comparáveis, sendo estas selecionadas com base em características semelhantes da empresa em avaliação. Na presente pesquisa ao aplicar a técnica de regressão linear múltipla é realizada uma forma de controle das diferenças das empresas, uma vez que a natureza das empresas envolve muitas especificidades e que sempre existirá algum grau de diferença entre as mesmas. Assim, com os modelos estimados é possível precificar os múltiplos de forma mais confiável, ao ponderar os impactos das características das empresas. A análise foi realizada de 2015 a 2018 e foram identificadas, para os múltiplos de valor de mercado P/L (preço sobre lucro) e P/PLC (preço sobre patrimônio líquido contábil), as variáveis explicativas: crescimento; taxa de distribuição de dividendos; risco; e rentabilidade. Para os múltiplos de valor de empresa EV/EBITDA (valor da empresa sobre EBITDA), EV/IC (valor da empresa sobre capital investido) e EV/Receita (valor da empresa sobre receita), foram identificadas as variáveis explicativas: crescimento; taxa de reinvestimento; risco; rentabilidade; taxa de tributação; e margem operacional. As variáveis determinantes dos múltiplos ou explicativas foram extraídas do modelo de Fluxo de Caixa Descontado e das variáveis de padronização utilizadas (lucro, EBITDA, patrimônio líquido contábil, capital investido e receita). Os modelos estimados para o múltiplo $\ln (\mathrm{EV} /$ Receita) foram os que apresentaram melhor resultado. Os modelos estimados para múltiplos de lucro estão em segundo lugar - na comparação entre os mesmos, o múltiplo $\ln (\mathrm{P} / \mathrm{L})$ apresenta maiores $\mathrm{R}^{2}$, enquanto os modelos estimados para o múltiplo $\ln (\mathrm{EV} / \mathrm{EBITDA})$ melhor satisfazem as suposições da regressão linear múltipla. Os modelos estimados para os múltiplos de patrimônio contábil foram os que apresentaram piores resultados.

Palavras-chave: Avaliação de empresas. Avaliação por múltiplos. Avaliação relativa. Determinantes dos múltiplos. 


\begin{abstract}
The object of this study is the company valuation methodology known as relative valuation or multiples valuation, in order to identify: which characteristics best explain the differences in the relative price of companies listed on the Brazilian stock exchange; and which estimated models have the best results. The research contributes to a better understanding of the methodology of valuation of companies by multiples, adding greater degree of reliability in the use of the technique. The traditional way of estimating company value by multiples uses an average of the values of multiples of companies considered comparable, which are selected based on similar characteristics of the company under evaluation. In the present research, applying the multiple linear regression technique, a form of controlling the differences of the companies is performed, since the nature of the companies involves many specificities and that there will always be some degree of difference between them. Thus, with the estimated models, it is possible to price the multiples more reliably by weighing the impacts of business characteristics. The analysis was performed from 2015 to 2018 and the explanatory variables were identified for the market value multiples P/L (price on profit) and P/PLC (price on book equity) are: growth; dividend distribution rate; risk; and profitability. For the EV/EBITDA (company value over EBITDA), EV/IC (company value over invested capital) and EV/Revenue (company value over revenue) multiples, the following explanatory variables were identified: growth; reinvestment rate; risk; profitability; tax rate; and operating margin. The determinants of the multiples or explanatory variables were extracted from the Discounted Cash Flow model and the standardization variables used (profit, EBITDA, book value, invested capital and revenue). The estimated models for the multiple $\ln (\mathrm{EV} / \mathrm{Revenue})$ presented the best results. Estimated models for profit multiples are in second place - when comparing them, the $\ln (\mathrm{P} / \mathrm{L})$ multiple has higher $\mathrm{R}^{2}$, while the estimated $\ln (\mathrm{EV} / \mathrm{EBITDA})$ best fits the assumptions of multiple linear regression. The estimated models for the accounting equity multiples showed the worst results.
\end{abstract}

Keywords: Valuation. Multiple valuation. Relative valuation. Value Drivers. 


\section{LISTA DE FIGURAS}

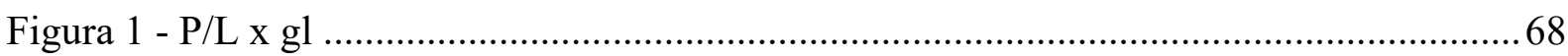

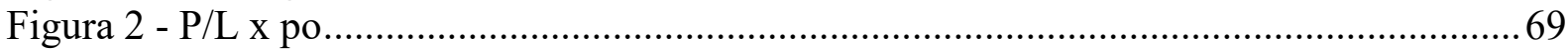

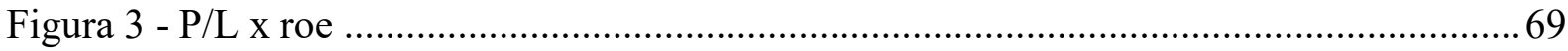

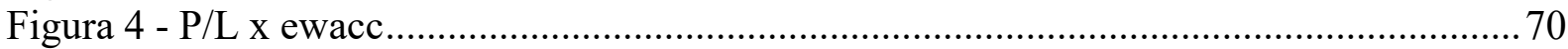

Figura 5 - P/PLC x roe

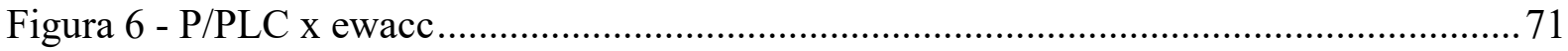

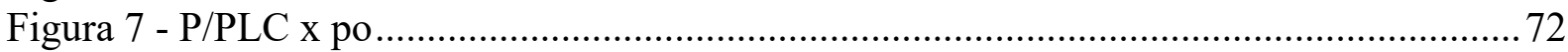

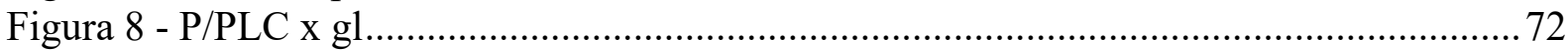

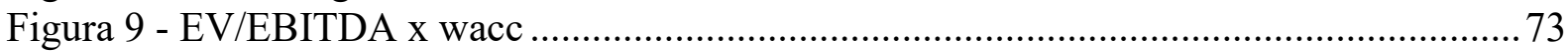

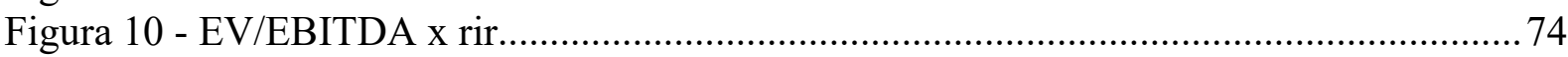

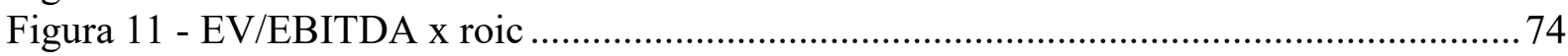

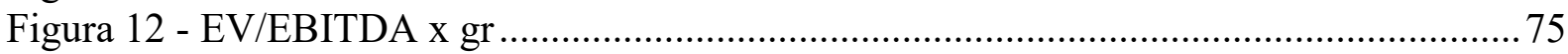

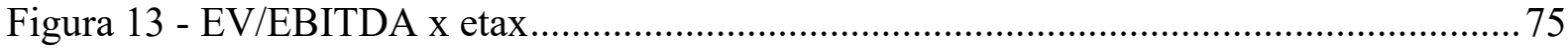

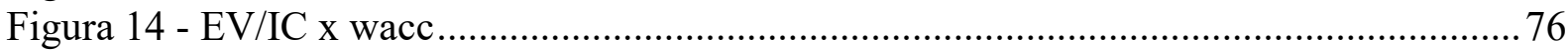

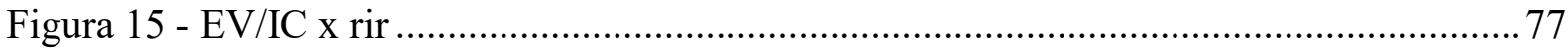

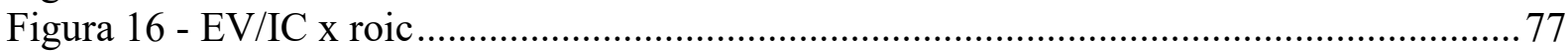

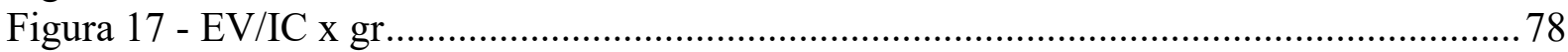

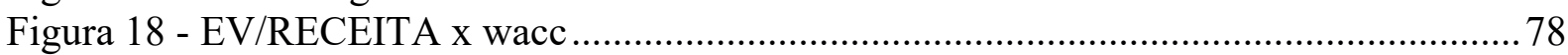

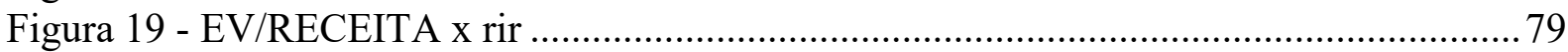

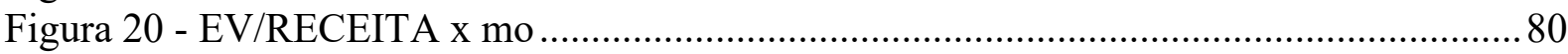

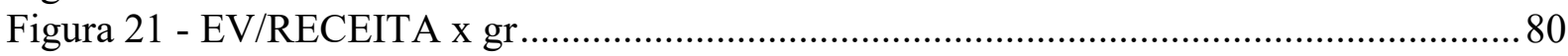

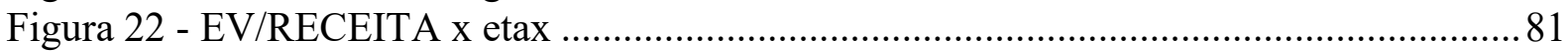

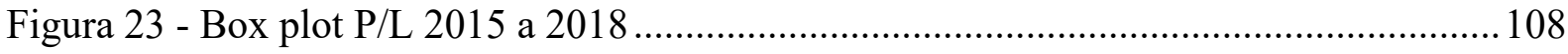

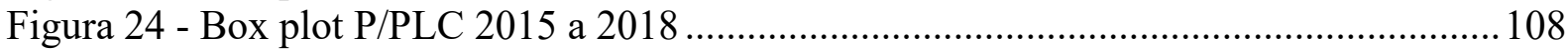

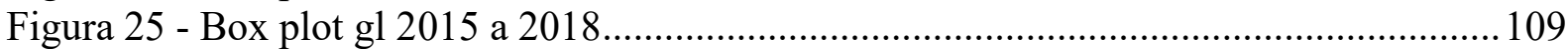

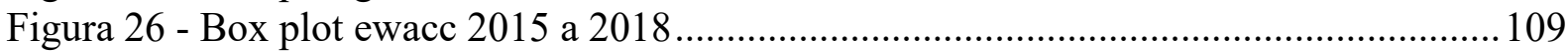

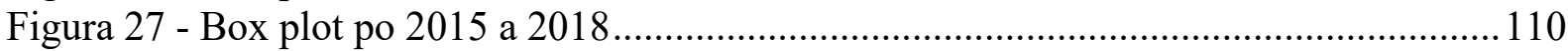

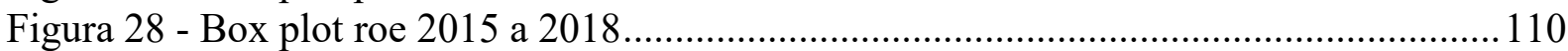

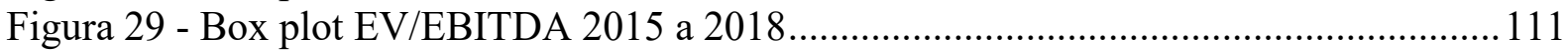

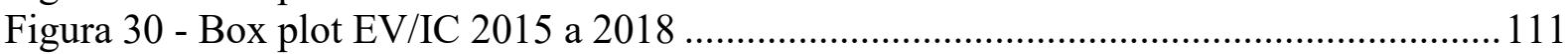

Figura 31 - Box plot EV/Receita 2015 a 2018 ............................................................. 112

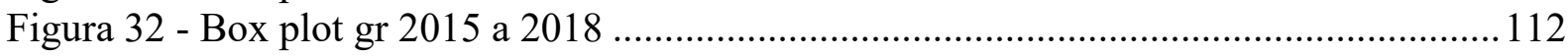

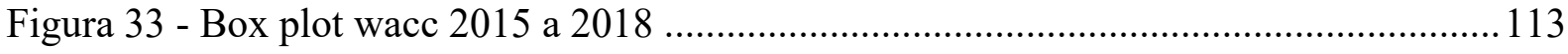

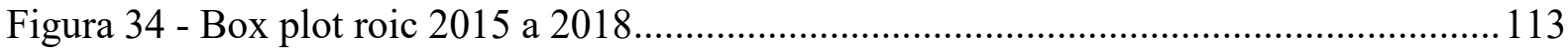

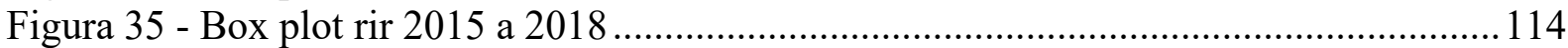

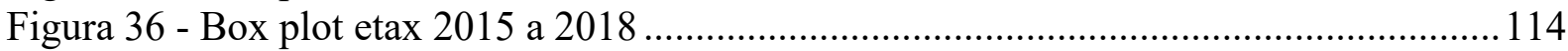

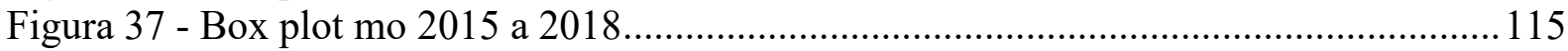





\section{LISTA DE TABELAS}

Tabela 1 - Resultados apresentados em pesquisas utilizando países emergentes.....................39

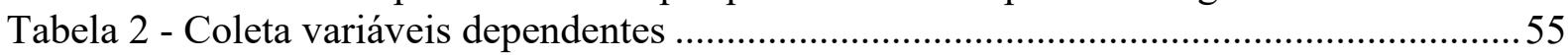

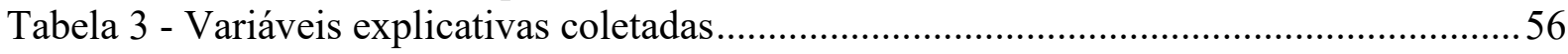

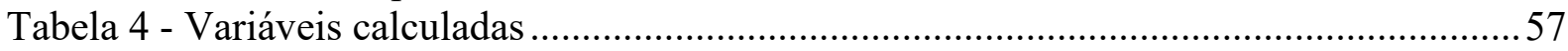

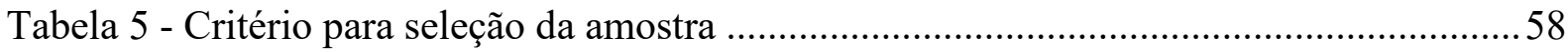

Tabela 6 - Quantidade múltiplo de valor de mercado por ano ............................................58

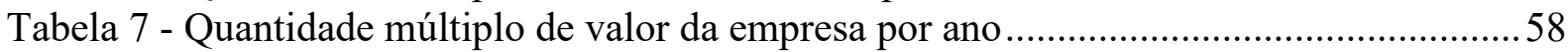

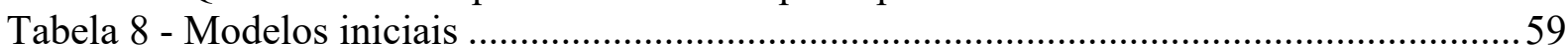

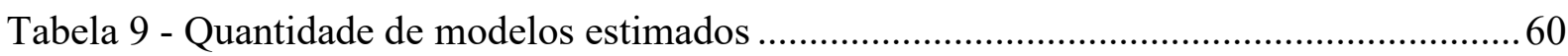

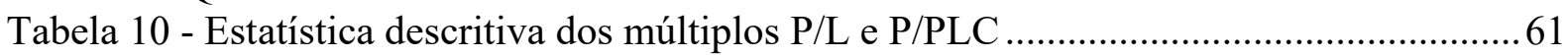

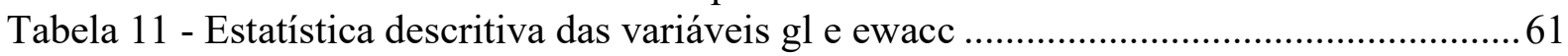

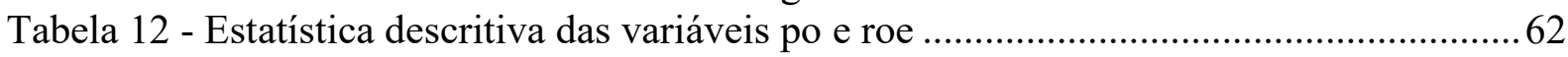

Tabela 13 - Estatística descritiva dos múltiplos EV/Ebitda, EV/IC e EV/Receita....................62

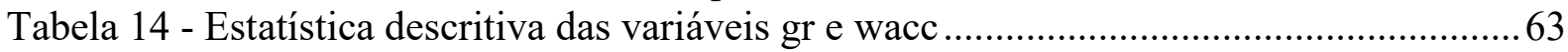

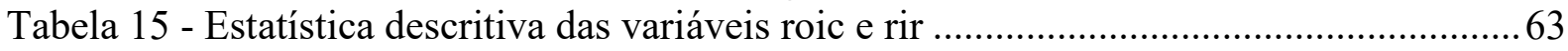

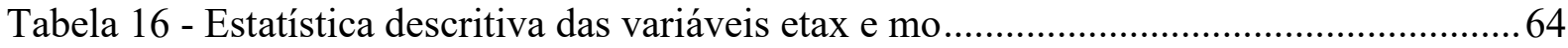

Tabela 17 - Correlação múltiplos de valor de mercado x variáveis explicativas (2015)..........64

Tabela 18 - Correlação múltiplos de valor de mercado x variáveis explicativas (2016)..........64 64

Tabela 19 - Correlação múltiplos de valor de mercado x variáveis explicativas (2017)..........65

Tabela 20 - Correlação múltiplos de valor de mercado x variáveis explicativas (2018)..........65

Tabela 21 - Correlação múltiplos de valor da empresa x variáveis explicativas (2015) ..........66

Tabela 22 - Correlação múltiplos de valor da empresa x variáveis explicativas (2016) ..........66

Tabela 23 - Correlação múltiplos de valor da empresa x variáveis explicativas (2017) ..........66

Tabela 24 - Correlação múltiplos de valor da empresa x variáveis explicativas (2018) ..........67

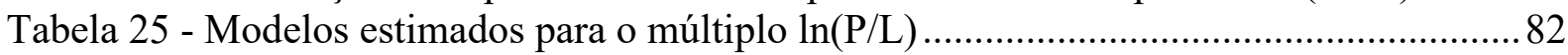

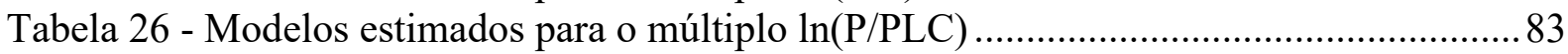

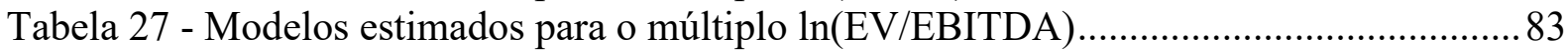

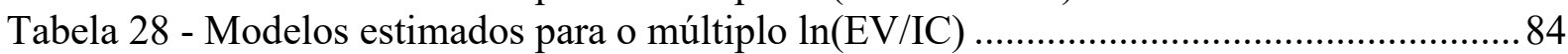

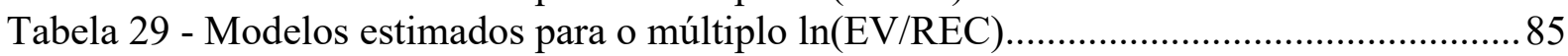





\section{SUMÁRIO}

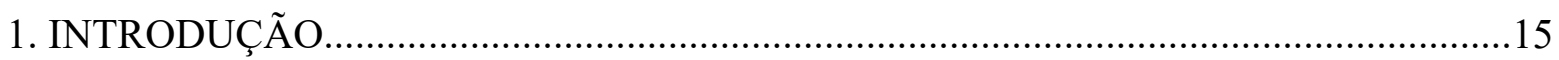

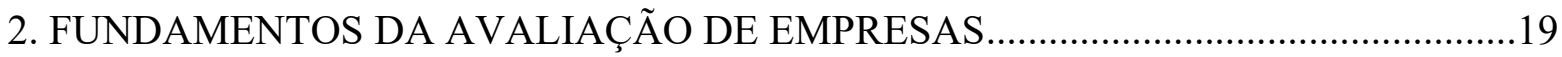

2.1 Metodologias de Avaliação de Empresas............................................................19

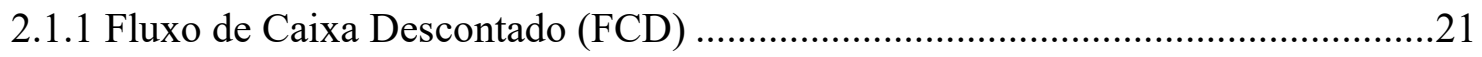

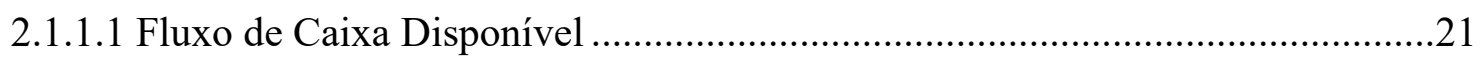

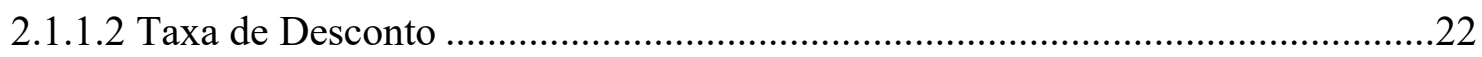

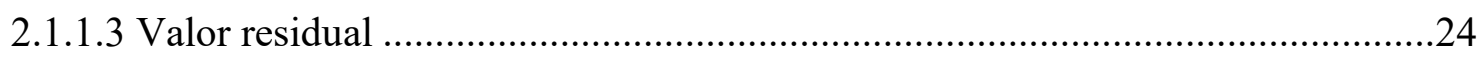

2.1.1.4 Valor Presente dos Fluxos de caixas descontados..........................................24

2.1.1.5 Vantagens e desvantagens da metodologia .......................................................25

2.1.2 Avaliação Relativa ou Avaliação de Múltiplos .......................................................25

2.1.2.1 Aplicação da técnica da Avaliação Relativa.......................................................26

2.1.2.2. Múltiplos de valor de mercado e múltiplos de valor da empresa ......................27

2.1.2.3 Pontos de atenção para correta utilização da avaliação relativa ........................29

2.1.2.3.1 Consistência e Uniformidade.....................................................................29

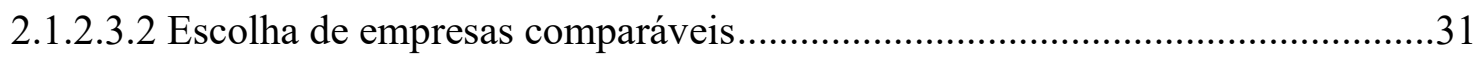

2.1.2.3.3.1 Controle das diferenças entre empresas.......................................................34

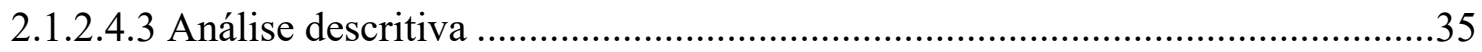

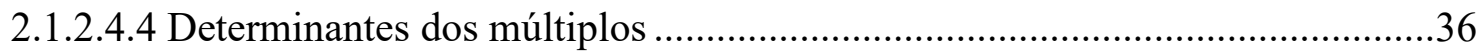

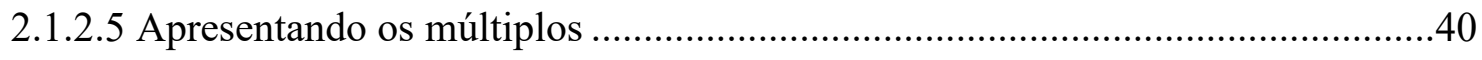

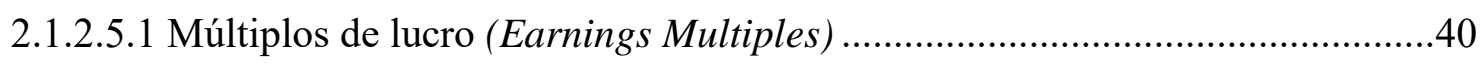

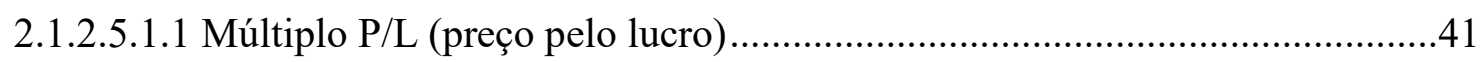

2.1.2.5.1.1.1 Variáveis explicativas do múltiplo $\mathrm{P} / \mathrm{L}$....................................................42

2.1.2.5.1.2 Múltiplo EV/EBITDA (valor da empresa pelo EBITDA)............................43

2.1.2.5.1.2.1 Variáveis explicativas do múltiplo EV/EBITDA .......................................44

2.1.2.5.2 Múltiplos de Patrimônio Contábil (Book value Múltiples).............................45

2.1.2.5.2.1 Múltiplo P/PLC (preço pelo patrimônio líquido contábil) ...........................45

2.1.2.5.2.1.1 Variáveis explicativas do múltiplo P/PLC ..............................................46

2.1.2.5.2.2 Múltiplo EV/IC (valor da empresa pelo capital investido) ..........................47

2.1.2.5.2.2.1 Variáveis explicativas do múltiplo EV/IC (investimento de capital) ........47

2.1.2.5.3 Múltiplo de receita.......................................................................................49

2.1.2.5.3.1 Variáveis explicativas do múltiplo EV/Receita........................................49

2.1.2.5.4 Múltiplos específicos/setoriais ..............................................................50

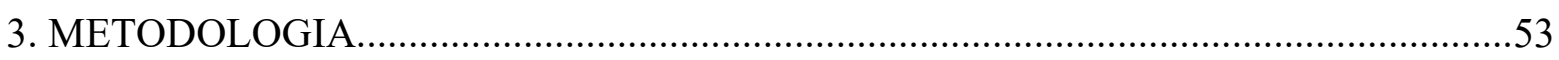

3.1 Modelos de Regressão Linear Múltipla............................................................53

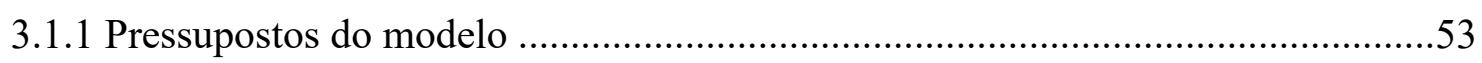




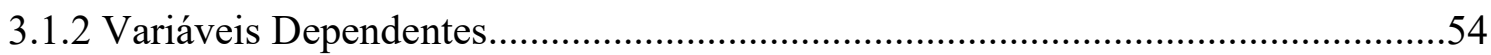

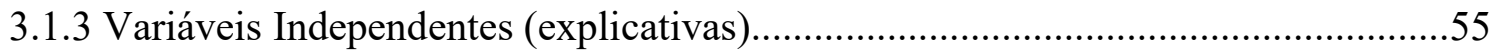

3.2 Base de dados e modo de coleta das variáveis.....................................................55

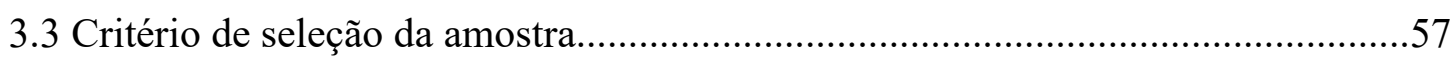

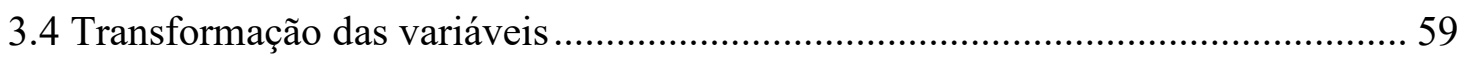

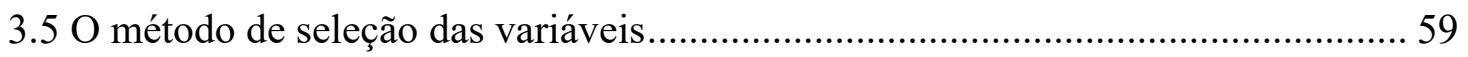

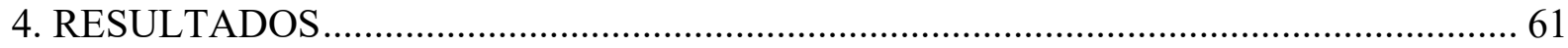

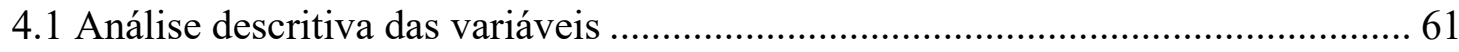

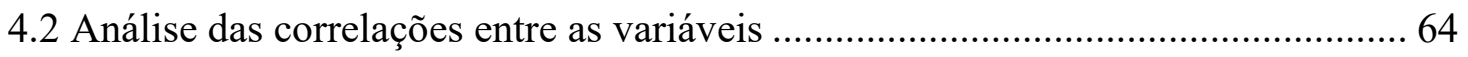

4.3 Análise da relação entre as variáveis dependentes e as independentes ................... 68

4.4 Apresentação dos modelos estimados ............................................................... 81

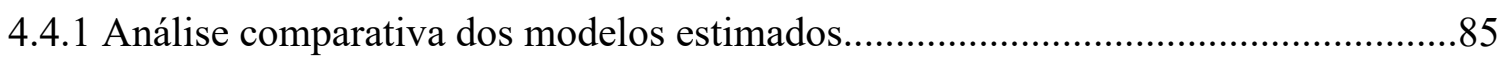

4.4.2 Análise comparativa entre as pesquisas realizadas em países emergentes..............87

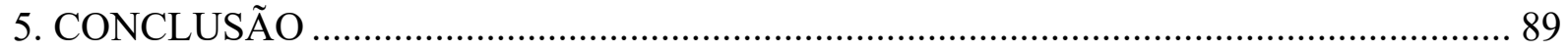

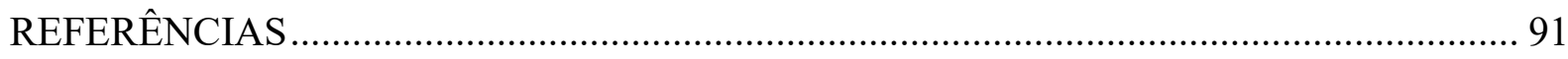

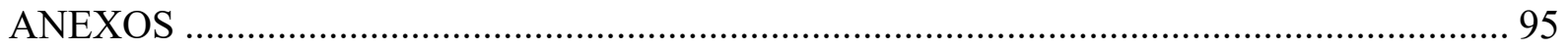

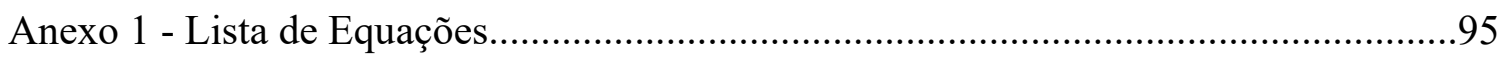

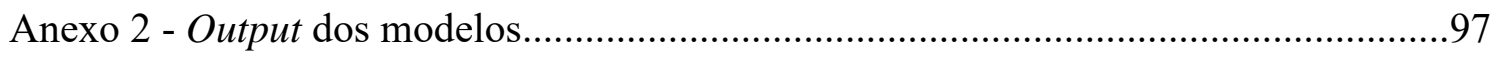

Anexo 3 - Box plot das variáveis dependentes e explicativas......................................108 


\section{INTRODUÇÃO}

A avaliação de empresas é utilizada para uma gama de tarefas, sendo essencial para abordar questões relacionadas à análise de compra e venda; às reestruturações societárias, como fusões e desinvestimentos (Maniar, 2014); à gestão de carteiras; para tratar de aspectos legais e tributários e, segundo Costa, Costa \& Alvim (2011), para fins de planejamento e gestão.

Segundo Assaf (2017), foi especialmente durante a década de 1980 que o tema da valoração de empresas e criação de valor começou a ter relevância em território nacional, devido à abertura econômica e às privatizações enraizando, nas mesmas, a importância do aspecto econômico para justificarem sua existência. Uma vez que o valor de uma empresa é reflexo do resultado das decisões financeiras, de suas estratégias e futuras oportunidades de crescimento, as metodologias de avaliação são empregadas para a mensuração do valor e a criação de valor desses ativos.

De acordo com Damodaran (2007), em termos gerais, há três abordagens principais de avaliação de empresas: Fluxo de Caixa Descontado (FCD); Avaliação Relativa; e Avaliação por Direitos Contingentes. Costa et al. (2011) citam outros métodos, como: Avaliação Patrimonial; e Avaliação pelo Lucro Econômico. As duas primeiras são as mais comumente utilizadas (Heveadi, 1999; Gupta, 2018), e a diferença entre as mesmas é que, enquanto o Fluxo de Caixa Descontado busca estimar o valor intrínseco da empresa, fundamentado pela geração futura de fluxos de caixas, a segunda busca avaliar a empresa com base no preço de similares negociadas no mercado (Damodaran, 2006), tendo como premissa que o mercado avalia corretamente as empresas.

Assim, a avaliação relativa, também conhecida como avaliação por múltiplos ou por pares, reflete a percepção do mercado pois, além de fornecer indicação do valor da empresa em análise, auxilia a identificar se o preço da empresa em avaliação está superavaliado ou subavaliado (Goh, Rasli, Dziekonski \& Khan, 2015). Se, por um lado, o analista perde os benefícios de uma análise mais completa e complexa, proporcionada pelo método do FDC, por outro há a conveniência de obter uma avaliação com resultados satisfatórios sem incorrer em grandes esforços em termos de custos e tempo (Bhojraj \& Lee, 2002). Além disso, é possível avaliar mais de uma empresa ao mesmo tempo e, nesse sentido, sua popularidade é atribuída à simplicidade, se comparada a outros métodos (Dittmann \&Weiner 2005). 
Conforme Alford (1992), a técnica de avaliação por múltiplos é utilizada extensivamente no mercado, e até mesmo defensores do método do Fluxo de Caixa Descontado frequentemente recorrem a empresas comparáveis para estimar o valor terminal (Bhojraj et al. 2002) o que, segundo Damodaran (2007) seria, em essência, uma avaliação relativa disfarçada.

Contudo, o fato da avaliação por múltiplos ser realizada com menos premissas explícitas pode se tornar um aspecto negativo, pois está mais sujeita à manipulação, de acordo com o interesse do responsável pela análise. Adicionalmente, como fragilidade da técnica, aponta-se que os múltiplos, ao refletirem o humor do mercado, podem estimar de forma equivocada o valor do ativo em análise quando o mercado está sobre-estimando, ou subavaliando as empresas consideradas comparáveis. Desta forma, apesar de todas as técnicas de avaliação estarem sujeitas à manipulação, a avaliação relativa é considerada mais vulnerável.

Damodaran (2012) refere que, para garantir a correta utilização dos múltiplos, é fundamental atentar para os seguintes pontos: (1) assegurar a consistência e uniformidade do múltiplo; (2) conhecer a distribuição dos múltiplos; (3) identificar as variáveis que determinam os múltiplos e como os impactam; (4) identificar as empresas comparáveis. Desta forma, antes de acatar o valor da empresa fornecido pela avaliação por múltiplo, é importante averiguar os parâmetros utilizados por quem a elaborou, referente aos pontos citados.

Em relação às pesquisas sobre avaliação por múltiplos, a maioria avalia a performance dos múltiplos e, dentro desse escopo analisa, principalmente, os pontos (3) e (4): a forma de selecionar empresas comparáveis, e a melhor forma de agrupá-las (Alford, 1992; Bhojraj \& Lee, 2002; Serra \& Fávero, 2017); as variáveis que estão relacionadas aos múltiplos e sua influência sobre os mesmos (Whitbeck \& Kisor, 1963; Damodaran, 2002; Liu, Nissim \& Thomas, 2002; Osmundsen, Asche, Misund \& Mohn 2006; Hashemzadeh, Davis, Wade, Prather, Topuz \& Uzmanoglu, 2008; Gupta, 2018); e em diferentes contextos, como em oferta pública inicial (Kim \& Ritter 1999; Orlovas, Serra \& Carrete 2018).

Os estudos que buscam identificar as variáveis que determinam os múltiplos e como os impactam, geralmente utilizam alguma técnica estatística, como regressão linear múltipla, e dados em painel, com o objetivo de observar se as variáveis independentes testadas são significativas para explicar os múltiplos. Esta prática é relevante porque permite apontar as características das empresas que melhor explicam as diferenças do preço relativo. Além disso, posto que a natureza das empresas envolve muitas especificidades, e que sempre existirá 
algum grau de diferença entre as empresas, ao aplicar a técnica de regressão linear múltipla, será realizada uma forma de controle dessas diferenças. Neste sentido, os modelos estimados precificam os múltiplos de forma mais confiável ao ponderarem os impactos de cada característica para estimar os múltiplos, diferenciando-se da forma tradicional de estimação, a qual utiliza a média dos valores dos múltiplos das empresas consideradas comparáveis.

Adicionalmente, nota-se que no contexto de países emergentes - caracterizados pela fragilidade econômica e volatilidade do mercado de capitais -, onde existem poucas pesquisas sobre o tema, e há diversos fatores de diferenciação em relação aos mercados desenvolvidos, os resultados encontrados nas literaturas nacional (Arruda, 2015) e internacional (Heveadi, 1999; Maniar, 2014; Gupta, 2018) não chegam a um consenso sobre quais seriam as variáveis que melhor explicariam as diferenças do preço relativo das empresas.

Nesse sentido, esta Dissertação tem como objetivo apresentar, no contexto de empresas brasileiras negociadas na bolsa de valores, uma análise sobre as características que melhor explicam as diferenças do preço relativo, e apontar qual método de precificação apresenta melhor resultado. Nesse sentido, esta pesquisa se insere no item (3) dos pontos apresentados anteriormente: identificar as variáveis que determinam os múltiplos e como os impactam. Para isto, primeiramente foram identificados, na literatura, alguns múltiplos para aplicar o método de avaliação relativa e as variáveis relacionadas a cada um. Em seguida, foi aplicada a técnica estatística de regressão linear múltipla, no período de 2015 a 2018.

De forma geral, o trabalho buscou ampliar a compreensão do método de avaliação de empresas, conhecido como avaliação relativa ou por múltiplos, agregando maior grau de confiabilidade na utilização da técnica, auxiliando a academia e os profissionais do mercado no campo das análises de avaliação de empresas.

A técnica de avalição por múltiplos é uma das mais utilizadas para fins de avaliação de empresas (Alford 1992; Damodaran, 2012), e possui como aspectos positivos: a possibilidade de avaliar mais de uma empresa ao mesmo tempo; a utilização da percepção do mercado para avaliar as empresas; e o fato de ser uma técnica complementar a outras mais robustas, oferecendo relativa rapidez e facilidade na aplicação.

Com isto, a contribuição do trabalho foi a de indicar quais características das empresas melhor explicam as diferenças do preço relativo, e apontar um modelo de estimação dos múltiplos que as precifique de forma mais confiável que a tradicional - na qual se utiliza a média dos valores dos múltiplos das empresas consideradas comparáveis. 
Por fim, analisar a técnica de avaliação por múltiplos no contexto de empresas brasileiras é uma contribuição para a literatura, pois há poucos estudos sobre o tema aplicados ao contexto brasileiro no qual existem, como referido, diversos fatores de diferenciação em relação aos mercados desenvolvidos, uma vez que os países emergentes são caracterizados pela fragilidade econômica, e a volatilidade do mercado de capitais. 


\section{FUNDAMENTOS DA AVALIAÇÃO DE EMPRESAS}

Damodaran (2007) considera a avaliação de empresas um aspecto crucial das finanças, pois está vinculada a diversos temas como: finanças corporativas; gestão de portfólio; e eficiência de mercado. O autor aponta, ainda, que conhecer o valor de um ativo e o que o determina é essencial para uma decisão inteligente.

Há ativos mais fáceis de serem avaliados e, neste caso, a metodologia mais adequada varia conforme a natureza e as incertezas associadas aos mesmos, contudo os princípios essenciais permanecem os mesmos. Alguns princípios que devem guiar o processo de avaliação de empresas se relacionam ao fato de que os ativos precisam ser avaliados pelo seu valor econômico criado, e pelas suas expectativas futuras em produzir um retorno em excesso, utilizando uma taxa de desconto que considera adequadamente o risco do investimento (Assaf, 2017).

Copeland e Antikarov (2002) referem outros fatores a serem observados na avaliação como condições de qualquer investimento: a irreversibilidade; a incerteza; e o momento de investir. A primeira condição se refere ao fato de que alguns custos são irreversíveis, pois uma vez iniciados, os investimentos são totalmente ou, pelo menos, parcialmente perdidos. Já a incerteza é condição inerente à análise e extrapola o risco, conhecido e mensurável; e o momento de investir se refere à possibilidade de adiar o investimento para que se possa aguardar por novas informações.

Por fim, o valor conhecido como "valor justo" é definido na negociação entre comprador e vendedor (por isso, também é conhecido como valor de mercado), com base numa faixa de referência fundamentada na expectativa de geração de resultados futuros.

\subsection{Metodologias de Avaliação de Empresas}

De acordo com Cerbasi (2003), existem diversos métodos para estabelecer o valor de uma empresa, e a opção por algum se baseia nas informações, ou nos instrumentos disponíveis para avaliação. Esta mesma perspectiva é assumida por Costa et al. (2011), que indicam que não existe uma metodologia superior às demais, mas algumas podem ser consideradas mais robustas, dependendo das informações disponíveis, e das premissas adotadas. As metodologias de avaliação têm por objetivo estimar uma faixa de referência que 
sirva como base nas negociações de empresas, dessa forma, ainda segundo Costa et al. (2011), quanto maiores as incertezas em relação ao futuro, maior a amplitude da faixa de valores.

Segundo Pasin (2004), os modelos de avaliação são essencialmente quantitativos, entretanto, o processo de avaliação contempla muitos aspectos subjetivos inseridos nos dados de entrada dos mesmos. Cerbasi (2003) aponta que alguns métodos se apoiam na utilização de técnicas estatísticas, enquanto outros requerem um conjunto maior de informações, e acrescenta que o fator 'tempo disponível para análise' também pode influenciar na metodologia escolhida. Para Cavallari (2006), os modelos compartilham características em comum, que são as variáveis econômico-financeiras.

No processo de avaliação há, de um lado, quem a defenda, quando bem aplicada, como uma ciência exata com pouca margem para opinião de analistas ou para erro humano, de outro, há quem considere a avaliação uma forma de arte que envolve considerável grau de subjetividade. Damodaran (2007) considera o meio-termo, desde que o analista saiba lidar com: (i) os vieses com que deparam antes e depois da análise e que se manifestam por uma visão pré-estabelecida da empresa em análise e nos remendos pós avaliação para se aproximar de valores esperados; (ii) as incertezas, que são inerentes à análise e a perspicácia do analista em mitigá-las; (iii) as tecnologias disponíveis e o acesso às informações que, atualmente, são mais facilmente coletadas. $\mathrm{O}$ mesmo autor ainda refere o princípio da parcimônia, relativa à atitude de se optar por modelos mais simples, caso cumpram a tarefa de modo adequado.

De acordo com Damodaran (2007), em termos gerais, há três abordagens principais de avaliação: Fluxo de Caixa Descontado (FCD); Avaliação Relativa; e a Avaliação por Direitos Contingentes. Outros modelos de avaliação de empresas também comumente utilizados são: Avaliação Contábil/Patrimonial e os métodos EVA (Economic Value Added - em português: valor econômico adicionado); e MVA (Market Value Added - em português: valor de mercado adicionado).

Pasin (2004) relata que o método do Fluxo de Caixa Descontado é o mais amplamente difundido entre empresas de consultoria e bancos de investimentos, e os métodos EVA/MVA e por direitos contingentes ou opções reais são desdobramentos do método do Fluxo de Caixa Descontado. Já o método contábil/patrimonial é indicado para casos de liquidação da empresa em análise, onde os ativos possuem mais valor do que o valor presente dos fluxos de caixa. Fernandez (2001) e Liu, Nissim \& Thomas (2002) sugerem a utilização das técnicas em conjunto, e defendem que os múltiplos devem ser utilizados como complemento de outras técnicas, geralmente para comparar o resultado da avaliação pelo FCD. 
As próximas subseções apresentam as técnicas de avaliação pelo Fluxo de Caixa Descontado e, na sequência, a Técnica de Avaliação por Múltiplos.

\subsubsection{Fluxo de Caixa Descontado (FCD)}

A seguir estão apresentados os elementos e principais conceitos para aplicar a técnica de avaliação pelo Fluxo de caixa Descontado. O motivo dessa técnica ser a primeira a ser apresentada é que, como já comentado anteriormente, ela é a mais completa, assim, os elementos e conceitos que englobam são utilizados para abordar a técnica de avaliação por múltiplos.

O método de Fluxo de Caixa Descontado (FDC) precifica a empresa como sendo o valor presente dos benefícios econômicos futuros esperados de caixa, descontado por uma taxa de risco (Heveadi, 1999; Gupta, 2018). Segundo Assaf (2017), é a metodologia mais utilizada para avaliações de empresas, e também a mais consagrada na literatura de Finanças.

Para o cálculo do valor da empresa em análise são necessários três elementos:

1. Fluxos de caixa futuros;

2. Taxa de desconto;

3. Estimativa do valor residual (perpetuidade).

\subsubsection{Fluxo de Caixa Disponível}

O Fluxo de caixa Disponível (ou livre) é o montante em caixa que a empresa possui após consideradas as despesas, necessidades de reinvestimentos, e investimento em capital de giro, ou seja, é o excedente do caixa.

O Fluxo de caixa Disponível é dividido em:

- Fluxo de caixa Disponível (livre) da Firma - FCDF

- Fluxo de caixa Disponível (livre) do Acionista - FCDA

E são calculados conforme procedimento abaixo:

(=) Lucro Operacional Líquido após IR

(+) Depreciação/amortização

(=) Fluxo de caixa Operacional 
(-) Investimentos em bens de capital $\left(\mathrm{CAPEX}^{1}\right)$

(-) Variação do investimento em capital de giro

(=) Fluxo de caixa Disponível da Firma (FCDF)

(-) Despesas Financeiras

(+) Benefício fiscal

(+) Entrada de novas dívidas

(=) Fluxo de caixa Disponível do Acionista - FCDA

\subsubsection{Taxa de Desconto}

A taxa de desconto reflete o custo do capital empregado para geração dos fluxos de caixa esperados, sendo esses últimos, fruto de investimentos em ativos. Na decisão de investir, deve ser levado em conta se estão sendo remuneradas adequadamente as fontes de recursos do capital empregado, que são duas: capital de terceiros $(\mathrm{Kd})^{2}$ e capital próprio $(\mathrm{Ke})^{3}$.

A seguir, são apresentadas estas duas fontes de recursos e como calculá-las:

Custo de Capital de terceiros: É o capital financiado via empréstimos e financiamentos ${ }^{4}$, considerado o custo explícito, pois pode ser identificado de forma objetiva. São as captações de recursos no mercado por meio de dívidas, títulos e compromissos, cujos valores são claramente identificados nos demonstrativos da empresa (Cerbasi, 2003). Para estimá-lo, utiliza-se uma média ponderada entre o montante do capital de cada fonte de recurso, e o respectivo custo (juro pago).

Essa fonte de capital é considerada a de menor custo para empresa. Uma vez que possui a vantagem fiscal, os juros pagos são dedutíveis do imposto de renda e contribuição social.

Custo de capital próprio e o modelo do CAPM: O custo de capital próprio é uma medida implícita que expressa a remuneração dos recursos próprios investidos na empresa, e apresenta dois componentes: a taxa de um investimento sem risco, que garante uma

\footnotetext{
${ }^{1}$ CAPEX é a sigla da expressão inglesa capital expenditure (em português, despesas de capital ou investimento em bens de capital) que designa o montante de dinheiro despendido na aquisição (ou introdução de melhorias) de bens de capital de uma determinada empresa.

${ }^{2} \mathrm{Kd}$ : Geralmente utiliza-se Kd para representar capital de terceiros, pois na literatura em inglês, para capital de terceiros, utiliza-se debt.

${ }^{3} \mathrm{Ke}$ : Geralmente utiliza-se Ke para representar capital próprio, pois em inglês, capital próprio é o equity.

${ }^{4}$ Empréstimos e financiamentos: A diferença entre esses dois termos é que, enquanto o financiamento possui um propósito específico (compra de máquinas, imóveis, automóveis, etc.), o empréstimo, quando solicitado, não precisa informar como o recurso será gasto.
} 
remuneração mínima $\left(r_{f}\right)$, na literatura representado pelos títulos públicos; e um prêmio $(\rho)$ para o risco, o qual representa uma remuneração exigida para compensar o risco de se investir em ativos mais arriscados.

Conforme Costa et al. (2011), o prêmio pelo risco pode ser analisado numa base isolada, ou num contexto de uma carteira. O primeiro caso se refere ao risco que um investidor corre caso possua única e exclusivamente um ativo. A segunda situação considera que o investidor não aplica num único ativo, mas numa carteira, sendo necessário analisar o prêmio de risco num contexto de diversificação.

Assim, a abordagem mais comumente utilizada para estimar o custo do capital próprio é pelo modelo de apreçamento CAPM (Capital Asset Pricing Model). O mesmo foi desenvolvido por William Sharpe em $1964^{5}$, tendo como alicerce a Teoria das Carteiras, de Harry Markowitz ${ }^{6}$, e assume que os investidores não podem esperar uma recompensa pelos riscos que são diversificáveis (não sistêmicos), mas somente para a parcela do risco não diversificável (sistêmico ou de mercado).

O coeficiente beta $(\beta)$ é uma medida de risco que mede o quanto do retorno da ação é afetado pelo risco de mercado ou risco sistêmico, conforme a equação (1):

$$
\beta=\frac{\operatorname{cov}\left(\mathrm{r}_{\mathrm{e}} \mathrm{RT}\right)}{\operatorname{war}(\mathrm{RT})},
$$

onde, r é retorno de uma empresa específica e RT da retorno da carteira.

Esta medida de risco (B) é empregada no cálculo do modelo CAPM, utilizado para estimar o custo do capital próprio. Segue abaixo a fórmula do modelo CAPM:

$$
\mathrm{Ke}=r_{\mathrm{f}}+\beta\left(\mathrm{Rm}-r_{\mathrm{f}}\right)
$$

onde, Ke é custo do capital próprio, $r_{f}$ é a taxa de juros do ativo livre de risco, $\beta$ é coeficiente beta da ação, $\mathrm{Rm}$ é o retorno do mercado. Sendo assim $\left(\mathrm{Rm}-r_{f}\right)$ é o prêmio pelo risco de mercado e $\beta\left(\mathrm{Rm}-r_{f}\right)$ é o prêmio pelo risco do ativo.

Com isso, foram apresentados ambos os fluxos de caixa: o Fluxo de caixa Disponível (livre) da Firma - FCDF, e Fluxo de caixa Disponível (livre) do Acionista - FCDA, e o conceito de caixa de desconto do capital de terceiros $(\mathrm{Kd})$ e capital próprio $(\mathrm{Ke})$. Contudo, uma vez que o Fluxo de caixa Disponível (livre) da Firma leva em consideração os recursos

\footnotetext{
${ }^{5}$ Sharpe, W. F. (1964). Capital asset prices: A theory of market equilibrium under conditions of risk. The journal of finance, 19(3), 425-442.

${ }^{6}$ Markowitz, H. (1952). Portfolio selection. The journal of finance, 7(1), 77-91.
} 
tanto dos credores como dos acionistas, é preciso utilizar a taxa de desconto que pondere o custo do capital empregado.

Para tanto, é utilizado o custo médio ponderado de capital ou weighted avegare cost of capital (WACC). Segundo Titman \& Martin (2009) o custo médio ponderado de capital é uma média ponderada das taxas de desconto do capital próprio, e do capital de terceiros após impostos e é expresso por:

$$
\mathrm{WACC}=\mathrm{K}_{\mathrm{e}} \times\left[\frac{\mathrm{E}}{\mathrm{E}+\mathrm{D}}\right]+\mathrm{K}_{\mathrm{d}} \mathrm{x}(1-\mathrm{T}) \mathrm{x}\left[\frac{\mathrm{E}}{\mathrm{E}+\mathrm{D}}\right],
$$

onde, $\mathrm{K}_{\mathrm{e}}$ é custo do capital próprio, $\mathrm{K}_{\mathrm{d}}$ é o custo do capital de terceiros, $\mathrm{T}$ é a alíquota dos impostos, E é o valor de mercado do capital próprio e D é valor de mercado do capital de terceiros.

\subsubsection{Valor residual}

O último elemento a ser apresentado para calcular o Fluxo de Caixa Descontado é o valor residual. Este é considerado, pois uma das características da empresa é a perenidade, assim, deve-se considerar esta natureza implícita das empresas nas projeções do fluxo de caixa.

O conceito de valor residual ou valor contínuo, conforme Goedhart, Koller \& Wessels (2015), representa os fluxos de caixa da empresa após o período de previsão explícito. Assim, essa questão pode ser solucionada dividindo-se o valor da empresa em dois períodos: o período de previsão explícita; e após o período de previsão explícita.

O tratamento utilizado para o valor residual pressupõe que, a partir do $n$-ésimo fluxo de caixa, a empresa comece a gerar fluxos de caixa estáveis, assim, se confere um valor total do resíduo.

\subsubsection{Valor Presente dos Fluxos de caixas descontados}

Uma vez apresentados os elementos e os conceitos do método do Fluxo de caixa descontado, pode-se definir o valor da empresa (V) utilizando a fórmula apresentada a seguir:

$$
\mathrm{V}=\sum_{t=1}^{n} \frac{F C D F_{t}}{(1+w a c c)^{1}}+\frac{F C D F_{t+1}}{(\text { wacc }-g)(1+\text { wacc })^{t+1}}
$$


onde, $F C D F_{t}$ é Fluxo de Caixa Disponível da Firma gerado pela empresa no tempo $t$, wacc é a taxa de desconto, $g$ é taxa perpétua de crescimento dos fluxos de caixa, $t$ é período de previsão do Fluxo de caixa e $n$ é o término da previsão do Fluxo de caixa da empresa.

Como abordado no item valor residual, a primeira parte da expressão é período de previsão explícito, e a segunda parte no período $(t+1)$ se refere ao valor residual.

Caso o interesse seja em identificar o valor presente para os acionistas, na fórmula acima o analista deve substituir o Fluxo de caixa da Firma (FCDF) pelo Fluxo de caixa do Acionista (FCDA), e utilizar como taxa de desconto o custo do capital próprio, apresentado anteriormente.

\subsubsection{Vantagens e desvantagens da metodologia}

O aspecto positivo da metodologia, segundo Damodaran (2007), é que a técnica utilizada de modo correto deve compreender o que sustenta os fluxos de caixa projetados com os respectivos riscos, e a natureza subjacente do negócio. De acordo com Costa et al. (2011), a metodologia permite fazer a análise da sensibilidade da empresa, com base em cenários macroeconômicos alternativos e na perspectiva de crescimento do Fluxo de caixa.

Como aspecto negativo, a análise pode ser manipulada de forma que se desvincule do valor intrínseco, além do fato de necessitar de uma quantidade relativamente maior de informações. Assim, para Goedhart, Koller \& Wessels (2015), de modo geral, as vantagens e desvantagens do método estão relacionadas à complexidade da metodologia, que busca proporcionar maior precisão ao processo de avaliação.

\subsubsection{Avaliação Relativa ou Avaliação de Múltiplos}

A avaliação relativa ou avaliação por múltiplos, é um método de avaliar ativos, com base em ativos semelhantes negociados no mercado (Damodaran, 2012; Gupta 2018; Orlovas, Serra, \& Carrete, 2018). Trata-se de uma ferramenta simples para comparar o valor entre empresas (Maniar, 2014). A premissa da técnica considera que as empresas são corretamente avaliadas pelo mercado e, com base nessa avaliação dos pares (empresas comparáveis), é estimado o valor da empresa alvo (Koller, 2005). 
As razões para a popularidade da avaliação relativa são: pode ser realizada com menos premissas explícitas, de uma forma mais rápida, e maior facilidade em apresentar a clientes comparado ao método do FCD. Além disso, é uma técnica que reflete o humor do mercado, uma vez que busca medir o valor relativo, e não o intrínseco, o que acarreta, na maioria das vezes, em precificações mais próximas ao valor de mercado do que o método do FCD. Além disso, possibilita-se avaliar mais de uma empresa em paralelo.

Para Koller (2005), no sentido de entender os motivos pelos quais os múltiplos das empresas em análise estão superiores ou inferiores aos das empresas comparáveis, pode-se trazer percepções dos fatores chave que criam valor para as empresas em análise (empresas em avaliação e dos competidores). Segundo Damodaran (2007), grande parte de regras práticas de investimentos se baseia em múltiplos para saber se a ação está barata, ou cara.

No contraponto, o mesmo autor (2012), faz a crítica ao fato de que é possível manipular facilmente as empresas comparáveis gerando, assim, estimativas inconsistentes. $\mathrm{O}$ fato dos múltiplos refletirem o humor do mercado pode gerar valores sobre avaliados para o ativo em análise, quando o mercado está sobre estimando às empresas consideradas comparáveis. Nesse sentido, apesar de todas as técnicas de avaliação estarem sujeitas à manipulação, a avaliação relativa é considerada mais vulnerável. Outra crítica apresentada por Fernandez (2001) é o fato de que, em pesquisas empíricas, a avaliação de empresas realizada via múltiplos geralmente apresenta alta dispersão, o que a torna muito debatida.

Nas próximas seções, primeiramente, indica-se como aplicar a técnica de avaliação por múltiplos; os tipos de múltiplos; os pontos de atenção para correta utilização da técnica; e finalmente são apresentados os múltiplos utilizados nesta pesquisa e as respectivas variáveis determinantes.

\subsubsection{Aplicação da técnica da Avaliação Relativa}

Segundo Assaf (2017), a precificação por múltiplos exige dois conjuntos de informações: (1) o valor da(s) empresa(s) comparável(eis) ${ }^{7}$; (2) e um respectivo padrão de referência para realizar a padronização, que pode ser: lucro, patrimônio líquido contábil, receita, alguma medida específica de um setor, etc.

\footnotetext{
${ }^{7}$ A escolha de empresa (s) comparável (eis) será abordada de forma mais aprofundada na subseção 2.1.2.3.2 - Escolha de empresas comparáveis.
} 
A padronização é necessária, pois as empresas comparáveis podem ter diferentes dimensões para as variáveis utilizadas como padrão de referência. Ao se comparar empresas, provavelmente o montante de lucro (ou qualquer outro padrão de referência utilizado) possui dimensões diferentes.

Desta forma, é preciso fazer a padronização, dividindo a informação (1) pela informação (2) para criar uma mesma base de comparação entre as empresas. Essas razões são os múltiplos utilizados para avaliar a empresa de interesse. A técnica parte da igualdade expressa pela equação 5, na qual é apresentado um exemplo de aplicação da técnica utilizando o múltiplo $\mathrm{P} / \mathrm{L}$ (preço dividido pelo lucro):

$$
\frac{P_{a}}{L_{a}}=\frac{P_{\varepsilon}}{L_{\varepsilon}},
$$

onde, $P_{a}$ é o preço empresa em avaliação, $L_{a}$ é o lucro empresa em avaliação, $P_{\varepsilon}$ é o preço empresa(s) comparável(eis) e $L_{c}$ é o lucro empresa(s) comparável(eis).

Para calcular $\frac{P_{G}}{L_{\varepsilon}}$ é utilizada a média dos múltiplos das empresas comparáveis, que pode ser: a média, mediana, média geométrica e média harmônica, etc.

Assim, isolando o valor da empresa em avaliação $\left(P_{a}\right)$, com base na equação (5) e sabendo o múltiplo das empresas comparáveis $\left(P_{c} / L_{c}\right)$ e o lucro da empresa em avaliação $\left(L_{a}\right)$, é possível estimar o valor da empresa em avaliação $\left(P_{a}\right)$. Conforme é apresentado na equação (6)

$$
P_{a}=\frac{P_{\sigma}}{L_{\varepsilon}} \times L_{a} .
$$

\subsubsection{Múltiplos de valor de mercado e múltiplos de valor da empresa}

Existem dois tipos de múltiplos, os de valor de mercado, e os de valor empresarial:

- $\quad$ Múltiplos de valor de mercado (equity value): utiliza o valor de mercado do capital próprio (Patrimônio Líquido) dos sócios da empresa. No caso de empresas negociadas em bolsa de valores é a cotação do preço da ação da empresa. Já o valor de mercado agregado leva em consideração a quantidade de ações que a empresa possui. Pode ser calculado da seguinte forma:

Valor de mercado agregado $=$ preço da ação $x$ quantidade de ações

- Múltiplos de valor da empresa (enterprise value): É a soma do valor de mercado agregado (apresentado acima) mais o endividamento oneroso (dívidas 
financeiras), subtraindo o caixa da empresa.

Valor da empresa $($ Enterprise value $)=$ Valor de mercado agregado + endividamento oneroso equivalente de caixa

Conforme Pearl \& Rosenbaum (2013), o endividamento oneroso é composto pelo total de débitos + ações preferenciais emitidas + juros pagos para os não controladores.

- Pontos adicionais para o cálculo do Capital próprio (valor de mercado) agregado

Para calcular o valor do capital próprio agregado, deve-se atentar para os diferentes tipos e classes de ações que são emitidos pelas empresas, pois estas variam em seus valores e quantidades, o que influencia no momento do cálculo do valor de mercado.

Preferencial e ordinária: Há diferentes classes de ações emitidas pelas empresas - as principais são as ações preferenciais, as quais possuem preferência no recebimento de dividendos, porém não têm direito a voto nas decisões estratégicas da empresa. As ações ordinárias, ao contrário, têm direito a voto, mas não preferência no recebimento dos dividendos. Estas classes de ações são negociadas a diferentes valores e possuem diferentes quantidades, o que é preciso considerar no momento do cálculo do valor de mercado agregado da empresa.

Ações primárias: As ações primárias são as ações emitidas pelas companhias, e não consideram outros ativos que podem ser convertidos em ação. Caso a empresa tenha emitido outros ativos que podem ser convertidos em ação, é necessário considerar este possível aumento na quantidade de ações, pois isso altera o valor agregado da mesma.

Accões diluídas: Há ativos emitidos pelas empresas que podem ser convertidos em ação. As ações diluídas (Fully Dilluted Shares Outstanding) são compostas por (ações em circulação) + (opções e garantias "dentro do dinheiro") + (títulos conversíveis "dentro do dinheiro"). São conhecidas por quantidade diluída de ações, pelo fato de que, caso estes derivativos sejam exercidos ou convertidos, representarão aumento da quantidade de ações. 


\subsubsection{Pontos de atenção para correta utilização da avaliação relativa}

Como referido, a técnica de avaliação relativa possui, como vantagem, a fácil aplicabilidade. Contudo, é fundamental atentar para alguns pontos que devem ser analisados para a correta aplicação da técnica (Damodaran, 2012):

1- $\quad$ Assegurar a consistência e uniformidade do múltiplo;

2- Identificar as empresas comparáveis, controlando as diferenças que existem entre as mesmas;

3- Conhecer a distribuição dos múltiplos entre empresas do mesmo setor e entre todas empresas do mercado (análise descritiva);

4- Identificar as variáveis fundamentalistas que determinam os múltiplos, e como estas os impactam;

\subsection{Consistência e Uniformidade}

O conceito de consistência está relacionado à verificação de quais métricas devem ser usadas para calcular os múltiplos. Conforme Damodaran (2012), o múltiplo é consistente quando, ao utilizar no numerador uma medida de capital próprio (equity value), o denominador também deve ser uma medida de capital próprio. Da mesma forma, caso for utilizado um numerador valor referente ao valor da empresa (enterprise value), o denominador também deve ser uma medida de valor da empresa.

O múltiplo P/L (preço pelo lucro) possui consistência, pois o numerador (preço) é um valor que pertence aos acionistas da empresa (capital próprio), e o denominador (lucro) também é uma medida que pertence aos acionistas. Outro múltiplo consistente é o EV/EBITDA (valor da empresa sobre o lucro antes de juros, imposto, depreciação e amortização), onde tanto o numerador como o denominador são medidas de valor da empresa. Por outro lado, o múltiplo P/EBITDA (preço sobre lucro antes de juros, imposto, depreciação e amortização) é inconsistente, pois ao considerar o EBITDA como medida de referência e não excluir as despesas com juros, uma empresa que possua maior alavancagem financeira pode gerar um múltiplo com valor relativamente menor e ser considerada subavaliada se comparada com uma empresa similar sem endividamento. 
Damodaran (2007) aponta outros aspectos que podem afetar a consistência: (1) utilizar a quantidade de ações primárias (em circulação) como medida de valor de mercado e para o lucro por ação, calcular com a quantidade de ações diluídas ou vice-versa; (2) não atentar para empresas que possuem participações acionárias relevantes. De um ponto de vista do mercado norte-americano, o autor expõe que existem três tipos de participação societárias: minoritária Passivo (participação < 20\%); minoritária Ativo (participação de 20\% - 50\%); e majoritária (participação > 50\%). Para cada tipo de participação societária existem diferentes regras para contabilização e apresentação de resultados que impactam nos múltiplos. O impacto nos múltiplos varia dependendo se o múltiplo analisado é de valor de mercado (equity value) ou valor da empresa (enterprise value).

A respeito da uniformidade, ao calcular os múltiplos, é preciso observar a uniformidade das informações coletadas das empresas para evitar comparar coisas diferentes como sendo iguais e vice-versa. Conforme Damodaran (2012), é preciso atentar para fatores, descritos a seguir, que podem alterar o valor de referência utilizado para calcular o múltiplo.

- $\quad$ O ano fiscal utilizado pelas empresas, uma vez que há empresas que possuem ano fiscal de julho a junho, enquanto outras possuem de janeiro a dezembro;

- O padrão contábil utilizado pelas empresas, evitando que empresas diferentes sejam consideradas similares ou diferentes, e atentar para o fato de que empresas com mesmo padrão contábil podem apresentar diferentes regras para lidar com despesas e depreciação;

- As participações societárias em outras empresas, pois há empresas que possuem balanço consolidado ou não consolidado. Goedhart et al. (2015) sugere que para avaliar empresas com diferentes tipos de negócio, pode-se separar a empresa por atividade e encontrar pares para cada tipo de negócio;

- Desconsiderar ativos não operacionais como o caixa das empresas, uma vez que a natureza do caixa é diferente dos ativos em operação, em termos de risco e retorno. Empresas com níveis de caixa diferentes podem distorcer a comparabilidade entre as empresas. Uma forma que alguns analistas utilizam para manter a uniformidade entre as empresas é desconsiderar ativos não operacionais, além do excesso de caixa, e fundo de pensão (Goedhart et al.,2015); 
- A quantidade de emissão de opções, ao se comparar empresas que possuem diferentes níveis de emissão de opções, pelo aspecto já apontado de as opções possuírem efeito de diluição das quantidades de ações e, consequentemente, dos direitos que cada ação tem vinculados. Empresas que possuem um grande número de emissão de opções podem apresentar um valor superestimado de lucro por ação, comparadas às empresas similares que possuem menos opções emitidas, caso não seja feito algum ajuste.

Assim, de modo geral, a uniformidade está relacionada ao fato de que, ao se comparar empresas, deve-se atentar para usar a mesma unidade de medida de comparação.

\subsection{Escolha de empresas comparáveis}

Segundo Bhojraj \& Lee (2002), há pelo menos três situações em que identificar empresas comparáveis é útil: (1) na avaliação de empresas por múltiplos, em que os múltiplos das empresas comparáveis são utilizados para estimar o valor de uma empresa alvo; (2) ao realizar uma análise fundamentalista será necessário projetar: vendas, taxa de crescimento, margem de lucro, risco e etc., e pode-se utilizar empresas comparáveis como fonte de referência; (3) em pesquisas empíricas, acadêmicos procuram identificar empresas comparáveis para pesquisar o efeito de uma variável de interesse isoladamente.

Para escolher as empresas comparáveis para fins de avaliação por múltiplos, há pesquisas que apontam, como método, a utilização de empresas do mesmo setor (Alford,1992). Outros autores sugerem utilizar empresas com características semelhantes de risco, rentabilidade e crescimento, não obrigatoriamente do mesmo setor (Bhojraj \& Lee, 2002; Herrmann \& Richter, 2003; Dittmann \& Weiner, 2005; Junior e Galdi, 2012; Serra \& Fávero, 2017).

Dentro do universo de autores que indicam a seleção de empresas comparáveis como sendo do mesmo setor, há o estudo de Alford (1992), uma das primeiras pesquisas empíricas que testou a performance de alguns métodos de seleção de empresas. O autor utilizou o múltiplo $\mathrm{P} / \mathrm{L}$ (preço dividido pelo lucro) com as empresas comparáveis selecionadas com base 
na indústria, no risco e no crescimento dos lucros, usando como variáveis o $\mathrm{SIC}^{8}$ código da indústria, o total de ativo e o roe $^{9}$ das empresas respectivamente.

Sugere-se, assim, que grande parte da variação transversal do $\mathrm{P} / \mathrm{L}$ explicada pelo risco e crescimento do lucro é também explicada pela indústria, porém, não se aconselha utilizar essas variáveis sozinhas. Observou-se que, utilizando o SIC para seleção das empresas comparáveis, há crescente melhora na acurácia até terceiro dígito do código. Em relação ao risco, representado pelo tamanho da empresa (ativo total), identificou-se que empresas comparáveis com maior ativo total apresentavam melhor performance na avaliação.

Já Bhojraj \& Lee (2002) chegaram à conclusão oposta. Para a escolha das empresas comparáveis, apresentaram uma abordagem quantitativa/objetiva. Utilizando a técnica de regressão linear múltipla, desenvolveram um modelo denominado de warrants, tendo como variável dependente, os múltiplos P/PLC (preço dividido pelo Patrimônio Líquido Contábil) e EV/Receita (valor da empresa dividido pela receita), e como variáveis independentes, informações setoriais e financeiras das empresas.

Substituindo as variáveis correntes da empresa alvo no modelo gerado, as empresas que ficassem mais próximas dos valores dos warrants gerados, seriam as empresas comparáveis. Sugere-se, no estudo, que o modelo desenvolvido seria capaz de explicar mais a variabilidade dos múltiplos do que outros fatores, como indústria e tamanho da empresa.

Em linha com estes autores, Dittmann \& Weiner (2005) sugerem que selecionar comparáveis com base no roic ${ }^{10}$ apresenta melhor performance, comparado à seleção via indústria ou ativo total (risco). Investigou-se se as comparáveis deveriam ser selecionadas por país, ou mesma região para os países membros da OECD (Organisation for Economic Cooperation and Development). Concluiu-se que, para a maioria dos países europeus, escolher as comparáveis utilizando os países membros melhorava a performance, contudo, para Reino Unido e Estados Unidos, utilizar como comparáveis somente empresas do mesmo país melhorava a performance.

\footnotetext{
${ }^{8}$ SIC (Standard Industrial Classification): É um sistema de classificação de indústria baseado em código de quatro dígitos. Foi estabelecido nos EUA em 1937, é usado por agências do governo para classificar as indústrias por área.

${ }^{9}$ roe: Retorno do capital próprio (Return on Equity).

${ }^{10} \mathrm{O}$ roic (retorno sobre o capital investido) é uma medida de desempenho financeiro e, como o próprio nome supõe, é o retorno sobre o capital investido. Representa o quanto a empresa consegue gerar de retorno com o capital investido, independente da fonte do recurso.
} 
Outro enfoque, exposto por Pearl \& Rosenbaum (2013), apresenta uma abordagem utilizada por profissionais da área financeira, onde se sustenta que, para a escolha das comparáveis, é necessário um profundo entendimento da empresa alvo, identificando empresas com negócios e características financeiras parecidas. Enquanto para algumas empresas que atuam no mesmo setor, este exercício pode ser bastante intuitivo e simples, para outras empresas, consiste em uma atividade complexa.

Neste caso, sugere-se, como ponto de partida, consultar analistas sênior. Caso não exista esta referência, deve-se realizar um exame detalhado de similaridades e discrepância das empresas em termos de tamanho, margens, taxa de crescimento, alavancagem, etc., começando com uma amostra mais ampla das comparáveis, minimizando a possibilidade de deixar alguma empresa relevante de fora da amostra, e aplicando filtros para afunilar o universo de comparáveis. Aconselha-se encontrar duas ou três empresas cuidadosamente selecionadas como comparáveis com um grupo de empresas mais amplo, servindo de pontos de referência.

Para a coleta destas informações, no caso de empresas negociadas em bolsa de valores, Pearl \& Rosenbaum (2013) indicam consultar relatórios anuais e trimestrais divulgados pela empresa, pesquisas de consenso realizadas por agentes do mercado, apresentações aos investidores, divulgações para imprensa, site próprio da empresa, etc. Também é indicado utilizar informação da classificação setorial como NAICS ${ }^{11}$ e SIC, e relatórios disponibilizados pelas agências de credit rating como a Moody`s, S\&P e Ficth.

Há autores que, para a escolha das empresas comparáveis, apontam que as metodologias de seleção de empresas apresentadas acima são complementares (Damodaran, 2012; Kim, \& Ritter, 1999). Assim, caso o setor possua uma quantidade suficiente de empresas, pode-se utilizar algum critério de seleção como: porte, lucratividade, crescimento e etc., para aumentar a similaridade entre as empresas. Esta abordagem ganha força no contexto de globalização, uma vez que as empresas possuem ações sendo negociadas em diferentes mercados e, paralelo a isto, há a dúvida sobre se empresas de um mesmo setor, mas com países em sedes diferentes, podem ser consideradas comparáveis.

Adicionalmente, Damodaran (2012) afirma que, apesar do cuidado na escolha das empresas comparáveis, diferenças entre as empresas comparáveis, e entre as comparáveis e a

11 NAICS (North American Industry Classification System): É um sistema de classificação de empresas estabelecido por tipo de atividade econômica (processo de produção). É utilizado no Canadá, México e Estados Unidos. 
empresa em avaliação sempre irão existir. Ademais, como há um trade off entre aumentar o número de empresas similares para aumentar a amostra de empresas comparáveis, contra o aumento da divergência das características entre as empresas da amostra, o autor sugere que fazer o controle das diferenças entre as empresas é parte essencial na avaliação relativa para gerar estimativas mais confiáveis.

\subsection{Controle das diferenças entre empresas}

Posto que a natureza das empresas envolve muitas especificidades, e que sempre existirá algum grau de diferença entre as empresas consideradas comparáveis que deve ser controlado, Damodaran (2012) indica 3 formas de se fazer isso:

1. Ajuste subjetivo:

Em casos em que o múltiplo da empresa analisada se distancia significativamente do múltiplo estimado para as empresas comparáveis, pode-se utilizar o ajuste subjetivo, analisando se alguma característica da empresa (risco, rentabilidade e crescimento) pode explicar a diferença. Caso alguma destas características seja diferente entre a empresa analisada e as empresas comparáveis, pode-se atribuir a esta dissimilaridade a diferença do múltiplo, e se não houver diferença em relação às características, conclui-se que a empresa analisada está subavaliada ou superavaliada.

O ponto negativo desse ajuste é que, como o próprio nome indica, é utilizado um julgamento por parte do analista, que pode conter vieses que o analista possui em relação a empresa.

2. Múltiplo modificado:

Nesta abordagem, sugere-se adicionar a variável mais relevante que determina o múltiplo utilizado. O estudo realizado por Wilcox (1984) analisou o múltiplo modificado $\mathrm{PL} / \mathrm{G}$, que divide o múltiplo $\mathrm{P} / \mathrm{L}$ pelo crescimento, introduzindo no múltiplo, um controle pelo crescimento. 
De acordo com Damodaran (2012), para realizar este controle é preciso considerar que as demais características das empresas são similares, e que a relação entre as variáveis fundamentais e o múltiplo são lineares.

3. Regressão do setor ou mercado:

Em situações em que há diferença em mais de uma característica das empresas (risco, rentabilidade e crescimento), o que torna a relação entre o múltiplo e as variáveis fundamentalistas/determinantes mais complexa e dificulta a utilização dos métodos anteriores, pode-se aplicar uma regressão linear múltipla entre o múltiplo e as variáveis explicativas, utilizando empresas que atuam no mesmo setor (Osmundsen, Asche, Misund \& Mohn, 2006; Gupta 2018). Já a regressão de mercado é uma alternativa em situações em que não haja número suficiente de empresas do mesmo setor ou a empresa em análise que atue em mais de um setor (Heveadi, 1999; Liu, Nissim, \& Thomas, 2002; Omran, 2003; Damodaran 2006; Maniar, 2014).

Para aplicar esta metodologia é preciso identificar as características das empresas que melhor explicam as diferenças do preço relativo. Na literatura, este estudo é, por vezes, denominado como determinantes dos múltiplos.

\subsection{Análise descritiva}

O terceiro ponto de atenção se refere à importância de conhecer qual é o valor típico (alto ou baixo do múltiplo), utilizado para empresas que atuam no mesmo setor, e em relação às empresas de todo o mercado. Para isto, Damodaran (2012) aconselha conhecer a distribuição de valores dos múltiplos: os percentis, medidas centrais e de dispersão. Conforme Serra \& Fávero (2017), para fins de calcular o múltiplo, o uso de médias é recomendável, pois as mesmas produzem estimadores com menos erros. As médias mais comumente utilizadas são: média aritmética, mediana, média geométrica, e média harmônica.

Os valores calculados para cada média podem apresentar vieses. Assim, é importante compreender o efeito causado pelos outliers na média, e evitar medidas enviesadas ao se calcular o múltiplo das empresas comparáveis. Seguem alguns pontos observados por Damodaram (2007) para evitar medidas não representativas: 
- Uma vez que os valores dos múltiplos das empresas são, em sua maioria, positivos (distribuição assimétrica à direita), os valores dos múltiplos calculados pela média aritmética são maiores que a mediana;

- A média aritmética pode apresentar valores muito discrepantes, por exemplo, em relação ao múltiplo $\mathrm{P} / \mathrm{L}$, caso a empresa seja negociada a um preço alto ou quando o lucro da empresa oscila bruscamente, isto pode causar valores discrepantes em relação aos pares;

- $\quad$ Outro fator importante a ser considerado é que para calcular alguns múltiplos não são utilizadas empresas com valores negativos. Assim, geralmente essas empresas são excluídas da amostra, o que gera um viés de seleção somente de empresas lucrativas.

\subsection{Determinantes dos múltiplos}

Whitbeck \& Kisor (1963) realizaram uma das primeiras pesquisas baseando-se no fato de que, na avaliação de empresas, os avaliadores consideram atrativas certas características que as empresas possuem, e as empresas que as possuem em patamares relativamente superiores às demais, deveriam ser negociadas em valores superiores. Sabendo disto, o foco do estudo foi responder o quanto a mais, ou a menos, as empresas deveriam estar sendo negociadas.

Para responder a esta pergunta, os autores utilizaram a técnica de regressão linear múltipla como ferramenta para análise, utilizando como variável dependente, o múltiplo $\mathrm{P} / \mathrm{L}$, e como variáveis independentes: taxa de crescimento do lucro; taxa de distribuição de dividendos; e desvio padrão do lucro, como variáveis representativas do crescimento, geração de fluxo de caixa e risco, respectivamente. Através da regressão estimada, pôde-se: (1) quantificar o quanto cada uma destas características impactavam no múltiplo e, inserindo os valores correntes das variáveis independentes de cada empresa, (2) definir o que os autores chamaram de preço teórico da empresa, para comparar com o preço de mercado (negociado no mercado).

Os autores concluíram que as variáveis determinantes conseguiam explicar o múltiplo e, inclusive defendem, como estratégia de investimento, comprar ações de empresas que estão 
subavaliadas (preço teórico inferior ao preço de mercado), tendo como hipótese que o preço de mercado converge para o preço teórico antes do preço teórico mudar.

Dentro desta linha de pesquisa, e em contexto de países emergentes, Heveadi (1999) replicou o estudo do Whitbeck \& Kisor (1963) no mercado da Indonésia (Jakarta stock Exchange) com uma base de dados dos anos de 1995 a 1997, usando como variável dependente o múltiplo $\mathrm{P} / \mathrm{L}$, e como variáveis independentes: crescimento; taxa de distribuição de dividendos; e desvio padrão do crescimento, fazendo um modelo de regressão linear múltipla para cada ano da base de dados. Os autores concluíram que o modelo é útil para entender a influência das variáveis independentes sobre o múltiplo, embora não aconselhem utilizá-lo para fins de tomada de decisão de compra ou venda de ação no curto prazo.

Seguindo metodologia bastante semelhante às dos trabalhos anteriores, o trabalho de Maniar (2014) utilizou uma base de dados do mercado acionário da Índia e testou diversas variáveis explicativas, sendo algumas destas com diferentes intervalos de tempo (1 ano a 5 anos) em relação aos múltiplos (P/L, EV/EBITDA, P/PLC e P/Receita).

Como resultado, encontrou que os modelos gerados conseguiram explicar grande parte da variação dos múltiplos, principalmente as variáveis: retorno; estimativa de crescimento para o próximo ano; taxa de distribuição de dividendos; e beta. Concluiu-se que o poder explicativo das variáveis mais próximas do período em análise é maior.

O estudo de Liu, Nissim, \& Thomas (2002) comparou variáveis explicativas utilizando dados históricos com estimativa de valor das empresas. Concluiu-se de forma consistente que a estimativa de lucro das empresas foi a que melhor explicou os múltiplos analisados. Estes dados corroboram com a pesquisa de Kim \& Ritter (1999), realizada anteriormente, na qual foi concluído que a estimativa de lucro prevê o múltiplo $\mathrm{P} / \mathrm{L}$ com maior performance do que o lucro histórico.

Omran (2003) realizou um estudo com dados de empresas do Emirados Árabes Unidos, e analisou os múltiplos P/Receita (preço sobre receita), P/PLC (preço sobre patrimônio líquido contábil) e P/L (preço sobre lucro), via regressão linear múltipla. O autor acrescentou à pesquisa a técnica de dados em painel, encontrando que os múltiplos analisados estão respectivamente relacionados com as variáveis explicativas: margem de lucro; roe (retorno sobre o patrimônio líquido contábil); e taxa de distribuição de dividendos. Os modelos para os múltiplos P/Receita e P/PLC apresentaram melhores resultados. 
Diferentemente dos artigos apresentados anteriormente, Osmundsen, Asche, Misund \& Mohn (2006) avaliaram empresas de somente um setor - o de petróleo e gás - no horizonte de 14 anos (1990 - 2003). Nesse sentido, os autores fizeram uma análise setorial aprofundada, abordando a trajetória, os principais players e, com base nos relatórios do setor, selecionou um múltiplo bastante difundido no setor $\left(\mathrm{EV} / \mathrm{DACF}^{12}\right)$.

Além disso, foram coletadas variáveis financeiras e operacionais para explicar o valor das empresas, aplicando a técnica de regressão linear múltipla e em dados em painel. Como resultado, encontraram que a variável explicativa $\operatorname{RoACE}^{13}$, ao contrário do que os participantes do setor acreditavam, possuía poder explicativo menor do que o esperado.

Em contexto nacional, Arruda (2015) realizou uma pesquisa de análise dos determinantes dos múltiplos $\mathrm{P} / \mathrm{L}, \mathrm{P} / \mathrm{PLC}$ e $\mathrm{P} /$ Receita, utilizando como variáveis explicativas: taxa de distribuição de dividendos; beta; taxa de crescimento; roe; margem líquida, tamanho da empresa (ativo total); momento (pontos do Ibovespa); liquidez (quantidade de negócios das ações); endividamento (dívida total líquida); e setor de atuação como dummie, para os anos 2004 a 2013. O autor considerou que os modelos estimados para os múltiplos P/L, P/PLC e $\mathrm{P} /$ receita eram significativos.

Orlovas, Serra \& Carrete (2018), também em contexto de empresas brasileiras, analisaram o múltiplo EV/EBITDA em oferta pública inicial, utilizando como variáveis explicativas: o múltiplo de empresas comparáveis; rentabilidade; alavancagem; tamanho e o ano como dummy - indicando o múltiplo de empresas comparáveis como a principal variável para explicar a variável dependente.

Damodaran (2006), para selecionar as variáveis explicativas dos múltiplos, utiliza a metodologia que serviu de base para a presente pesquisa. Nesta, o autor extrai as variáveis via derivação do modelo do FCD e da variável de padronização, atualizando e disponibilizando, anualmente, em seu site, ${ }^{14}$ as regressões estimadas.

A tabela (1) sintetiza estudos realizados em contexto de países emergentes, em que a metodologia utilizada foi próxima da utilizada na presente pesquisa - são expostos os múltiplos analisados; as respectivas variáveis explicativas utilizadas; o ano que se refere à base de dados; e o coeficiente de determinação $\left(R^{2}\right)$ dos modelos:

\footnotetext{
12 EV/DACF: EV (valor da empresa) dividido por DACF (Debt-Ajusted cash flow), reflete o fluxo de caixa operacional acrescido dos pagamentos de serviço de débitos após imposto.

${ }^{13}$ RoACE (Return on average capital employed): retorno médio do capital investido.

$14 \mathrm{http}: / /$ people.stern.nyu.edu/adamodar/New_Home_Page/dataarchived.html\#multiples.
} 
Tabela 1 - Resultados apresentados em pesquisas utilizando países emergentes

\begin{tabular}{|c|c|c|c|c|c|}
\hline autor/ano & país & variáveis explicativas & múltiplo & ano & $\mathbf{R 2}$ \\
\hline \multirow{3}{*}{ Heveadi (1999) } & \multirow{3}{*}{ Indonésia } & \multirow{3}{*}{$\begin{array}{l}\text { desvio-padrão do lucro, payout e taxa } \\
\text { de crescimento }\end{array}$} & $\mathrm{P} / \mathrm{L}$ & 1995 & 0,12 \\
\hline & & & $\mathrm{P} / \mathrm{L}$ & 1996 & 0,33 \\
\hline & & & $\mathrm{P} / \mathrm{L}$ & 1997 & 0,49 \\
\hline \multirow{4}{*}{ Maniar (2014) } & \multirow{4}{*}{ Índia } & \multirow{4}{*}{$\begin{array}{c}\text { lucratividade, alavancagem, roe, roce, } \\
\text { beta, crescimento }(\mathrm{t}+1) \text {, crescimento } \\
\text { longo prazo, retorno }(\mathrm{t}-1) \text {, retorno } \\
(\mathrm{t}-5) \text {, payout }\end{array}$} & $\mathrm{P} / \mathrm{L}$ & 2012 & 0,72 \\
\hline & & & $\mathrm{P} / \mathrm{PLC}$ & 2012 & 0,63 \\
\hline & & & $\mathrm{P} /$ receita & 2012 & 0,66 \\
\hline & & & EV/Ebitda & 2012 & 0,49 \\
\hline \multirow{3}{*}{ Arruda (2015) } & \multirow{3}{*}{ Brasil } & \multirow{3}{*}{$\begin{array}{l}\text { beta, taxa de crescimento, roe, } \\
\text { margem líquida, payout, ativo total, } \\
\text { pontos do Ibovesp, liquidez e }\end{array}$} & $\mathrm{P} / \mathrm{L}$ & 2004 a 2013 & 0,19 \\
\hline & & & $\mathrm{P} / \mathrm{PLC}$ & 2004 a 2013 & 0,32 \\
\hline & & & $\mathrm{P} /$ receita & 2004 a 2013 & 0,50 \\
\hline \multirow{12}{*}{ Gupta (2018) } & \multirow{12}{*}{ Índia } & \multirow{12}{*}{$\begin{array}{l}\text { margem operacional, beta, roe, anos, } \\
\text { roic, crescimento, payout, } \\
\text { depreciação, endividamento }\end{array}$} & $\mathrm{P} / \mathrm{L}$ (setor automóvel) & 2014 a 2016 & 0,02 \\
\hline & & & P/PLC (setor automóvel) & 2014 a 2016 & 0,25 \\
\hline & & & P/receita (setor automóvel) & 2014 a 2016 & 0,37 \\
\hline & & & EV/Ebitda (setor automóvel) & 2014 a 2016 & 0,55 \\
\hline & & & $\mathrm{P} / \mathrm{L}$ (setor bancário) & 2014 a 2016 & 0,30 \\
\hline & & & P/PLC (setor bancário) & 2014 a 2016 & 0,59 \\
\hline & & & $\mathrm{P} /$ receita (setor bancário) & 2014 a 2016 & 0,64 \\
\hline & & & EV/Ebitda (setor bancário) & 2014 a 2016 & 0,74 \\
\hline & & & $\mathrm{P} / \mathrm{L}$ (setor aço) & 2014 a 2016 & 0,04 \\
\hline & & & P/PLC (setor aço) & 2014 a 2016 & 0,29 \\
\hline & & & $\mathrm{P} /$ receita (setor aço) & 2014 a 2016 & 0,33 \\
\hline & & & EV/Ebitda (setor aço) & 2014 a 2016 & 0,53 \\
\hline \multirow{20}{*}{$\begin{array}{l}\text { Damodaran } \\
\text { (Atualizado } \\
\text { anualmente) }\end{array}$} & \multirow{20}{*}{$\begin{array}{c}\text { Países } \\
\text { Emergentes }\end{array}$} & \multirow{4}{*}{$\begin{array}{c}\text { expectativa lucro }(\mathrm{t}+5) \text {, beta, payout } \mathrm{e}- \\
\text { roe }\end{array}$} & $\mathrm{P} / \mathrm{L}$ & 2015 & 0,27 \\
\hline & & & $\mathrm{P} / \mathrm{L}$ & 2016 & 0,12 \\
\hline & & & $\mathrm{P} / \mathrm{L}$ & 2017 & 0,12 \\
\hline & & & $\mathrm{P} / \mathrm{L}$ & 2018 & 0,25 \\
\hline & & \multirow{4}{*}{$\begin{array}{c}\text { expectativa lucro }(\mathrm{t}+5) \text {, beta, payout e } \\
\text { roe }\end{array}$} & P/PLC & 2015 & 0,47 \\
\hline & & & $\mathrm{P} / \mathrm{PLC}$ & 2016 & 0,34 \\
\hline & & & $\mathrm{P} / \mathrm{PLC}$ & 2017 & 0,42 \\
\hline & & & $\mathrm{P} / \mathrm{PLC}$ & 2018 & 0,35 \\
\hline & & \multirow{4}{*}{$\begin{array}{l}\text { expectativa receita }(\mathrm{t}+5) \text {, taxa de } \\
\text { reinvesimento, wacc, taxa de } \\
\text { imposto, roic e débito/capital }\end{array}$} & EV/Ebitda & 2015 & 0,03 \\
\hline & & & EV/Ebitda & 2016 & 0,06 \\
\hline & & & EV/Ebitda & 2017 & 0,06 \\
\hline & & & EV/Ebitda & 2018 & 0,13 \\
\hline & & \multirow{4}{*}{$\begin{array}{l}\text { expectativa receita }(\mathrm{t}+5) \text {, taxa de } \\
\text { reinvesimento, wacc, taxa de } \\
\text { imposto, roic e débito/capital }\end{array}$} & $\mathrm{EV} / \mathrm{IC}$ & 2015 & 0,46 \\
\hline & & & $\mathrm{EV} / \mathrm{IC}$ & 2016 & 0,32 \\
\hline & & & $\mathrm{EV} / \mathrm{IC}$ & 2017 & 0,53 \\
\hline & & & $\mathrm{EV} / \mathrm{IC}$ & 2018 & 0,48 \\
\hline & & \multirow{4}{*}{$\begin{array}{l}\text { expectativa receita }(\mathrm{t}+5) \text {, taxa de } \\
\text { reinvesimento, wacc, taxa de imposto } \\
\text { efetiva, margem operacional, } \\
\text { débito/capital e cobertura de juros }\end{array}$} & EV/receita & 2015 & 0,10 \\
\hline & & & EV/receita & 2016 & 0,14 \\
\hline & & & EV/receita & 2017 & 0,07 \\
\hline & & & EV/receita & 2018 & 0,16 \\
\hline
\end{tabular}

Fonte: Elaboração própria

Nas pesquisas apresentadas na tabela (1), ressalta-se que, embora o escopo seja avaliar a performance dos múltiplos testando diferentes variáveis para explicar as diferenças do preço relativo de cada empresa, a comparação entre os trabalhos é limitada, por conta das diferentes metodologias utilizadas pelos autores para estimar os modelos. 
Heveadi (1999), Maniar (2014) e Arruda (2015) não retiraram do modelo final as variáveis explicativas sem significância. Gupta (2018) retirou as variáveis explicativas sem significância, contudo, na pesquisa, os modelos gerados utilizam empresas de mesmo setor, enquanto que nas demais, são utilizadas empresas de todos os setores. Damodaran (2006), para os modelos estimados, apresenta somente o $R^{2}$, os coeficientes angulares $\left(b_{j}\right)$ para variáveis explicativas com significância, e não apresenta a análise dos resíduos. Com exceção de Heveadi (1999) e Damodaran (2006), nas demais pesquisas, mesmo utilizando dados de mais de um ano, os autores consideraram os dados como todos de um mesmo período, além das variáveis explicativas também serem diferentes.

\subsubsection{Apresentando os múltiplos}

Os múltiplos também podem ser classificados de acordo com a variável de padronização utilizada. Os principais são: múltiplos de lucro; valor patrimonial contábil; receita; e setoriais.

Nas seções a seguir são apresentados os múltiplos analisados nesta pesquisa (múltiplos de lucro; valor patrimonial contábil; e receita) e adicionalmente são abordados os múltiplos setoriais. Ressalta-se que não foi escopo desta pesquisa exaurir todos os múltiplos existentes, mas sim, apresentar os principais, especialmente os considerados consistente conforme conceito exposto na seção 2.1.2.3.1 (Consistência e Uniformidade). A seguir, apresentamos, apontando seus respectivos pontos fortes e fracos e suas respectivas variáveis determinantes.

\subsection{Múltiplos de lucro (Earnings Multiples)}

O múltiplo de lucro é o mais comumente utilizado na avaliação relativa (Koller, 2015) e, segundo Gewehr (2007), é o mais utilizado no mercado brasileiro. Uma das formas mais intuitivas de avaliar um ativo é pelo lucro gerado, assim, é comum, ao se avaliar uma empresa, analisar o lucro gerado em relação ao preço.

Nesta subseção, serão apresentados, portanto, os múltiplos $\mathrm{P} / \mathrm{L}$ (preço dividido pelo lucro líquido) e EV/EBITDA - enterprise value (valor da empresa) divido pelo EBITDA (earnings before interest, taxes, depreciation and amortization) em português LAJIDA - 
Lucro antes dos juros despesas financeiras; impostos ( $\operatorname{IR}^{15}$ e $\left.\operatorname{CSLL}^{16}\right)$; depreciação e amortização.

\subsection{Múltiplo P/L (preço pelo lucro)}

O múltiplo P/L faz parte dos múltiplos de valor de mercado e é calculado pela divisão do preço do capital próprio (equity value) pelo lucro líquido. Pode ser entendido como uma medida de quantos reais, ou unidade monetária, os investidores estão dispostos a pagar pelos lucros corrente e futuro da empresa. Com isto, entende-se que as empresas com maiores $\mathrm{P} / \mathrm{Ls}$ possuem maiores expectativas de lucros. A seguir, são destacados alguns pontos de atenção ao utilizá-lo.

Segundo Goedhart, Koller \& Wessels (2015), o múltiplo de lucro é uma medida que mescla aspectos operacionais, não operacionais e financeiros. Pode ser bastante volátil de um exercício para outro, principalmente para empresas de maior risco, que têm o lucro e variação da cotação da ação instáveis. Isto faz com que o múltiplo de uma mesma empresa tenha grandes variações no decorrer do tempo, e também em comparação com outras empresas num mesmo período.

Damodaran (2012) adverte que muitas empresas crescem via aquisição de outras empresas, e não há um padrão de como contabilizar o incremento no lucro. Embora as empresas devam contabilizar a aquisição como goodwill ${ }^{17}$ no ativo do Balanço Patrimonial, não existe uma regra de como reportar o lucro na Demonstração de Resultado de Exercício, o que pode ocasionar em diferentes medidas de lucro líquido e, consequentemente, do múltiplo $\mathrm{P} / \mathrm{L}$.

Outro fator é que as empresas podem contabilizar determinados gastos, ou como despesa na Demonstração de Resultado de Exercício, ou como investimento no Balanço Patrimonial. Desta forma, em uma empresa que opte por considerar um gasto como investimento, o valor será contabilizado no Balanço Patrimonial, e não como resultado de exercício e, consequentemente, irá inflar o lucro líquido do exercício.

\footnotetext{
15 IR: Imposto de renda.

${ }^{16}$ CSLL: Contribuição Social sobre o Lucro Líquido.

${ }^{17}$ Goodwill diz respeito à diferença entre o que uma empresa paga para adquirir outra, e o seu respectivo valor patrimonial contábil.
} 
Pearl \& Rosenbaum (2013), acrescentam que empresas que possuem prejuízos, geralmente não são utilizadas no universo de empresas comparáveis, pois um múltiplo negativo geraria uma avaliação de valor também negativa, o que não faz sentido. E ter uma amostra somente com empresas lucrativas gera uma amostra enviesada.

O lucro é uma medida que depende da estrutura de capital da empresa, consequentemente, empresas similares em termos de tamanho e margens operacionais podem ter diferentes margens de lucro devido ao grau de alavancagem e, similarmente, diferenças contábeis entre as empresas, tais como depreciação e taxa de impostos, que podem gerar múltiplos díspares entre empresas comparáveis.

\subsection{1 Variáveis explicativas do múltiplo $\mathrm{P} / \mathrm{L}$}

As variáveis explicativas do múltiplo apresentada nesta subseção e para os demais múltiplos utilizados nesta pesquisa, foram identificadas a partir de um método exposto por Damodaran (2012). De acordo com o autor, os determinantes dos múltiplos podem ser extraídos do modelo de Fluxo de Caixa Descontado e da variável de padronização.

O modelo mais simples do Fluxo de Caixa Descontado para capital próprio é o modelo de fluxo de dividendos descontado com crescimento estável:

$$
\mathrm{P}=\frac{\mathrm{D}}{\text { ewace }-\mathrm{B}},
$$

onde, $\mathrm{P}$ é valor do capital próprio (equity), o $D$ é a expectativa de dividendos por ação, ewacc é o custo do capital próprio (ke) é o custo médio ponderado do capital próprio e o $g$ é o crescimento estável esperado.

Dividindo ambos os lados pelo parâmetro em estudo, que é lucro líquido, se obtêm:

$$
\frac{\mathrm{P}}{\mathrm{LPA}}=\mathrm{PL}=\frac{\text { pox }(1+\mathrm{g})}{\text { ewace }-\mathrm{g}}
$$

Na equação, a variável lucro por ação (LPA) que divide o lado direito da equação, ao dividir o $D$, resulta na razão (D/LPA), a qual pode ser entendida como taxa de distribuição de dividendos (po) ou payout ratio em inglês, e considerando o crescimento esperado dos dividendos multiplicando a po, chega-se na equação (10). Com isto é identificada as variáveis que estão relacionadas ao múltiplo P/L, que são: po, crescimento (g) e risco (ewacc).

Uma forma alternativa de analisar o múltiplo é inserindo o roe na equação (10), através da expressão da taxa de crescimento (equação 11): 


$$
\mathrm{g}=\operatorname{roe} \mathrm{x}(1-\mathrm{po})
$$

onde, se estabelece que o crescimento depende do quanto a empresa retém do lucro e da qualidade do investimento. Sendo diretamente proporcional a medida de rentabilidade (roe) multiplicado pelo o que a empresa retém do lucro (1-po).

Isolando-se a taxa de distribuição de dividendos (po), tem-se:

$$
\text { po }=1-\frac{\mathrm{g}}{\mathrm{ROE}}
$$

e substituindo a variável po pela sua igualdade, na equação (10), temos:

$$
\frac{\mathrm{P}}{\mathrm{LPA}}=\frac{1-\frac{\mathrm{g}}{\mathrm{ROE}} \mathrm{x}(1+\mathrm{g})}{\text { ewace }-\mathrm{g}} .
$$

Com esta reformulação o roe seria uma variável que também impacta o múltiplo e é positivamente relacionada.

Assim, as variáveis explicativas do múltiplo P/L e suas respectivas relações são:

- 1-po: Relação positiva;

- roe: Relação positiva;

- $\quad$ g: Relação positiva;

- ewacc: Relação negativa.

\subsection{Múltiplo EV/EBITDA (valor da empresa pelo EBITDA)}

O múltiplo EV/EBITDA faz parte dos múltiplos de valor da empresa. Comparando o múltiplo $\mathrm{P} / \mathrm{L}$ ao EV/EBITDA, o segundo possui a vantagem de ser mais fácil de comparar com um número maior de empresas e, inclusive, de diferentes setores, pois não há influência da estrutura de capital, uma vez que representa uma medida que antecede o pagamento de juros, impostos, depreciação e amortização.

Segundo Koller (2005), o EBITDA, ao contrário do lucro líquido, não considera aspectos não operacionais, e a quantidade de empresas com EBITDA negativo é consideravelmente menor. 


\subsection{1 Variáveis explicativas do múltiplo EV/EBITDA}

Utilizando o conceito de consistência, para avaliar o valor da empresa em oposição ao valor do capital próprio (equity), a referência utilizada para avaliação ao invés do preço pelo lucro líquido passa a ser o valor da empresa (enterprise value) e o seu respectivo EBITDA.

Assim para analisar os determinantes do EV/EBITDA é utilizado o modelo do Fluxo de Caixa Descontado para Firma (FCDF) considerando o crescimento estável, conforme equação abaixo:

$$
\mathrm{EV}=\frac{\mathrm{FCDF}}{\text { wace }-\mathrm{g}},
$$

onde, EV é o valor da empresa, wacc é custo médio ponderado de capital e g taxa de crescimento. A seguir é apresentado a forma de se calcular FCDF a partir do Lucro Operacional Líquido após Imposto de renda:
(=) Lucro Operacional Líquido após IR $\operatorname{EBIT}(1-\mathrm{t})$
(+) Depreciação/amortização DA
(=) Fluxo de caixa Operacional
(-) Investimentos em bens de capital CAPEX
(-) Variação do investimento em giro $\Delta$ capital de giro

\section{(=) Fluxo de caixa Disponível da Firma (FCDF)}

Uma vez expostas as contas e os respectivos impactos (negativo ou positivo) no FCDF, temos que:

$\mathrm{FCDF}=\operatorname{EBIT}(1-\mathrm{t})-(-\mathrm{DA}+\mathrm{CAPEX}+\Delta$ capital de giro $)$

$=($ EBITDA - DA $)(1-t)-(-$ DA + CAPEX $+\Delta$ capital de giro $)$

$=($ EBITDA $)(1-t)-D A(1-t)-($ reinvestimento $)$.

Com isto, substituindo o FCDF na equação (14):

$$
\mathrm{EV}=\frac{E B I T D A_{1}(1-\mathrm{t})-D A(1-\mathrm{t})-\text { reinvestimento }}{\text { wace }-g},
$$

e dividindo ambos os lados pela variável de padronização EBITDA, tem-se:

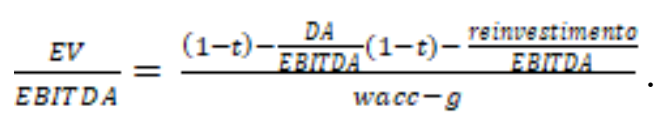

E, com isto, são obtidas as variáveis explicativas do múltiplo EV/EBITDA, e suas respectivas relações: 
- $\quad$ t (taxa de tributação): Relação negativa;

- $\quad$ roic: Relação positiva;

- rir: Relação positiva;

- $\quad$ wacc: Relação negativa;

- $\mathrm{g}$ (crescimento): Relação positiva.

\subsection{Múltiplos de Patrimônio Contábil (Book value Múltiples)}

A relação entre o Patrimônio Contábil com alguma medida de valor é uma métrica de interesse utilizada por muitos analistas, empresas negociadas abaixo do Patrimônio Contábil são alvo de atenção.

Nesta seção são apresentados múltiplos de valor contábil, P/PLC (preço pelo Patrimônio Líquido Contábil) e EV/IC (Valor empresarial pelo Capital investido).

\subsection{Múltiplo P/PLC (preço pelo patrimônio líquido contábil)}

O P/PLC é um múltiplo de valor de mercado e utiliza o Patrimônio Líquido Contábil como variável de padronização. Esta é uma medida determinada por regras contábeis, a qual é apresentada no Balanço Patrimonial, sendo a diferença entre o Ativo e o Passivo da empresa. Geralmente difere do numerador, Patrimônio Líquido (capital próprio), o qual, considera adicionalmente a expectativa de lucro e a geração de fluxo de caixa da empresa.

Possui, como aspectos positivos: (1) o valor do Patrimônio Líquido Contábil comparado às outras variáveis de padronização é relativamente estável; (2) é um método simples para encontrar um parâmetro de referência para comparar com o valor; (3) a quantidade de empresas com Patrimônio Líquido Contábil negativo é relativamente menor se comparado às empresas que tenham lucro negativo.

Como aspectos negativos: (1) possui forte influência de regras contábeis e decisões contábeis, isto pode prejudicar a comparação com empresas de setores e/ou com sede em diferentes países, e também tem forte influência do valor pago nos ativos e nos ajustes contábeis; (2) sua utilização em setores de serviço e tecnologia pode ter pouca significância, uma vez que são setores que não possuem ativo tangível relevante; (3) o múltiplo de Patrimonial Líquido Contábil pode variar bastante entre as empresas da mesma indústria, dependendo do potencial de crescimento e da qualidade de cada investimento. 


\subsection{1 Variáveis explicativas do múltiplo P/PLC}

Uma vez que o múltiplo P/PLC utiliza o valor de capital próprio (equity), é preciso utilizar o modelo de fluxo de dividendo descontado (equação 9):

$$
\mathrm{P}=\frac{\mathrm{D}}{\text { ewace }-\mathrm{g}} \text {. }
$$

E considerando que a expectativa de dividendos por ação (D) para o próximo período pode ser expressa como:

$$
\mathrm{D}=\mathrm{L}_{1} \mathrm{xpo} \text {, }
$$

onde, $L_{1}$ é expectativa de lucro para o próximo período e po a taxa de distribuição de dividendos. E substituindo D por $\mathrm{L}_{1} \times$ po na Equação 9:

$$
\mathrm{P}=\frac{\mathrm{L}_{1} \mathrm{xpo}}{\text { ewace }-\mathrm{g}},
$$

e utilizando a expressão do roe:

$$
\text { roe }=\frac{\mathrm{LL}}{\mathrm{PLC}},
$$

em que LL é lucro líquido e PLC é Patrimônio Líquido contábil. E isolando o lucro líquido da equação (19) e substituindo-o na equação (18) temos que:

$$
P=\frac{\text { PLCx roexpo }}{\text { ewace }-g},
$$

e dividindo ambos os lados pela variável de padronização, Patrimônio Líquido contábil (PLC), tem-se que:

$$
\frac{\mathrm{P}}{\mathrm{PLC}}=\frac{\text { roe } \mathrm{xpo}}{\text { ewace }-\mathrm{g}} .
$$

Antes de se obter a formatação final do múltiplo e suas respectivas variáveis explicativas, utiliza-se um passo intermediário, isolando o po com base na equação dos determinantes da taxa de crescimento $(\mathrm{g})$ :

$$
g=(1-p o) \times \text { roe }
$$

e isolando-se o po, temos: 


$$
\text { po }=\frac{-\mathrm{g}}{\text { roe }}+1
$$

E retomando na equação 21, encontra-se a equação abaixo:

$$
\frac{\mathrm{P}}{\mathrm{PLC}}=\frac{\text { roe }-\mathrm{g}}{\text { ewacc }-\mathrm{g}}
$$

Assim, as variáveis que estão relacionadas ao múltiplo P/PLC são roe, po, ewacc e g, as quais tem a seguinte relação:

- roe: Relação positiva;

- 1-po: Relação positiva;

- g: Relação positiva;

- $\quad$ ewacc: Relação negativa.

\subsection{Múltiplo EV/IC (valor da empresa pelo capital investido)}

O EV/IC é um múltiplo de valor da empresa, ao invés de relacionar o valor de mercado com Patrimônio Líquido Contábil, utiliza o valor empresarial com capital da empresa.

O capital investido (IC) é calculado, somando o Patrimônio Líquido Contábil, mais valor contábil do endividamento menos o caixa. Assim, é preciso manter a consistência entre o que é considerado como endividamento e caixa no cálculo do valor da empresa (EV) e no cálculo do capital investido.

\subsection{1 Variáveis explicativas do múltiplo EV/IC (investimento de capital)}

As variáveis do múltiplo EV/CI são extraídas do modelo de Fluxo de Caixa Descontado da Firma (FCDF), utilizando a Equação 14:

$$
\mathrm{EV}=\frac{\mathrm{FCDF}}{\text { waec- } \mathrm{g}} \text {. }
$$

E desmembrando o FCDF, tem-se:

$$
\mathrm{FCDF}=\mathrm{EBIT}_{1}(1-\mathrm{t}) \times(1-\text { rir }),
$$


onde, $t$ taxa de tributação e rir é a taxa de reinvestimento, a qual é calculada da seguinte forma:

$$
\text { rir }=\frac{\text { reinwestimento }}{\text { NOPAT }}
$$

onde, reinvestimento é o CAPEX mais a variação dos investimentos em capital de giro de um exercício para o seguinte menos a depreciação do período, e o NOPAT é lucro operacional líquido depois de impostos. E substituindo o FCDF na equação 14, tem-se:

$$
\mathrm{EV}=\frac{\mathrm{EBIT}(1-\mathrm{t}) \mathrm{x}(1-\mathrm{ri \tilde {r }})}{\text { wace }-\mathrm{g}} .
$$

Ao inserir a variável de padronização, divide-se ambos os lados da equação pelo capital investido $(\mathrm{CI})$ :

$$
\frac{\mathrm{EV}}{\mathrm{CI}}=\frac{\text { roie }(1-\mathrm{rir})}{\text { wace }-\mathrm{g}}
$$

onde, a razão $\left(\frac{\operatorname{EBIT}_{1}(1-t)}{\mathrm{CI}}\right)$ foi substituída pela variável roic.

Uma segunda forma de se analisar o múltiplo EV/IC é através da expressão da taxa de crescimento ( $\mathrm{g}=$ rir $\mathrm{x}$ ROIC), a qual também pode ser expressa por:

$$
\operatorname{rir}=\frac{\text { g }}{\text { roic }}
$$

e substituindo na equação 27, tem-se:

$$
\frac{\mathrm{EV}}{\mathrm{CI}}=\frac{\text { roic }-\mathrm{g}}{\text { wacc }-\mathrm{g}}
$$

Desta forma, as variáveis explicativas de ambos os múltiplos P/PLC e EV/CI são as mesmas, porém substituindo-se o roe pelo roic, o ewacc pelo wacc e a taxa de distribuição de dividendos (po) pela taxa de reinvestimento (rir).

Segue a relação do múltiplo EV/CI com as variáveis explicativas:

- $\quad$ roic: Relação positiva;

- $\quad$ rir: Relação positiva;

- g: Relação positiva;

- $\quad$ wacc: Relação negativa;

- $\quad$ t: Relação negativa. 


\subsection{Múltiplo de receita}

O múltiplo de receita, em relação aos anteriores, possui a vantagem de ser uma medida alternativa que não é afetada por normas contábeis, o que facilita a comparação com outras empresas: que atuam em diferentes setores, com diferentes sistemas contábeis; nascentes, que ainda não possuem lucro; de tecnologia, que possuem expectativa de crescimento agressivo, porém que ainda não geram lucro.

Ao contrário dos múltiplos de lucro e do patrimônio contábil que podem ser negativos, o múltiplo de receita não apresenta valor negativo e, consequentemente, não enfrenta o viés de se excluir empresas que geram múltiplos negativos, o que reduz o universo da amostra. Outra vantagem é que a receita costuma ser menos volátil, comparado ao lucro, o que gera menos variações no múltiplo.

Contudo, Pearl \& Rosenbaum (2013) consideram o múltiplo de receita menos relevante, comparado aos discutidos anteriormente, receita é um indicativo de tamanho, porém não necessariamente é traduzido em fluxo de caixa e lucratividade, as quais são medidas chave de valor. Assim, aponta-se que este múltiplo deveria ser utilizado como complementar aos anteriores.

O múltiplo de receita diferente dos anteriores que possuem múltiplo de preço (p) e valor da empresa (EV), pelo fato da variável Receita não ser de propriedade somente dos acionistas, de acordo com o conceito de consistência só pode ser calculado, utilizando a medida de valor da empresa (EV).

\subsection{Variáveis explicativas do múltiplo EV/Receita}

Assim como os múltiplos anteriores de valor da empresa, o múltiplo de receita tem como ponto de partida o modelo de Fluxo de Caixa Descontado para Firma:

$$
\mathrm{EV}=\frac{\operatorname{EBIT}(1-\mathrm{t}) \times(1-\text { rir })}{\text { wace }-\mathrm{g}}
$$

E dividindo ambos os lados pela variável de padronização, tem-se:

$$
\frac{\mathrm{EV}}{\text { Receita }}=\frac{\frac{\text { EBIT(1-t) }}{\text { Receita }} \mathrm{x}(1-\mathrm{rir})}{\text { wacc }-\mathrm{g}},
$$


onde, $\frac{E B I_{1}(1-t)}{\text { Receita }}$ é a margem operacional antes do pagamento de impostos (mo).

Assim, as variáveis explicativas do múltiplo são a margem operacional (mo), a taxa de reinvestimento (rir), taxa de crescimento (g), o risco (wacc) e taxa de tributação (t).

Relação do múltiplo EV/Receita com as variáveis determinantes:

- mo: Relação positiva;

- $\quad$ rir: Relação positiva;

- $\quad$ g: Relação positiva;

- $\quad$ wacc: Relação negativa;

- $\quad$ t: Relação negativa.

\subsection{Múltiplos específicos/setoriais}

Os múltiplos setoriais são bastante comuns em determinados setores, uma vez que se relacionam com algum aspecto operacional da empresa, a exemplo do setor de transporte, em que a quantidade de assentos, a taxa de ocupação, ou o custo por assento provavelmente serão métricas bastante importantes - desta forma, no momento de se avaliar uma empresa nesse setor, pode fazer mais sentido olhar para essas métricas, do que para os múltiplos tradicionais.

Nos últimos anos, com o avanço de empresas de alta tecnologia a demandarem avaliação por parte do mercado, surgiram alguns múltiplos alternativos aos tradicionais. Isto se deve ao fato de que as mesmas poderiam, no momento da análise, não gerar resultados, devendo ser avaliadas pelo potencial de crescimento e pela evolução da margem da operação. De acordo com Pearl \& Rosenbaum (2013), muitos setores utilizam múltiplos específicos de forma complementar, ou substituindo as métricas tradicionais apresentadas nas seções anteriores.

Damodaran (2012) aponta algumas vantagens dos múltiplos setoriais: (1) permite relacionar o valor da empresa com alguma especificidade operacional ou de produção; (2) não há influência de regras contábeis, assim, comparar a métrica entre empresas de um mesmo setor pode trazer uma melhor compreensão do valor da empresa em análise; (3) pode ser uma alternativa para casos em que o setor analisado tenha resultados negativos.

Contudo, uma limitação desses múltiplos é que podem induzir a conclusões equivocadas. O múltiplo pode não ser estendido a outras empresas do mercado e, desta forma, 
pode considerar uma determinada empresa subavaliada, utilizando como ponto de visto o múltiplo do setor, mas a mesma estaria superavaliada se utilizasse outros múltiplos, e fosse comparada com o mercado como um todo. 


\section{METODOLOGIA}

Para atingir o escopo proposto, será realizada uma pesquisa descritiva, uma vez que, conforme Cooper e Schindler (2003), a mesma constitui o método adequado quando se objetiva descobrir associações entre variáveis. Segundo Mattar (1993, p. 162): “A pesquisa descritiva visa prover o pesquisador de dados sobre as características de grupos, estimar proporções de determinadas características e verificar a existência de relações entre as variáveis".

\subsection{Modelos de Regressão Linear Múltipla}

A regressão linear múltipla permite que seja analisada a relação entre uma ou mais variáveis explicativas e a variável dependente. O modelo de regressão linar múltipla é dado por:

$$
\mathrm{Y} i=b_{0}+b_{1}\left(X_{1 \tilde{i}}\right)+b_{2}\left(X_{2 i ்}\right)+\ldots+b_{k}\left(X_{k i \tilde{i}}\right)+u_{\tilde{i}}
$$

onde, $Y i$ é variável dependente associada a $i$-ésima empresa, $b_{0}$ é coeficiente do modelo, $b_{j}(j=1,2, \ldots, k)$ é o coeficiente associado a $j$-ésima empresa, $X_{j}(j=1,2, \ldots, k)$ é a $j$-ésima variável explicativa e $u_{i}$ é o $i$-ésimo erro.

Os coeficientes $b_{0}$ e $b_{j}$ são estimados a partir do método de mínimos quadrados ordinário (MQO). E o coeficiente de determinação $\left(\mathrm{R}^{2}\right)$ avalia a qualidade do modelo estimado.

\subsubsection{Pressupostos do modelo}

Para que os resultados dos testes $(t$ e $F$ ) tenham validade, é preciso testar as suposições:

- $\quad$ Normalidade dos resíduos;

- Homocedasticidade;

Normalidade dos resíduos: os resíduos devem apresentar distribuição normal, pois garantem a validade do p-valor dos testes $t$ e $F$. Para verificar este pressuposto, pode-se 
utilizar o teste de Shapiro-wilk ou teste de Shapiro-Francia. Nesta pesquisa, para analisar a normalidade dos resíduos, é utilizado o teste Shapiro-Wilk. Espera-se não rejeitar a hipótese nula de que a amostra provém de uma população normal, para isto, o valor calculado para o teste deve ser superior a 0,05 .

Homocedasticidade: neste pressuposto, é analisado se a variância nos resíduos do modelo estimado é constante.

Um diagnóstico utilizado para análise da homocedasticidade é o teste de BreuschPagan em que, considera como hipótese nula a variância dos erros ser constante, espera-se que a hipótese nula do teste não seja rejeitada.

Nesta pesquisa, para analisar a homocedasticidade dos resíduos, é utilizado o teste Breusch-Pagan ao nível de significância de 0,05. Com isto, se o p-valor $>0,05$ há indícios de que o modelo não apresenta problemas de homocedasticidade.

\subsubsection{Variáveis Dependentes}

As variáveis dependentes dos modelos são os múltiplos de valor de mercado e os múltiplos de valor da empresa:

- P/L: preço sobre o lucro;

- P/PLC: preço sobre Patrimônio líquido contábil;

- EV/EBITDA: valor da firma sobre o EBITDA;

- $\quad \mathrm{EV} / \mathrm{IC}$ : valor da firma sobre o investimento de capital;

- EV/Receita: valor da firma sobre a Receita.

Estes múltiplos foram os selecionados pois englobam os principais múltiplos existentes, são utilizados tanto no mercado como na academia e são múltiplos consistentes, uma vez que, ao utilizar no numerador uma medida de capital próprio (lucro líquido e patrimônio líquido contábil) o denominador também usa uma medida de capital próprio $(\mathrm{P})$. $\mathrm{E}$ da mesma forma, quando utiliza um numerador que remete a um valor referente ao valor da empresa (EBITDA, investimento de capital e receita) o denominador usa uma medida de valor da empresa $(\mathrm{EV})$. 


\subsubsection{Variáveis Independentes (explicativas)}

As variáveis independentes (explicativas) são as variáveis determinantes dos múltiplos, as quais foram identificadas durante a apresentação dos múltiplos.

Para os múltiplos de valor de mercado (p), foram identificadas as variáveis:

- Crescimento;

- Taxa de distribuição de dividendos;

- Rentabilidade;

- Risco.

E para os múltiplos de valor da empresa $(\mathrm{EV})$, foram identificadas as variáveis:

- Crescimento;

- Taxa de reinvestimento;

- Taxa de tributação;

- Rentabilidade;

- Margem operacional;

- Risco.

\subsection{Base de dados e modo de coleta das variáveis}

A base de dados utilizada nesta pesquisa é composta de empresas brasileiras negociadas na bolsa de valores do Brasil, formada por dados secundários coletados na base de dados da Thomson Reuters. O período de análise é de 2015 a 2018.

Nas tabelas 2, 3 e 4 são apresentadas as variáveis utilizadas na pesquisa. Na primeira coluna são apresentados os nomes das variáveis, que são abreviações das respectivas variáveis, expostas na segunda coluna e, na última coluna, estão a data da coleta, ou a forma de cálculo.

Tabela 2 - Coleta variáveis dependentes

\begin{tabular}{ccc}
\hline nome & variável & data coleta \\
\hline $\mathrm{p}$ & valor de mercado & $01 / 04 / 16,01 / 04 / 17,01 / 04 / 18$ e $01 / 04 / 19$ \\
$\mathrm{ev}$ & valor da firma & $01 / 04 / 16,01 / 04 / 17,01 / 04 / 18$ e $01 / 04 / 19$ \\
\hline
\end{tabular}

Fonte: Elaboração própria

Para coleta das variáveis dependentes (valor de mercado e valor da empresa), que são formadas pelo preço de negociação das empresas (cotação da ação), foi definido como data de referência o dia $01 / 04$ do ano seguinte à divulgação do Balanço encerrado do exercício. $\mathrm{O}$ 
motivo de se escolher esta data foi que, ao realizar a análise das datas que as empresas divulgam o Balanço encerrado do exercício, foi constatado que, embora as empresas tenham como prazo para apresentação do Balanço do exercício o último dia do terceiro mês de cada ano, a data 01/04 de cada ano foi a que garantia que 95\% das empresas já tivessem entregue os Balanços encerrados do exercício. Nesse sentido, a presente pesquisa optou por priorizar que, no valor de negociação das empresas (cotação da ação), estivessem embutidas as informações de resultado do exercício das empresas.

Adicionalmente, para a coleta do valor de mercado das empresas, foram considerados: (1) os valores dos Balanço consolidado ${ }^{18}$ das empresas; (2) a quantidade de ações primárias (ações emitidas em circulação); (3) valor de mercado calculado pela média ponderada do preço das classes de ações emitidas pela empresa com a respectiva quantidade de ações de cada classe, conforme indicado pela base de dados da Thomson Reuters.

Tabela 3 - Variáveis explicativas coletadas

\begin{tabular}{|c|c|c|}
\hline nome & variável & data coleta \\
\hline lucro & lucro líquido & $(2015,2016,2017$ e 2018$)$ \\
\hline plc & Patrimônio Líquido Contábil & $(2015,2016,2017$ e 2018$)$ \\
\hline ebitda & EBITDA & $(2015,2016,2017$ e 2018$)$ \\
\hline rec & receita & $(2015,2016,2017$ e 2018$)$ \\
\hline deb & débito total & $(2015,2016,2017$ e 2018$)$ \\
\hline wacc & custo médio ponderado de capital & $(2015,2016,2017$ e 2018$)$ \\
\hline ewacc & $\begin{array}{c}\text { custo médio ponderado de capital } \\
\text { próprio }\end{array}$ & $(2015,2016,2017$ e 2018$)$ \\
\hline ebit & ebit & $(2015,2016,2017$ e 2018$)$ \\
\hline roe & roe & $(2015,2016,2017$ e 2018$)$ \\
\hline roic & roic & $(2015,2016,2017$ e 2018$)$ \\
\hline $\operatorname{div}$ & dividendos pago & $(2015,2016,2017$ e 2018$)$ \\
\hline etax & imposto efetivo & $(2015,2016,2017$ e 2018$)$ \\
\hline capex & capex & $(2015,2016,2017$ e 2018$)$ \\
\hline wc & variação no capital de giro & $(2015,2016,2017$ e 2018$)$ \\
\hline estimativa lucro (3 anos) & estimativa lucro ( 3 anos) & $(2015(+3), 2016(+3), 2017(+3)$ e $2018(+3)$ \\
\hline estimativa Ebit (3 anos) & estimativa Ebit ( 3 anos) & $(2015(+3), 2016(+3), 2017(+3)$ e $2018(+3)$ \\
\hline
\end{tabular}

Fonte: Elaboração própria

Para as variáveis explicativas da tabela (3), compostas por variáveis de demonstração financeiras, os dados coletados foram do Balanço encerrado de cada exercício (2015 a 2018) informados pelas empresas, também considerando o balanço consolidado.

\footnotetext{
${ }^{18}$ Balanço consolidado: Apresenta o resultado da empresa controladora em conjunto com as suas participações em outras empresas.
} 
As variáveis de crescimento selecionadas foram a expectativa (consenso de mercado) do lucro líquido (gl) e o ebit (gr) para serem utilizados nos modelos de valor de mercado e valor da empresa, respectivamente. Utilizou-se dados de expectativa, uma vez que, de acordo com a literatura, esses possuem melhor ajuste com os múltiplos.

A estimativa escolhida foi de três exercícios à frente $(\mathrm{t}+3)$. As variáveis de crescimento (gl e gr) foram calculadas comparando o lucro e ebit respectivamente da empresa no exercício (t0), com a expectativa (consenso de mercado) para três exercícios à frente $(\mathrm{t}+3)$, realizando um cálculo percentual entre os dois períodos.

Tabela 4 - Variáveis calculadas

\begin{tabular}{|c|c|c|}
\hline nome & variável & forma de calculo \\
\hline ic & investimento de capital & $\mathrm{ic}=\mathrm{plc}+\mathrm{deb}$ \\
\hline p.1 & múltiplo $\mathrm{P} / \mathrm{L}$ & p. $1=\mathrm{pm} /$ lucro \\
\hline p.plc & múltiplo P/PLC & $\mathrm{p} \cdot \mathrm{plc}=\mathrm{pm} / \mathrm{plc}$ \\
\hline ev.ebitda & múltiplo EV/Ebitda & ev.ebitda $=$ ev $/$ ebitda \\
\hline ev.ic & múltiplo EV/IC & ev.ic $=e v / i c$ \\
\hline ev.rec & múltiplo EV/REC & ev.rec $=\mathrm{ev} / \mathrm{rec}$ \\
\hline $\mathrm{gl}$ & crescimento do lucro esperado & $\mathrm{gl}=$ estimativa lucro $\mathrm{t}(\mathrm{n})+3$ / lucro líquido $\mathrm{t}(\mathrm{n})$ \\
\hline gr & crescimento do ebit esperado & gr $=$ estimativa ebit $\mathrm{t}(\mathrm{n})+3 /$ ebit $\mathrm{t}(\mathrm{n})$ \\
\hline po & taxa de distribuição de dividendos & po $=\operatorname{div} /$ lucro \\
\hline nopat & ebit $(1-t)$ & nopat $=$ ebit $x(1-$ etax $)$ \\
\hline reinv & reinvestimento & reinv $=$ capex $+\mathrm{wc}$ \\
\hline rir & taxa de reinvestimento & rir $=$ reinv $/$ nopat \\
\hline mo & margem operacional & $\mathrm{mo}=$ nopat $/ \mathrm{rec}$ \\
\hline
\end{tabular}

Fonte: Elaboração própria

As variáveis da tabela (4) foram calculadas a partir dos dados das tabelas (2 e 3), na terceira coluna é apresentada a forma de cálculo.

\subsection{Critério de seleção da amostra}

Foram coletadas da base de dados, um universo inicial de 477 empresas. A partir do universo inicial foram excluídas algumas empresas da amostra, conforme tabela de critério de seleção da amostra: 
Tabela 5 - Critério para seleção da amostra

\begin{tabular}{|c|c|}
\hline Critério para seleção da amostra & $\mathbf{N}$ \\
\hline Universo inicial & 477 \\
\hline $\begin{array}{l}\text { Exclusão: Empresas que não possuiam dados de estimativa de } \\
\text { analistas fornecidas pela base de dados Thomson Reuters. }\end{array}$ & 287 \\
\hline Remaneceu: & 190 \\
\hline Exclusão: Empresas que atuam no setor de banco comercial. & 9 \\
\hline Remaneceu: & 181 \\
\hline
\end{tabular}

Fonte: Elaboração própria

O primeiro critério foi excluir aquelas que não são acompanhadas pelos analistas responsáveis por fazerem as estimativas/projeções das empresas (consenso do mercado) em nenhum dos anos da análise. Empresas do setor banco comercial foram excluídas por terem demonstração financeiras diferentes dos demais setores. Com isto, a base de dados inicial da pesquisa possui 181 empresas.

O terceiro critério de exclusão foi utilizado: empresas com múltiplos negativos para o ano em análise. O motivo de excluir esses dados é que não faz sentido as empresas terem valor negativo, os múltiplos negativos são gerados por resultados contábeis negativos, contudo, as empresas não possuem valor de mercado negativo. Nas tabelas 6 e 7 são apresentadas as quantidades $(\mathrm{N})$ de cada múltiplo em cada ano da análise.

Tabela 6 - Quantidade múltiplo de valor de mercado por ano

\begin{tabular}{ccccc|cccc} 
& \multicolumn{6}{c|}{ P/PLC } & \multicolumn{4}{c}{ P/L } \\
\cline { 2 - 8 } & $\mathbf{2 0 1 5}$ & $\mathbf{2 0 1 6}$ & $\mathbf{2 0 1 7}$ & $\mathbf{2 0 1 8}$ & $\mathbf{2 0 1 5}$ & $\mathbf{2 0 1 6}$ & $\mathbf{2 0 1 7}$ & $\mathbf{2 0 1 8}$ \\
\hline $\mathrm{N}$ & 153 & 155 & 163 & 164 & 113 & 109 & 129 & 142
\end{tabular}

Fonte: Elaboração própria

Nota-se que a quantidade de observações para o múltiplo P/PLC é superior à do múltiplo $\mathrm{P} / \mathrm{L}$ pois, como já comentando anteriormente, a variável lucro líquido apresenta maior quantidade de valores negativos.

Tabela 7 - Quantidade múltiplo de valor da empresa por ano

\begin{tabular}{ccccc|cccc|cccc}
\multicolumn{5}{c}{ EV/ EBITDA } & \multicolumn{4}{c|}{ EV/IC } & \multicolumn{4}{c}{ EV/ RECEITA } \\
\cline { 2 - 12 } & $\mathbf{2 0 1 5}$ & $\mathbf{2 0 1 6}$ & $\mathbf{2 0 1 7}$ & $\mathbf{2 0 1 8}$ & $\mathbf{2 0 1 5}$ & $\mathbf{2 0 1 6}$ & $\mathbf{2 0 1 7}$ & $\mathbf{2 0 1 8}$ & $\mathbf{2 0 1 5}$ & $\mathbf{2 0 1 6}$ & $\mathbf{2 0 1 7}$ & $\mathbf{2 0 1 8}$ \\
\hline $\mathrm{N}$ & 140 & 145 & 151 & 155 & 158 & 161 & 169 & 171 & 160 & 164 & 176 & 177
\end{tabular}

Fonte: Elaboração própria 
Nota-se que a quantidade de observações para o múltiplo EV/Receitas são superiores aos dos múltiplos EV/IC e EV/EBITDA. Além disso, de forma geral, a quantidade de observações para os múltiplos de valor de empresa é maior que a de valor de mercado, por ter variáveis de padronização com menos valores negativos.

\subsection{Transformação das variáveis}

Para analisar as variáveis determinantes dos múltiplos e gerar os modelos para os mesmos, foi realizada transformação logarítmica das variáveis dependentes. O motivo desta transformação é que a variável dependente, após a transformação, reduz a variabilidade e apresenta distribuição mais próximo da normal, o que melhora os resultados dos testes dos pressupostos do modelo de regressão.

\subsection{O método de seleção das variáveis}

Para estimar os modelos de regressão, parte-se de um modelo inicial em que, para cada variável dependente, se considera todas as variáveis explicativas relacionadas a cada múltiplo, conforme a tabela seguinte:

Tabela 8 - Modelos iniciais

\begin{tabular}{ccccccc} 
múltiplo & \multicolumn{7}{c}{ variáveis explicativas } \\
\hline$(\ln ) \mathbf{P} / \mathbf{L}$ & $=$ & $\mathrm{gL}$ & ewacc & po & roe & \\
$(\ln ) \mathbf{P} / \mathbf{P L C}$ & $=$ & $\mathrm{gL}$ & ewacc & po & roe & \\
$(\ln ) \mathbf{E V} / \mathbf{E B I T D A}$ & $=$ & $\mathrm{gR}$ & wacc & etax & rir & roic \\
$(\ln ) \mathbf{E V} / \mathrm{IC}$ & $=$ & $\mathrm{gR}$ & wacc & etax & rir & roic \\
$(\ln ) \mathbf{E V} / \mathbf{R e c e i t a}$ & $=$ & $\mathrm{gR}$ & wacc & etax & rir & mo
\end{tabular}

Fonte: Elaboração própria

Estimou-se os modelos utilizando o método Backward, o nível de significância estabelecido foi de 0,10 . Caso o modelo estimado apresentasse algum coeficiente com sinal ao contrário do esperado, o que não teria significado prático, retirava-se a variável e rodava-se novamente a regressão para estimar o modelo considerado final. 
Foi estimado, para cada múltiplo, uma regressão para os quatro anos da amostra (2015 a 2018). Assim, como são 5 os múltiplos analisados, são estimados 20 modelos, conforme a tabela seguinte:

Tabela 9 - Quantidade de modelos estimados

$\begin{array}{llll}2015 & 2016 & 2017 & 2018\end{array}$

\begin{tabular}{ccccc}
\hline P/L & modelo 1 & modelo 2 & modelo 3 & modelo 4 \\
\hline P/BV & modelo 5 & modelo6 & modelo 7 & modelo8 \\
\hline EV/EBITDA & modelo 9 & modelo 10 & modelo 11 modelo 12 \\
\hline EV/IC & modelo 13 & modelo 14 & modelo 15 & modelo 16 \\
\hline EV/Receita & modelo 17 & modelo 18 & modelo 19 & modelo 20
\end{tabular}

Fonte: Elaboração própria

Optou-se estimar um modelo de regressão por ano, pois utilizar dados históricos por períodos mais longos pode não refletir o valor justo. 


\section{RESULTADOS}

\subsection{Análise descritiva das variáveis}

Seguem, nesta subseção, as estatísticas descritivas das variáveis utilizadas na pesquisa. Para esta análise, são apresentados os valores mínimo e máximo, os percentis $(0,25,0,50$ e 0,75) e o intervalo interquartil (Q3 - Q1) de cada variável para os quatro anos da análise (2015 - 2018). Uma vez que a amostra possui outliers, conforme será apresentado, não foram calculadas as medidas de dispersão e a média aritmética.

Tabela 10 - Estatística descritiva dos múltiplos P/L e P/PLC

\begin{tabular}{|c|c|c|c|c|c|c|c|c|c|}
\hline & \multicolumn{4}{|c|}{ P/PLC } & \multicolumn{4}{|c|}{$\mathbf{P} / \mathbf{L}$} \\
\hline & & 2015 & 2016 & 2017 & 2018 & 2015 & 2016 & 2017 & 2018 \\
\hline mínimo & & 0,07 & 0,18 & 0,24 & 0,25 & 0,52 & 0,08 & 0,80 & 0,16 \\
\hline máximo & & 17,05 & 24,51 & 64,57 & 15,05 & 685,16 & 868,88 & 931,25 & 1068,99 \\
\hline \multirow{3}{*}{ percentil } & 25 & 0,58 & 0,77 & 0,98 & 1,19 & 7,71 & 10,69 & 12,01 & 9,85 \\
\hline & 50 & 1,14 & 1,40 & 1,66 & 1,88 & 13,88 & 17,90 & 18,10 & 14,77 \\
\hline & 75 & 2,09 & 2,65 & 3,07 & 3,54 & 23,33 & 31,49 & 38,16 & 31,69 \\
\hline Q3 - Q1 & & 1,52 & 1,88 & 2,09 & 2,34 & 15,62 & 20,80 & 26,15 & 21,84 \\
\hline
\end{tabular}

Fonte: Elaboração própria

Nota-se pela Tabela 10 e pelas Figuras 23 e 24 apresentadas no anexo, que a mediana dos múltiplos P/L e P/PLC apresentam variação durante os anos em análise, a mesma indicação pode ser observada pela medida de variabilidade $(\mathrm{Q} 3$ - Q1), e nota-se também que há presença de outliers e há grande variabilidade entre os valores mínimo e máximo de ambos os múltiplos.

Tabela 11 - Estatística descritiva das variáveis gl e ewacc

\begin{tabular}{|c|c|c|c|c|c|c|c|c|c|}
\hline & \multicolumn{4}{|c|}{ gL } & \multicolumn{4}{|c|}{ ewacc } \\
\hline & & 2015 & 2016 & 2017 & 2018 & 2015 & 2016 & 2017 & 2018 \\
\hline mínimo & & $-1,05$ & $-1,21$ & $-4,29$ & $-0,72$ & 0,04 & 0,04 & 0,03 & 0,03 \\
\hline máximo & & 167,42 & 98,07 & 70,01 & 81,10 & 0,11 & 0,18 & 0,19 & 0,23 \\
\hline \multirow{3}{*}{ percentil } & 25 & 0,23 & 0,25 & 0,16 & 0,17 & 0,06 & 0,07 & 0,07 & 0,07 \\
\hline & 50 & 0,73 & 0,83 & 0,67 & 0,39 & 0,07 & 0,08 & 0,08 & 0,09 \\
\hline & 75 & 1,45 & 1,76 & 1,35 & 1,14 & 0,07 & 0,09 & 0,10 & 0,11 \\
\hline Q3 - Q1 & & 1,22 & 1,51 & 1,19 & 0,97 & 0,01 & 0,03 & 0,03 & 0,04 \\
\hline
\end{tabular}

Fonte: Elaboração própria 
Nota-se, pela Tabela 11 e pelas Figuras 25 e 26 apresentadas no anexo, que para os anos da análise, há presença de valores bastante discrepantes para as observações da variável gl, distanciando-se de forma bastante expressiva da mediana da amostra, sendo esses outliers na maioria positivos, e a mediana apresenta variação de nível durante os anos da análise e há grande variabilidade entre os valores mínimo e máximo. Os ewacc das empresas apresentam mediana em nível parecido e no decorrer dos anos, há uma crescente dispersão dos valores das observações e nota-se também a presença de outliers em todos os anos da análise.

Tabela 12 - Estatística descritiva das variáveis po e roe

\begin{tabular}{|c|c|c|c|c|c|c|c|c|c|}
\hline & & \multirow{2}{*}{\multicolumn{4}{|c|}{ po }} & \multirow{2}{*}{\multicolumn{4}{|c|}{ roe }} \\
\hline & & & & & & & & & \\
\hline & & 2015 & 2016 & 2017 & 2018 & 2015 & 2016 & 2017 & 2018 \\
\hline mínimo & & 0,00 & 0,00 & 0,00 & 0,00 & $-16,73$ & $-12,50$ & $-0,95$ & $-8,83$ \\
\hline máximo & & 5,83 & 4,13 & 4,59 & 2,54 & 1,02 & 2,85 & 1,32 & 1,44 \\
\hline \multirow{3}{*}{ percentil } & 25 & 0,12 & 0,14 & 0,13 & 0,12 & $-0,02$ & $-0,04$ & 0,00 & 0,02 \\
\hline & 50 & 0,24 & 0,24 & 0,24 & 0,24 & 0,06 & 0,06 & 0,08 & 0,10 \\
\hline & 75 & 1,00 & 1,00 & 1,00 & 0,37 & 0,15 & 0,17 & 0,17 & 0,18 \\
\hline Q3 - Q1 & & 0,88 & 0,86 & 0,87 & 0,25 & 0,17 & 0,21 & 0,17 & 0,16 \\
\hline
\end{tabular}

Fonte: Elaboração própria

Nota-se, pela Tabela 12 e pelas Figuras 27 e 28 apresentadas no anexo, que as observações da variável po mantêm nível constante para mediana, há grande variabilidade entre os valores mínimo e máximo e pode se observar A medida de variabilidade (Q3 - Q1) se reduzindo no decorrer dos anos de análise. As observações da roe apresentam mediana com variação, e pode ser observado pela medida de variabilidade (Q3 - Q1) que não há variação expressiva durante os anos da análise.

Tabela 13 - Estatística descritiva dos múltiplos EV/Ebitda, EV/IC e EV/Receita

\begin{tabular}{|c|c|c|c|c|c|c|c|c|c|c|c|c|c|}
\hline & \multicolumn{4}{|c|}{ EV/EBITDA } & \multicolumn{4}{|c|}{ EV/IC } & \multicolumn{4}{|c|}{ EV/RECEITA } \\
\hline & & 2015 & 2016 & 2017 & 2018 & 2015 & 2016 & 2017 & 2018 & 2015 & 2016 & 2017 & 2018 \\
\hline mínimo & & 0,17 & 0,17 & 1,27 & 1,27 & 0,03 & 0,07 & 0,24 & 0,38 & 0,01 & 0,12 & 0,10 & 0,09 \\
\hline máximo & & 115,07 & 200,11 & 87,50 & 71,80 & 16,01 & 23,54 & 64,44 & 11,98 & 544,79 & 2598,27 & 354,44 & 444,01 \\
\hline \multirow{3}{*}{ percentil } & 25 & 6,15 & 6,58 & 6,59 & 6,79 & 0,66 & 0,78 & 0,89 & 0,99 & 0,80 & 0,98 & 1,07 & 1,15 \\
\hline & 50 & 8,79 & 9,94 & 10,05 & 9,53 & 0,89 & 1,08 & 1,24 & 1,27 & 1,52 & 1,80 & 2,07 & 2,12 \\
\hline & 75 & 12,77 & 14,51 & 14,80 & 14,41 & 1,33 & 1,74 & 2,02 & 1,96 & 2,89 & 3,59 & 3,80 & 3,95 \\
\hline$\overline{Q 3}-\mathrm{Q1}$ & & 6,63 & 7,93 & 8,21 & 7,63 & 0,67 & 0,96 & 1,13 & 0,97 & 2,09 & 2,60 & 2,72 & 2,80 \\
\hline
\end{tabular}

Fonte: Elaboração própria

Nota-se, pela Tabela 13 e pelas nas Figuras 29, 30 e 31 apresentadas no anexo, que as observações dos múltiplos EV/EBITDA, EV/IC e EV/Receita se comportam de forma 
parecidas. Nos anos da análise há variação da mediana, grande distanciamento entre os valores mínimos e máximo e apresentam outliers em todos os anos da análise

Tabela 14 - Estatística descritiva das variáveis gr e wacc

\begin{tabular}{lccccc|cccc} 
& \multicolumn{5}{c}{ gR } & \multicolumn{4}{c}{ wacc } \\
\cline { 2 - 10 } & $\mathbf{2 0 1 5}$ & $\mathbf{2 0 1 6}$ & $\mathbf{2 0 1 7}$ & $\mathbf{2 0 1 8}$ & $\mathbf{2 0 1 5}$ & $\mathbf{2 0 1 6}$ & $\mathbf{2 0 1 7}$ & $\mathbf{2 0 1 8}$ \\
\hline mínimo & $-0,88$ & $-1,13$ & $-0,89$ & $-0,66$ & 0,03 & 0,03 & 0,03 & 0,03 \\
\hline máximo & 717,27 & 668,53 & 38,17 & 25,78 & 0,17 & 0,14 & 0,15 & 0,17 \\
\hline \multirow{3}{*}{ percentil } & $\mathbf{2 5}$ & 0,25 & 0,23 & 0,17 & 0,13 & 0,05 & 0,05 & 0,05 & 0,06 \\
\cline { 2 - 10 } & $\mathbf{5 0}$ & 0,54 & 0,55 & 0,38 & 0,34 & 0,06 & 0,06 & 0,06 & 0,07 \\
\cline { 2 - 10 } & $\mathbf{7 5}$ & 1,35 & 1,24 & 0,81 & 0,98 & 0,07 & 0,07 & 0,08 & 0,09 \\
\hline Q3 - Q1 & & 1,10 & 1,01 & 0,64 & 0,85 & 0,02 & 0,02 & 0,02 & 0,03 \\
\hline
\end{tabular}

Fonte: Elaboração própria

Nota-se, pela Tabela 14 e pelas Figuras 32 e 33 apresentadas no anexo, que as empresas da amostra possuem a mediana do gr variando durante os anos da análise, há presença de outliers e há grande diferença entre os valores mínimos e máximos. As empresas apresentam a mediana do wacc em nível similar durante os anos da análise, a medida de variabilidade (Q3 - Q1) é constante e há presença de outliers.

Tabela 15 - Estatística descritiva das variáveis roic e rir

\begin{tabular}{lccccc|cccc} 
& & \multicolumn{4}{c|}{ roic } & \multicolumn{4}{c}{ rir } \\
\cline { 2 - 10 } & & $\mathbf{2 0 1 5}$ & $\mathbf{2 0 1 6}$ & $\mathbf{2 0 1 7}$ & $\mathbf{2 0 1 8}$ & $\mathbf{2 0 1 5}$ & $\mathbf{2 0 1 6}$ & $\mathbf{2 0 1 7}$ & $\mathbf{2 0 1 8}$ \\
\hline mínimo & $-0,84$ & $-3,78$ & $-1,84$ & $-1,25$ & $-33,60$ & $-216,01$ & $-10,31$ & $-117,81$ \\
\hline máximo & & 0,78 & 1,90 & 0,80 & 0,55 & 54,06 & 34,67 & 16,26 & 51,05 \\
\hline \multirow{3}{*}{ percentil } & $\mathbf{2 5}$ & $-0,02$ & $-0,02$ & 0,00 & 0,01 & $-0,59$ & $-0,71$ & $-0,75$ & $-0,70$ \\
\cline { 2 - 10 } & $\mathbf{5 0}$ & 0,03 & 0,03 & 0,04 & 0,06 & $-0,05$ & $-0,20$ & $-0,12$ & $-0,12$ \\
\cline { 2 - 10 } & $\mathbf{7 5}$ & 0,09 & 0,08 & 0,11 & 0,11 & 0,54 & 0,32 & 0,32 & 0,38 \\
\hline Q3 - Q1 & & 0,11 & 0,10 & 0,11 & 0,10 & 1,14 & 1,03 & 1,07 & 1,08 \\
\hline
\end{tabular}

Fonte: Elaboração própria

Nota-se, pela Tabela 15 e pelas Figuras 34 e 35 apresentadas no anexo, que na amostra das empresas a mediana da roic e da rir apresentam variação nos anos da análise, há grande diferença entre os valores mínimos e máximos e há presença de outliers. 
Tabela 16 - Estatística descritiva das variáveis etax e mo

\begin{tabular}{lccccc|cccc} 
& \multicolumn{4}{c}{ etax } & \multicolumn{4}{c}{ mo } \\
\cline { 2 - 10 } & & $\mathbf{2 0 1 5}$ & $\mathbf{2 0 1 6}$ & $\mathbf{2 0 1 7}$ & $\mathbf{2 0 1 8}$ & $\mathbf{2 0 1 5}$ & $\mathbf{2 0 1 6}$ & $\mathbf{2 0 1 7}$ & $\mathbf{2 0 1 8}$ \\
\hline mínimo & $-96,66$ & $-10,51$ & $-0,68$ & $-0,05$ & $-1955,22$ & $-35,78$ & $-25,25$ & $-2,81$ \\
\hline máximo & 1,80 & 1,94 & 5,35 & 10,67 & 0,76 & 0,74 & 1,08 & 0,88 \\
\hline \multirow{3}{*}{ percentil } & $\mathbf{2 5}$ & 0,65 & 0,67 & 0,67 & 0,70 & 0,04 & 0,05 & 0,06 & 0,08 \\
\cline { 2 - 10 } & $\mathbf{5 0}$ & 0,76 & 0,77 & 0,76 & 0,79 & 0,10 & 0,11 & 0,13 & 0,14 \\
\cline { 2 - 9 } & $\mathbf{7 5}$ & 0,87 & 0,93 & 0,88 & 0,90 & 0,17 & 0,22 & 0,26 & 0,23 \\
\hline Q3 - Q1 & & 0,22 & 0,27 & 0,22 & 0,20 & 0,12 & 0,17 & 0,20 & 0,16 \\
\hline
\end{tabular}

Fonte: Elaboração própria

Nota-se, pela Tabela 16 e pelas figuras 36 e 37 apresentadas no anexo, que as empresas possuem mo variando anos da análise, há presença de outliers e a medida de variabilidade (Q3 - Q1) possui aumento da variação. Já a mediana da etax das empresas possui pouca variação, o intervalo interquartil se mantém constante, há presença de outliers e os valores mínimos e máximos vão se aproximando no decorrer dos anos de análise.

\subsection{Análise das correlações entre as variáveis}

As tabelas 17 a 24 apresentam o coeficiente de correlação linear de pearson de cada múltiplo com cada uma das variáveis independentes para os anos de 2015 a 2018

Tabela 17 - Correlação múltiplos de valor de mercado x variáveis explicativas (2015)

\begin{tabular}{|c|c|c|c|c|}
\hline 2015 & gL & po & ewacc & roe \\
\hline $\ln (P / L)$ & $0,60^{* * *}$ & $0,31^{* * *}$ & $-0,17^{*}$ & $-0,21^{* *}$ \\
\hline $\ln (\mathrm{P} / \mathrm{PLC})$ & 0,03 & $-0,09$ & $-0,11$ & $0,65^{* * \star}$ \\
\hline gL & 1 & 0,13 & $-0,17^{\star}$ & $-0,20$ * \\
\hline po & & 1 & 0,16 & $-0,16$ \\
\hline ewacc & & & 1 & $-0,02$ \\
\hline roe & & & & 1 \\
\hline
\end{tabular}

Fonte: Elaboração própria

Tabela 18 - Correlação múltiplos de valor de mercado x variáveis explicativas (2016)

\begin{tabular}{|c|c|c|c|c|}
\hline 2016 & gL & po & ewacc & roe \\
\hline $\ln (\mathbf{P} / L)$ & $0,77^{\star \star \star}$ & $0,52^{\star \star \star}$ & 0,004 & $-0,41^{\star \star \star}$ \\
\hline $\ln (P / P L C)$ & 0,14 & $0,21^{*}$ & $-0,17$ & $0,55^{* \star *}$ \\
\hline gL & 1 & $0,855^{\star \star \star}$ & 0,004 & $-0,23^{*}$ \\
\hline po & & 1 & 0,03 & $-0,10$ \\
\hline ewacc & & & 1 & $-0,21^{*}$ \\
\hline roe & & & & 1 \\
\hline
\end{tabular}

Fonte: Elaboração própria 
Tabela 19 - Correlação múltiplos de valor de mercado x variáveis explicativas (2017)

\begin{tabular}{|c|c|c|c|c|}
\hline 2017 & gL & po & ewacc & roe \\
\hline $\ln (P / L)$ & $0,726^{* \star *}$ &, $31^{* * *}$ & 0,03 & $-0,33^{*+*}$ \\
\hline $\ln (P / P L C)$ & $-0,07$ & $-0,005$ & $-0,19$ & $0,59^{*+*}$ \\
\hline gL & 1 & $0,26^{* *}$ & 0,06 & $-0,25^{* \prime}$ \\
\hline po & & 1 & $0,25^{* *}$ & $-0,06$ \\
\hline ewacc & & & 1 & $-0,10$ \\
\hline roe & & & & 1 \\
\hline
\end{tabular}

Fonte: Elaboração própria

Tabela 20 - Correlação múltiplos de valor de mercado x variáveis explicativas (2018)

\begin{tabular}{|c|c|c|c|c|}
\hline 2018 & gL & po & ewacc & roe \\
\hline $\ln (P / L)$ & $0,70^{\star \star \star}$ & $0,20^{* \star}$ & $-0,10$ & $-0,42^{* \star \star}$ \\
\hline $\ln (\mathrm{P} / \mathrm{PLC})$ & $-0,06$ & 0,03 & $-0,27^{\star \star \star}$ & $0,51^{* * *}$ \\
\hline gL & 1 & $0,20^{* *}$ & $-0,002$ & $-0,26^{\star \star \star}$ \\
\hline po & & 1 & 0,03 & 0,01 \\
\hline ewacc & & & 1 & $-0,05$ \\
\hline roe & & & & 1 \\
\hline
\end{tabular}

Fonte: Elaboração própria

Análise correlação múltiplo $\ln (\mathrm{P} / \mathrm{L})$ : A variável com maior correlação e significância foi o gl, sendo a relação positiva; a variável po também apresentou boa correlação, relação positiva com significância; o roe mostrou relação negativa com significância para os anos em análise; e o ewacc não apresentou uma relação constante durante os anos de análise, e não teve significância.

Análise correlação múltiplo $\ln (\mathrm{P} / \mathrm{PLC})$ : Para o múltiplo $\ln (\mathrm{P} / \mathrm{PLC})$, o roe foi a variável com maior correlação em todos os anos e significância, sendo a relação positiva; a variável ewacc teve relação negativa, mas com significância somente em 2018. Já as variáveis gl e po apresentaram alternância na relação com o múltiplo; relativo à significância das variáveis, o gl não expôs significância em nenhum ano da análise e o po teve somente em 2016.

Correlação entre variáveis explicativas: Entre as variáveis independentes, no geral, não há correlação alta entre as variáveis. Porém, no ano de 2016, as variáveis gl e po apresentaram correlação alta $(0,86)$. 
Tabela 21 - Correlação múltiplos de valor da empresa x variáveis explicativas (2015)

\begin{tabular}{|c|c|c|c|c|c|c|}
\hline $\mathbf{2 0 1 5}$ & $\mathbf{g R}$ & wacc & etax & rir & roic & mo \\
\hline $\operatorname{In}(\mathrm{EV} / \mathrm{EBITDA})$ & $0,444^{* * *}$ & 0,14 & $-0,04$ & $-0,01$ & 0,07 & $-0,04$ \\
\hline $\operatorname{In}(\mathrm{EV} / \mathrm{IC})$ & $-0,19^{*}$ & $0,18^{*}$ & 0,008 & $-0,01$ & $0,67^{* * *}$ & 0,01 \\
\hline $\operatorname{In}(\mathrm{EV} / \mathbf{R E C E I T A )}$ & 0,04 & 0,16 & $-0,17^{*}$ & $0,17^{*}$ & $0,20^{*}$ & $-0,14$ \\
\hline gR & 1 & 0,05 & $-0,04$ & $0,30^{* * *}$ & $-0,22^{* *}$ & $-0,05$ \\
\hline wacc & & 1 & $-0,010$ & 0,08 & $0,24^{* *}$ & $-0,01$ \\
\hline etax & & & 1 & 0,002 & 0,15 & $0,99^{* * *}$ \\
\hline rir & & & & 1 & $-0,05$ & 0,005 \\
\hline roic & & & & & 1 & 0,15 \\
\hline mo & & & & & & 1 \\
\hline
\end{tabular}

$* * *$ p-valor $<0.01 * *$ p-valor $<0.05 *$ p-valor $<0.1$

Fonte: Elaboração própria

Tabela 22 - Correlação múltiplos de valor da empresa x variáveis explicativas (2016)

\begin{tabular}{|c|c|c|c|c|c|c|}
\hline $\mathbf{2 0 1 6}$ & $\mathbf{g R}$ & wacc & etax & rir & roic & mo \\
\hline $\operatorname{In}(\mathrm{EV} / \mathrm{EBITDA})$ & $0,39^{* * *}$ & $0,22^{*}$ & $-0,09$ & $-0,34^{* * *}$ & $-0,04$ & $-0,12$ \\
\hline $\operatorname{In}(\mathrm{EV} / \mathrm{IC})$ & $-0,19$ & 0,18 & 0,06 & $0,20^{*}$ &, $673^{* * *}$ & 0,09 \\
\hline $\operatorname{In}(\mathrm{EV} / \mathbf{R E C E I T A )}$ & $-0,13$ & 0,09 & $-0,21$ & 0,13 & 0,16 & $0,22^{*}$ \\
\hline gR & 1 & 0,01 & $-0,13$ & $-0,98^{* * *}$ & $-0,10$ & $-0,10$ \\
\hline wacc & & 1 & 0,02 & $-0,02$ & 0,14 & 0,02 \\
\hline etax & & & 1 & 0,15 & 0,08 & $0,75^{* * *}$ \\
\hline rir & & & & 1 & 0,08 & 0,06 \\
\hline roic & & & & & 1 & $0,24^{* *}$ \\
\hline mo & & & & & & 1 \\
\hline
\end{tabular}

$* * *$ p-valor $<0.01 * *$ p-valor $<0.05 *$ p-valor $<0.1$

Fonte: Elaboração própria

Tabela 23 - Correlação múltiplos de valor da empresa x variáveis explicativas (2017)

\begin{tabular}{|c|c|c|c|c|c|c|}
\hline $\mathbf{2 0 1 7}$ & gR & wacc & etax & rir & roic & mo \\
\hline In(EV/EBITDA) & $0,52^{* * *}$ & 0,161 & $-0,009$ & 0,11 & 0,12 & 0,03 \\
\hline In(EV/C) & $-0,11$ & $0,19^{*}$ & $0,19^{*}$ & $-0,02$ &, $70^{* * *}$ & 0,006 \\
\hline $\operatorname{In}(\mathrm{EV} / \mathbf{R E C E I T A )}$ & 0,02 & 0,003 & $-0,06$ & 0,11 & 0,14 & $0,66^{* * *}$ \\
\hline gR & 1 & 0,11 & $-0,15$ & 0,09 & $-0,24^{* *}$ & $-0,26^{* *}$ \\
\hline wacc & & 1 & 0,10 & 0,10 & 0,12 & 0,0007 \\
\hline etax & & & 1 & 0,01 & 0,11 & $0,35^{* * *}$ \\
\hline rir & & & & 1 & $-0,03$ & 0,04 \\
\hline roic & & & & & 1 & 0,12 \\
\hline mo & & & & & & 1 \\
\hline
\end{tabular}

$* * *$ p-valor $<0.01 * *$ p-valor $<0.05 *$ p-valor $<0.1$

Fonte: Elaboração própria 
Tabela 24 - Correlação múltiplos de valor da empresa x variáveis explicativas (2018)

\begin{tabular}{|c|c|c|c|c|c|c|}
\hline $\mathbf{2 0 1 8}$ & $\mathbf{g R}$ & wacc & etax & rir & roic & mo \\
\hline $\operatorname{In}(\mathrm{EV} / \mathrm{EBITDA})$ & $0,43^{* * *}$ & 0,04 & $-0,005$ & $0,21^{* *}$ & 0,04 & $-0,08$ \\
\hline $\operatorname{In}(\mathrm{EV} / \mathrm{IC})$ & $-0,01$ & 0,08 & 0,008 & 0,09 & $0,57^{* * *}$ & $-0,02$ \\
\hline $\operatorname{In}(\mathrm{EV} / \mathbf{R E C E I T A )}$ & $-0,05$ & $-0,09$ & 0,10 & 0,16 & 0,06 & $0,65^{* * *}$ \\
\hline $\mathbf{g R}$ & 1 & 0,14 & 0,04 & $0,16^{*}$ & $-0,247^{* *}$ & $-0,325^{* * *}$ \\
\hline wacc & & 1 & $-0,16^{*}$ & $-0,15$ & 0,09 & $-0,15$ \\
\hline etax & & & 1 & $0,36^{* * *}$ & 0,06 & $0,44^{* * *}$ \\
\hline rir & & & & 1 & 0,10 & 0,12 \\
\hline roic & & & & & 1 & 0,12 \\
\hline mo & & & & & & 1 \\
\hline
\end{tabular}

$* * *$ p-valor $<0.01 * *$ p-valor $<0.05 *$ p-valor $<0.1$

Fonte: Elaboração própria

Análise correlação múltiplo $\ln ($ EV/EBITDA): De modo semelhante ao múltiplo $\ln (\mathrm{P} / \mathrm{L})$, o múltiplo $\ln (\mathrm{EV} /$ Ebitda) também teve como variável de melhor correlação o gr, sendo a relação positiva e significativa para todos os anos. Para as demais variáveis explicativas deste múltiplo (wacc, roic, rir e etax), o wacc teve relação positiva sem significância; o roic se relacionou de forma negativa e sem significância; a rir expôs uma relação variando no decorrer dos anos com significância em dois dos quatro anos; e o etax teve relação negativa e sem significância.

Análise correlação múltiplo $\ln (\mathrm{EV} / \mathrm{IC})$ : Também de modo parecido ao que ocorreu com múltiplo de preço $\ln (\mathrm{P} / \mathrm{PLC})$, o múltiplo $\ln (\mathrm{EV} / \mathrm{IC})$ apresentou como variável de alta correlação o roic, com relação positiva e com significância, para as demais variáveis explicativas deste múltiplo (wacc, gr e rir), o wacc relacionou-se de forma positiva com significância em dois dos quatros anos, para o etax houve relação positiva e com significância em um dos anos, e a rir teve a relação variando durantes os anos da análise, com significância em um dos quatros anos.

Análise correlação múltiplo $\ln (\mathrm{EV} /$ Receita): De modo geral, a variável com maior correlação e com significância foi a mo, sendo a relação positiva, contudo 2015 parece ser um ano atípico para o múltiplo, pois a relação da mo foi negativa e sem significância, e para as demais variáveis explicativas deste múltiplo (rir, gr, wacc e extax), com exceção do wacc, essas variáveis foram significativas em 2015, sendo a etax com sinal negativo e as demais com positivo, o que não se perpetuou nos próximos anos da análise, onde a significância não foi mantida, e a relação entre as variáveis (rir, gr, wacc e extax) nos anos seguintes foi respectivamente: positiva, alternada, alternada e alternada. 
Correlação entre variáveis explicativas: Entre as variáveis independentes, no geral, não há correlação alta entre as variáveis. Porém, no ano de 2015, as variáveis mo e etax apresentam correlação alta $(0,99)$, e no ano de 2016 as mesmas variáveis novamente apresentaram alta correlação $(0,75)$; e as variáveis gr e rir apresentam correlação alta $(-0,98)$ em 2016.

\subsection{Análise da relação entre as variáveis dependentes e as independentes}

Complementarmente à apresentação das correlações entre as variáveis, são apresentadas as relações entre as variáveis dependentes com as independentes, via gráfico scatter plot para os anos em análise, analisando se a relação encontrada confirma ou não o que era esperado pelo exposto no referencial teórico (nas seções onde são expostas as variáveis explicativas de cada múltiplo e suas respectivas relações esperadas).

Nas figuras de 1 a 4 são apresentadas a relação do múltiplo P/L, e as variáveis explicativas para os 2015 a 2018.

Figura $1-\mathrm{P} / \mathrm{L}$ x gl
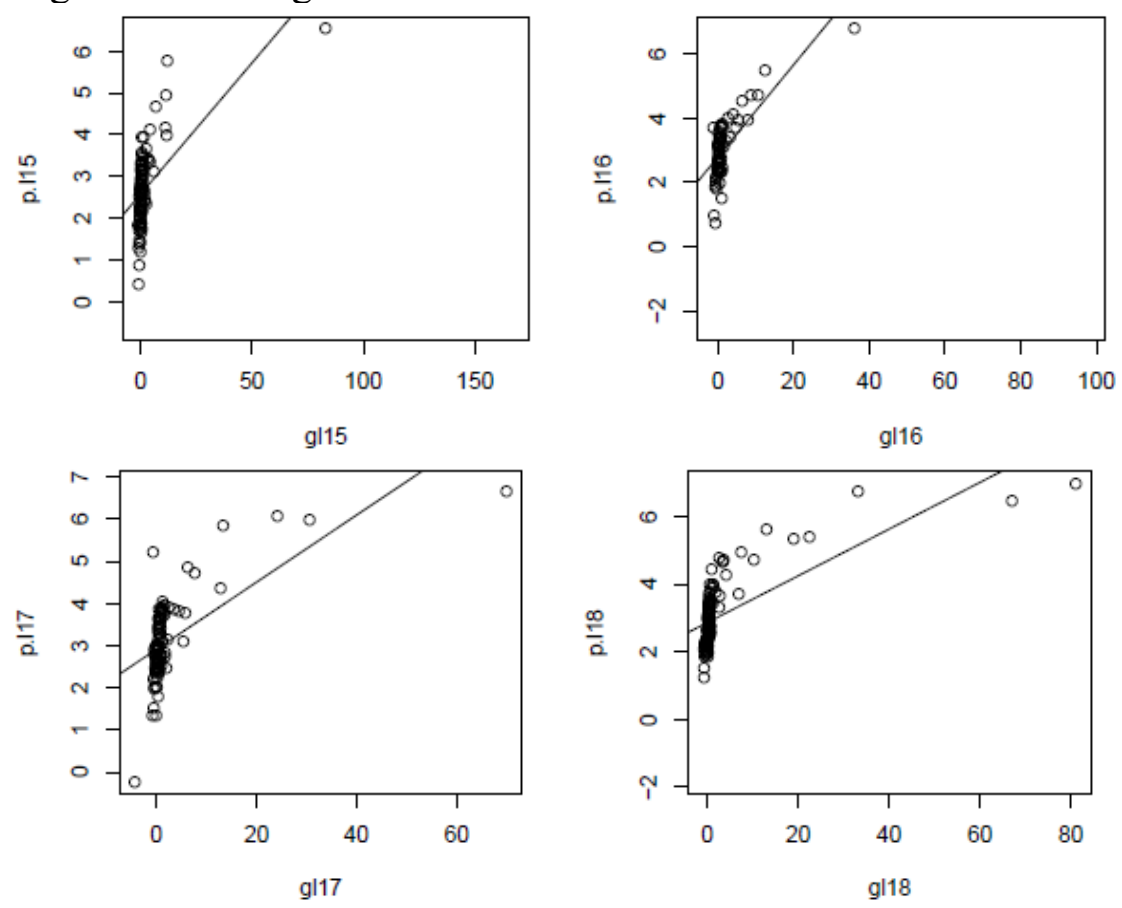

Fonte: Elaboração própria

A linha de tendência entre o múltiplo $\mathrm{P} / \mathrm{L}$ e a variável gl é positiva, confirmando o que era esperado pelo exposto no referencial teórico. Desta forma, empresas com maiores 
expectativas de crescimento do lucro tendem a ter o múltiplo P/L maior. Nota-se, pelo gráfico, a presença de valores discrepantes (outliers).

Figura $2-\mathrm{P} / \mathrm{L}$ x po
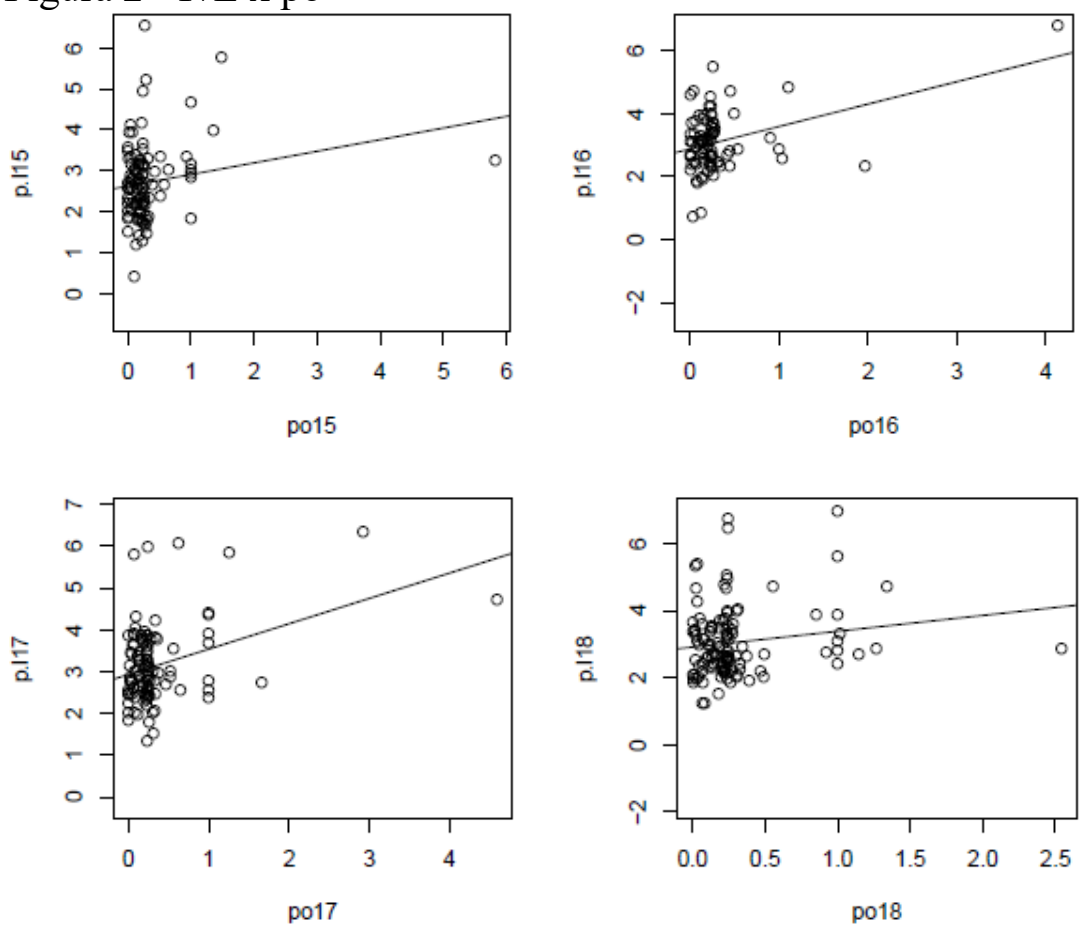

Fonte: Elaboração própria

A relação esperada para a variável po (taxa de distribuição de dividendos) e o múltiplo P/L é negativa, o que contrapõe a relação esperada. Nota-se, no gráfico, que há presença de outliers, e que o coeficiente é positivo, o que contrapõe a relação esperada.

Figura $3-\mathrm{P} / \mathrm{L} \mathrm{x}$ roe
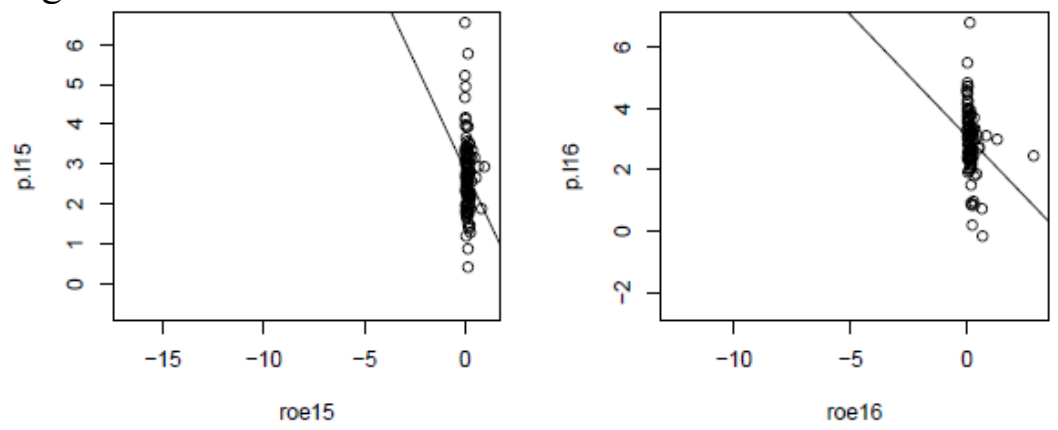

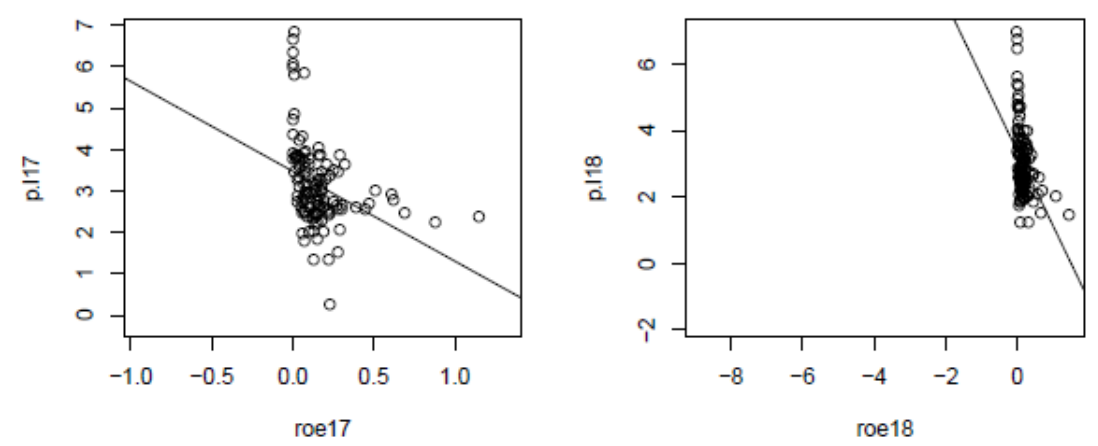

Fonte: Elaboração própria

A relação entre o roe e o múltiplo $\mathrm{P} / \mathrm{L}$ é negativa para os anos analisados, indo contra o esperado. De acordo com a teoria, quanto maior o roe, melhor avaliada deveria ser a empresa, pois esta é uma medida de rentabilidade.

Figura 4 - P/L x ewacc
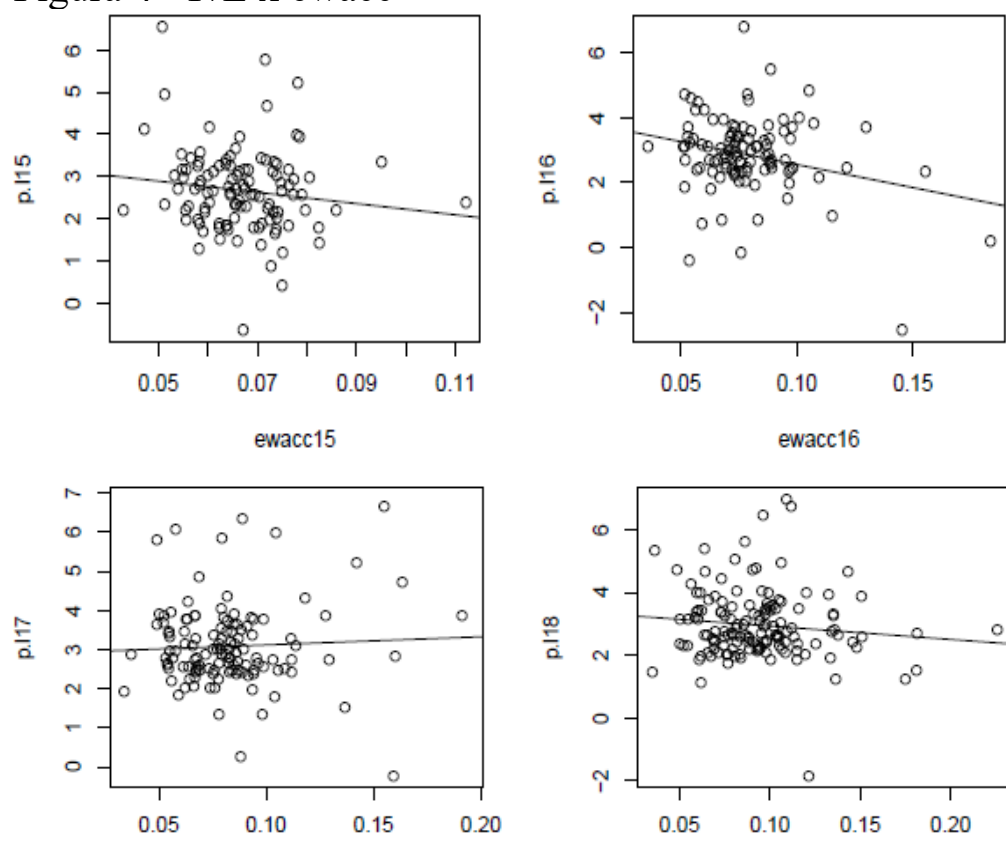

ewacc17

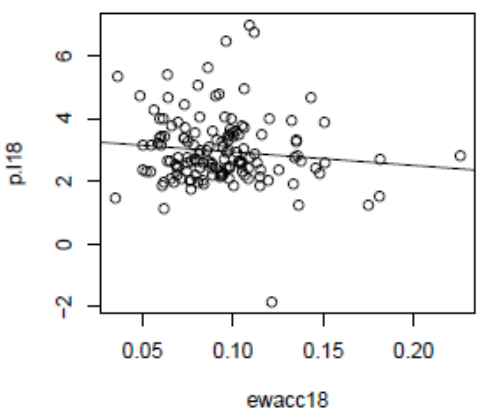

Fonte: Elaboração própria

A relação entre o múltiplo $\mathrm{P} / \mathrm{L}$ e a variável ewacc, possui relação negativa para três, dos quatro anos (tendência negativa). De acordo com o exposto no referencial teórico, a relação esperada é negativa, o que, de forma geral, converge com o esperado.

Nas figuras de 5 a 8 são apresentadas a relação do múltiplo P/PLC e as variáveis explicativas para os 2015 a 2018. 
Figura 5 - P/PLC x roe
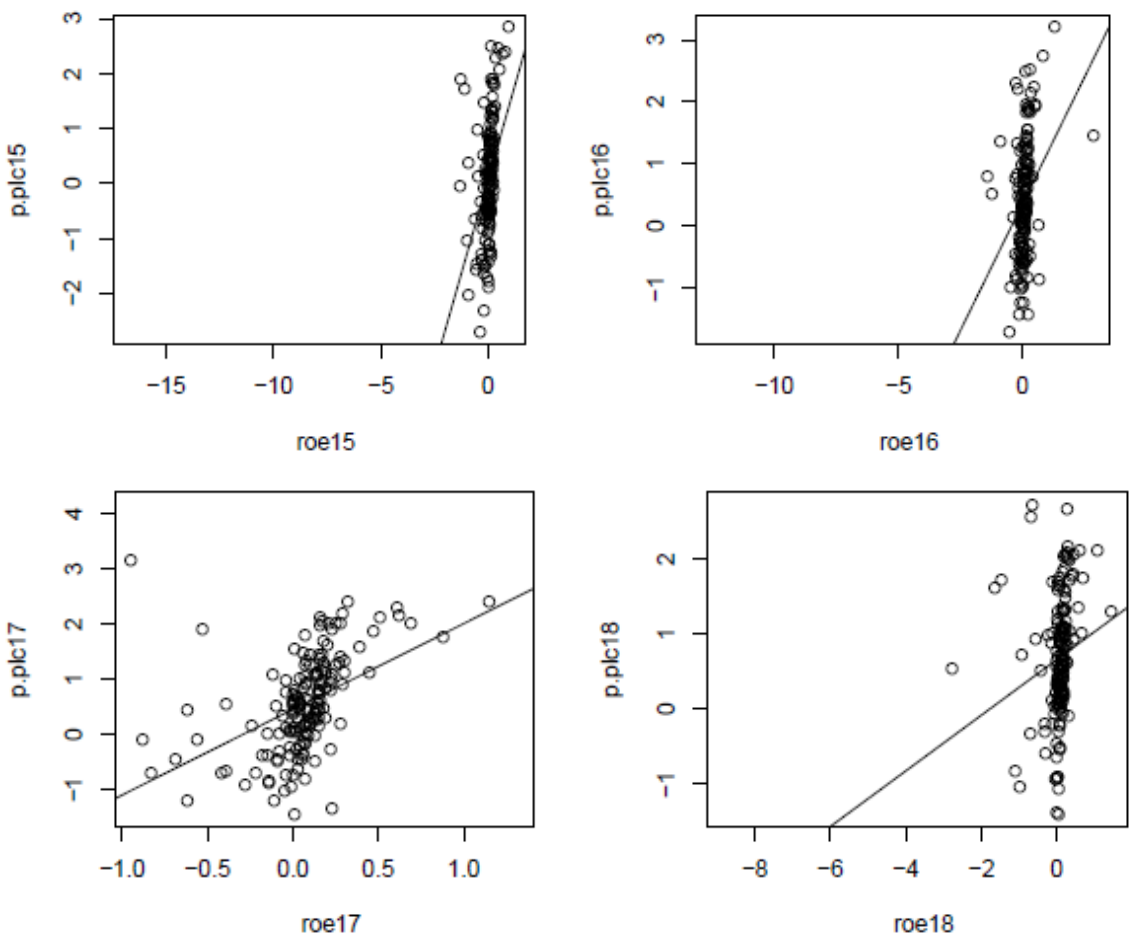

Fonte: Elaboração própria

O roe possui relação positiva, em favor do esperado convergindo com o referencial teórico.

Figura 6 - P/PLC x ewacc
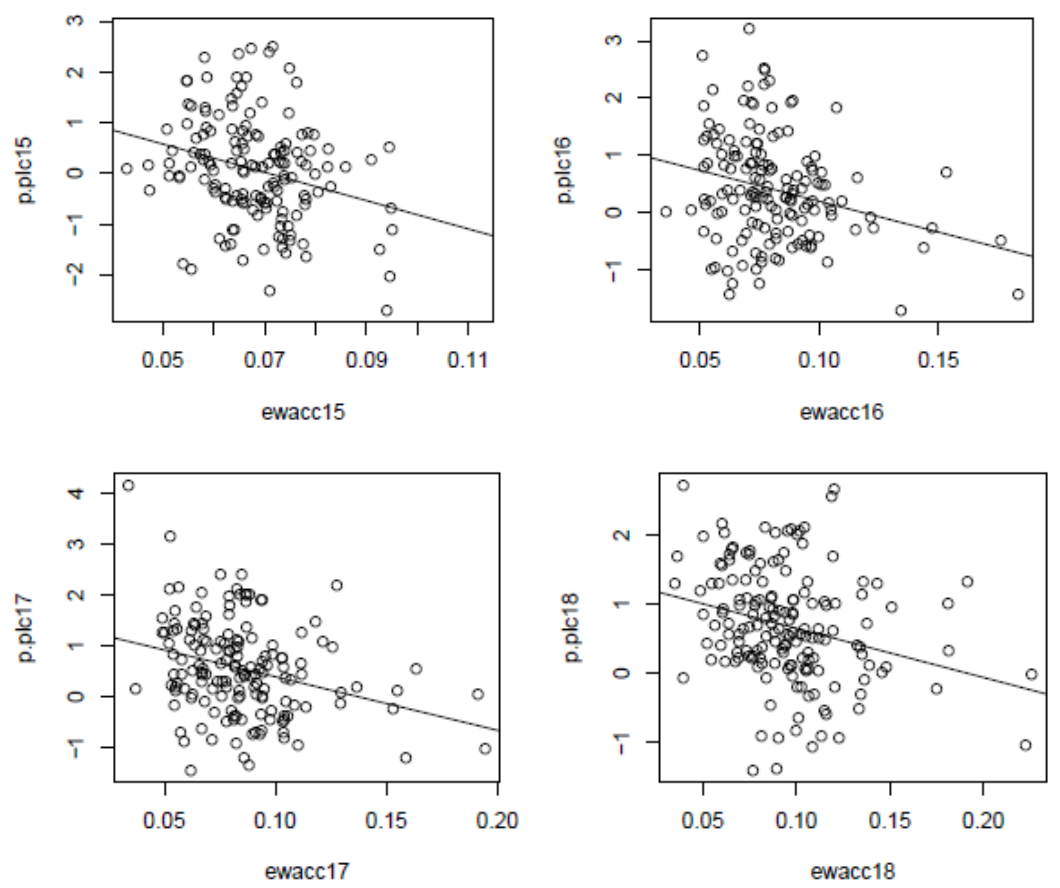

Fonte: Elaboração própria 
A relação entre o múltiplo P/PLC e a variável ewacc para os anos analisados, de acordo com o esperado, possui relação negativa. Na tabela de correlação, apresentou significância em somente um dos quatro anos.

Figura 7 - P/PLC x po
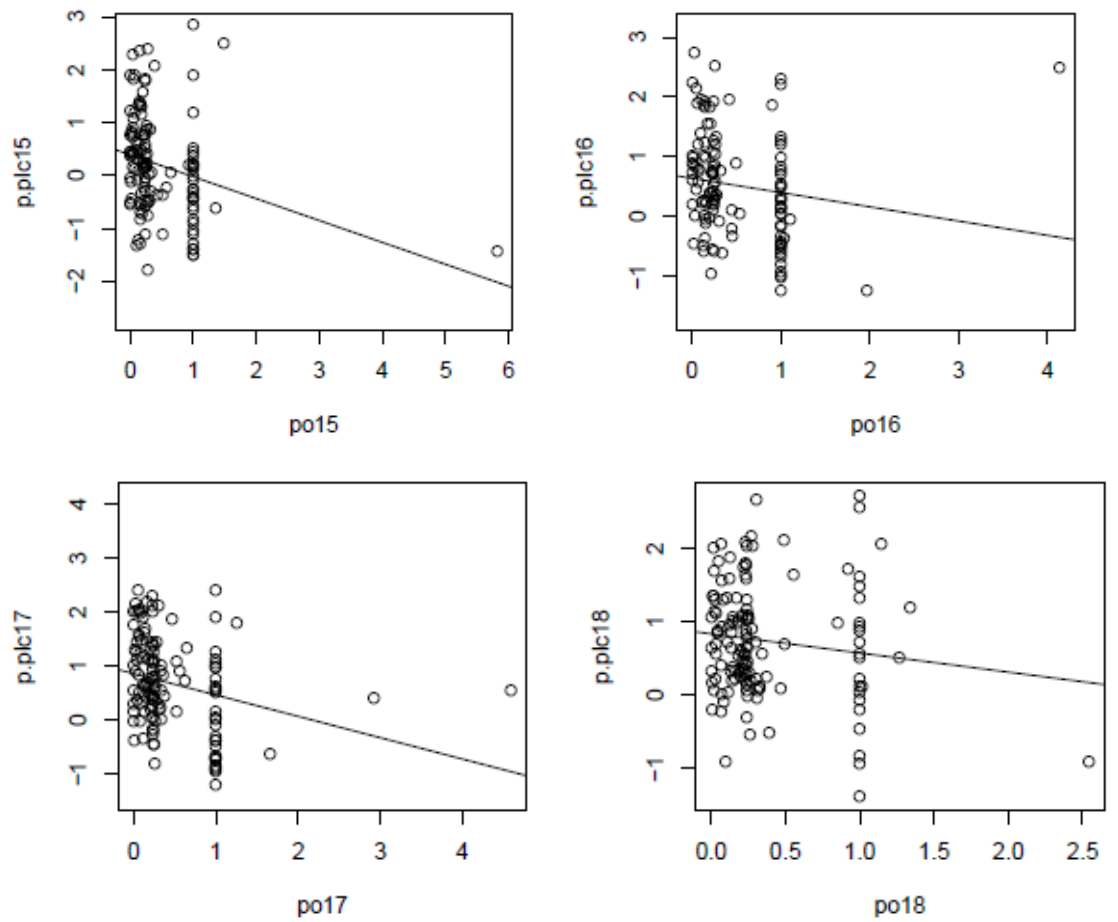

Fonte: Elaboração própria

A relação entre essas variáveis é negativa, convergindo com o referencial teórico. $\mathrm{Na}$ tabela de correlação, apresentou significância em somente um dos quatro anos. Nota-se a presença de outliers.

Figura 8 - P/PLC x gl
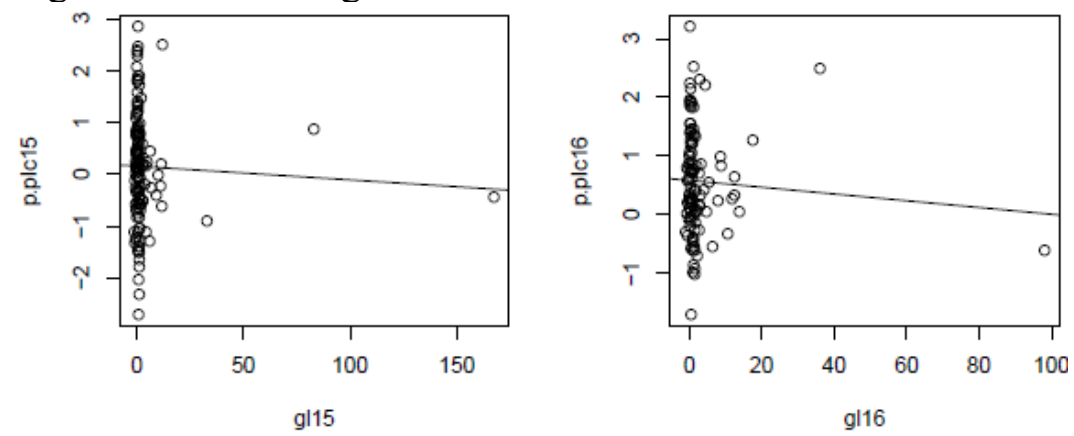

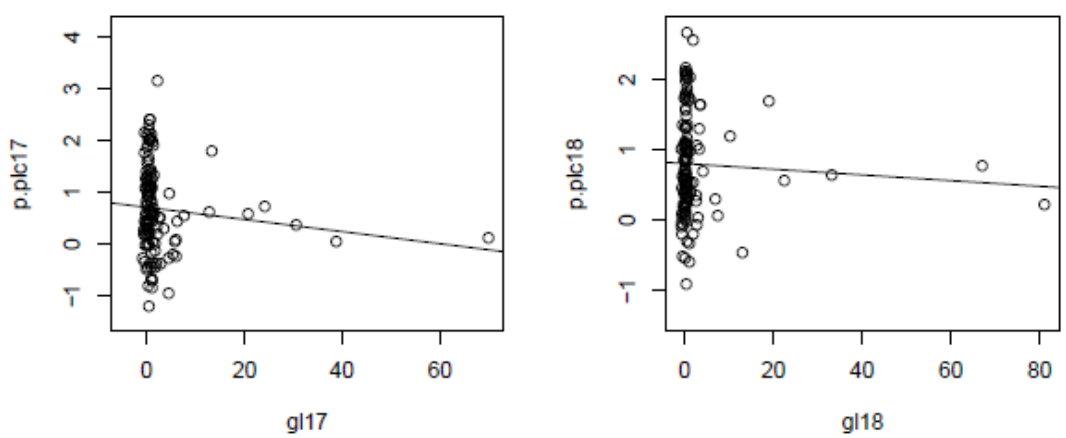

Fonte: Elaboração própria

O gl, ao contrário do esperado, apresentou relação negativa e a correlação não foi significativa. Nota-se a presença de outliers.

Nas figuras de 9 a 13 são apresentadas a relação do múltiplo EV/EBITDA e as variáveis explicativas para os 2015 a 2018.

Figura 9 - EV/EBITDA x wacc
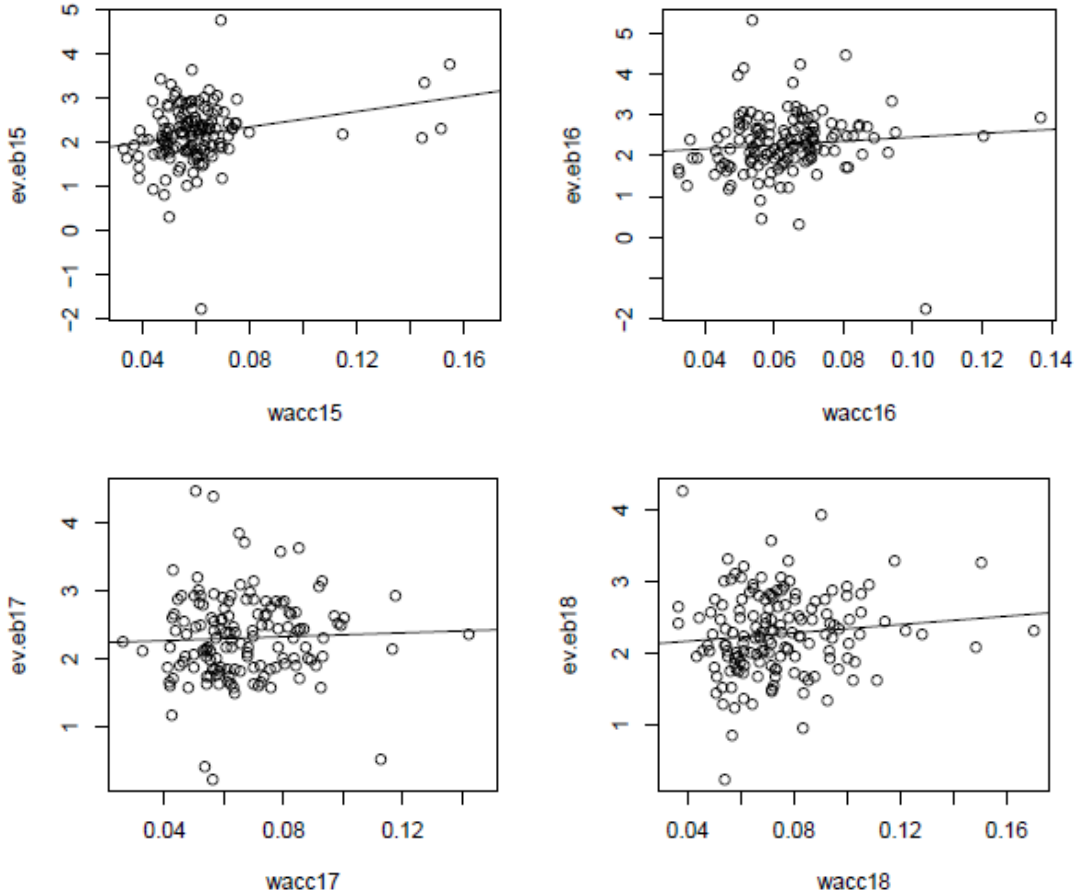

Fonte: Elaboração própria

A linha de tendência é levemente positiva, se aproximando de uma relação neutra e, de acordo com a tabela de correlação, apresenta significância somente para um dos quatros anos da análise. 
Figura 10 - EV/EBITDA x rir
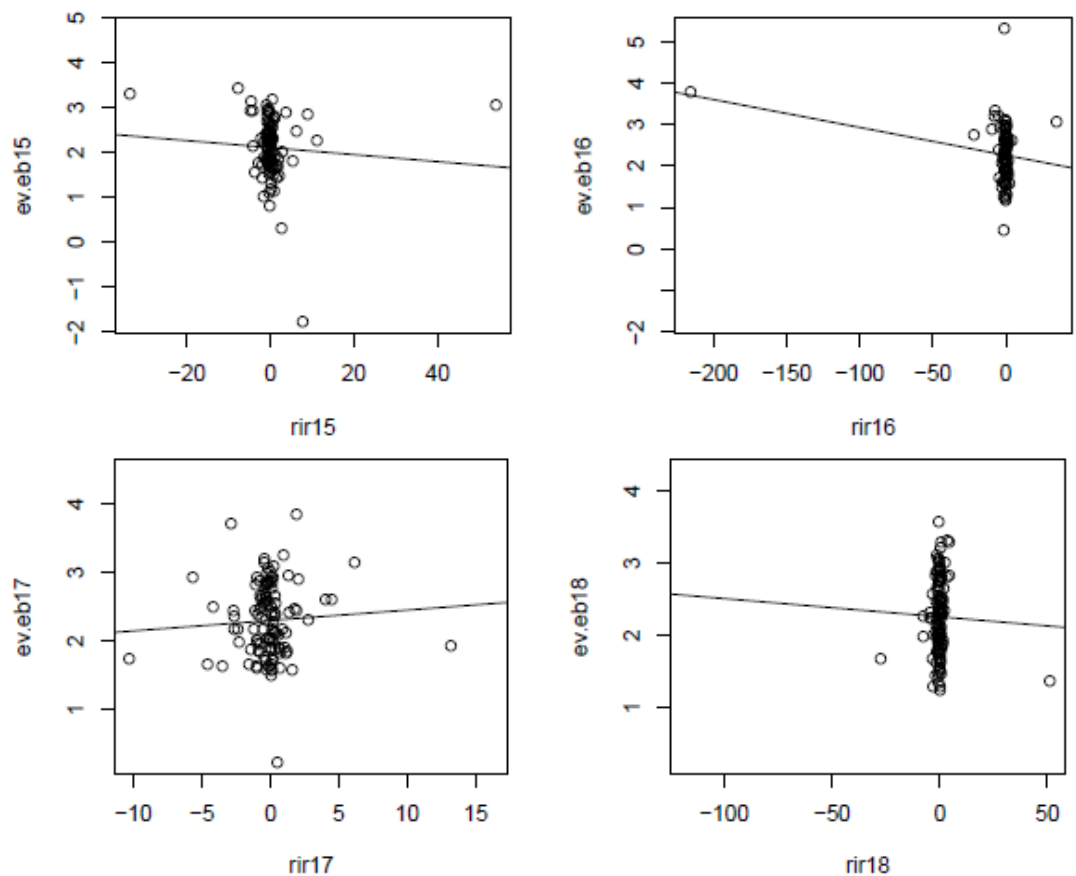

Fonte: Elaboração própria

A rir esperada é que seja positivamente relacionada com múltiplo - o gráfico demonstra uma relação negativa, sendo assim, indo contra o esperado. A correlação é significativa para dois dos quatro anos. Nota-se a presença de outliers.

Figura $11-$ EV/EBITDA $\mathrm{x}$ roic
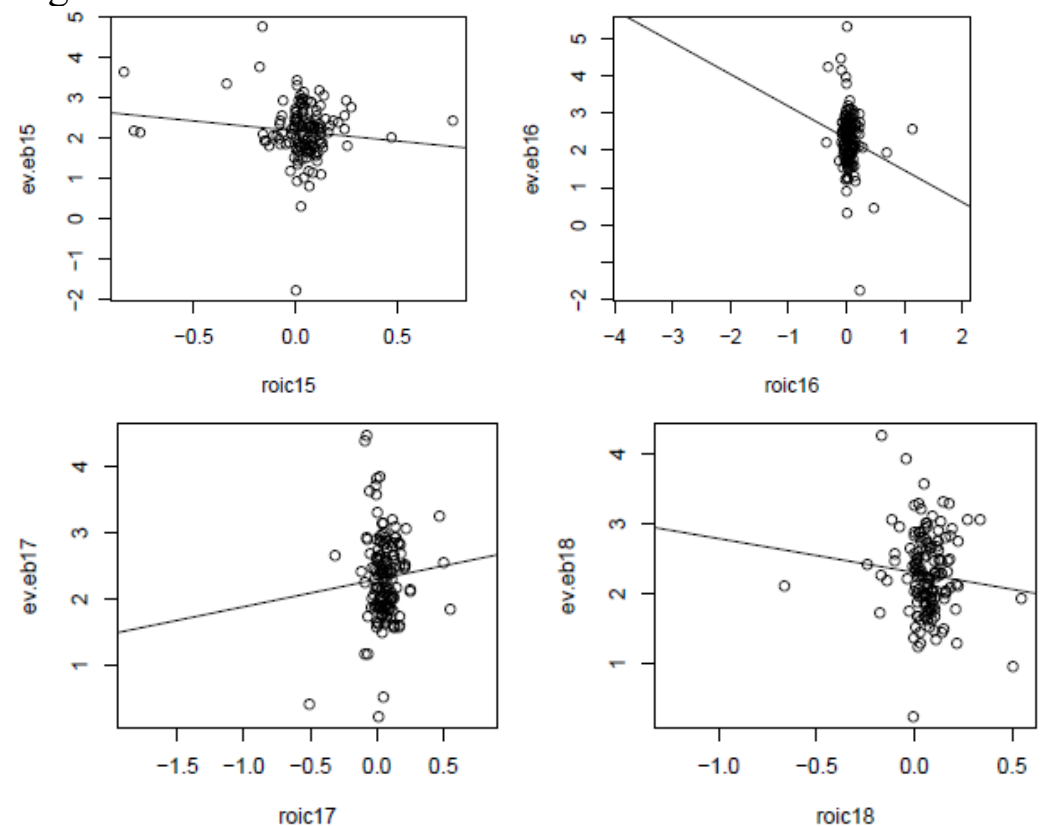

Fonte: Elaboração própria 
O roic, com base no referencial teórico, tem relação positiva com o múltiplo. A linha de tendência gerada apresentou-se com coeficiente negativo para a maioria dos anos, divergindo do esperado e a correlação não foi significância.

Figura 12 - EV/EBITDA x gr
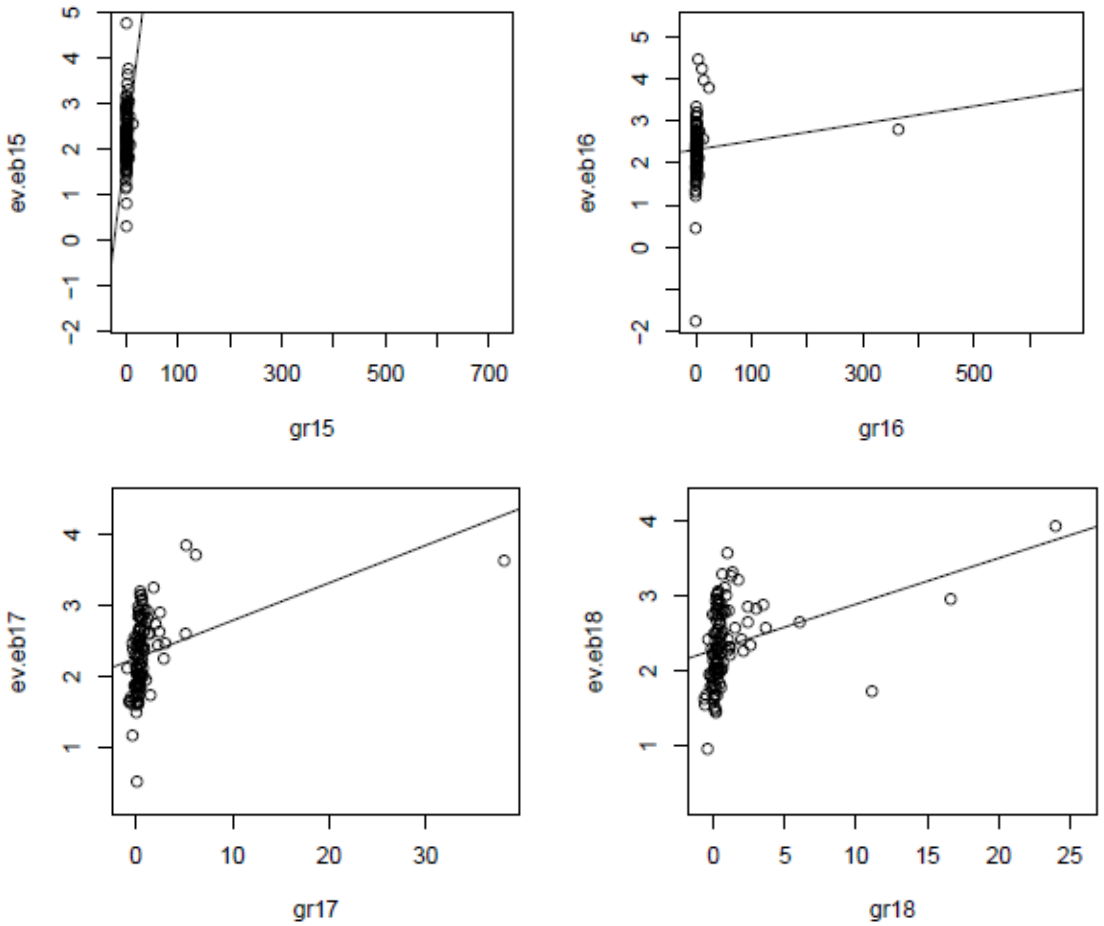

Fonte: Elaboração própria

O gr, variável com maior correlação com o múltiplo apresentou tendência positiva, conforme o esperado pelo referencial teórico, e nota-se a presença de valores outliers.

Figura 13 - EV/EBITDA x etax
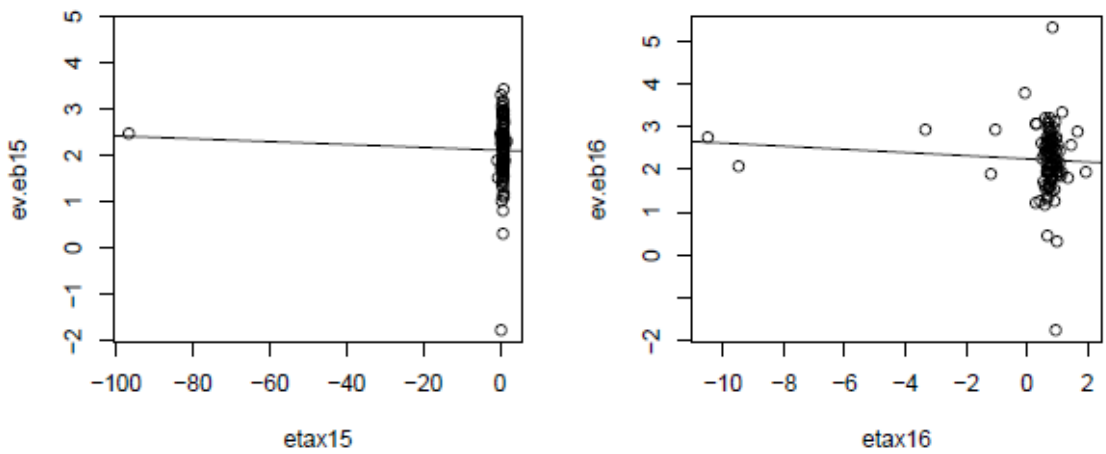

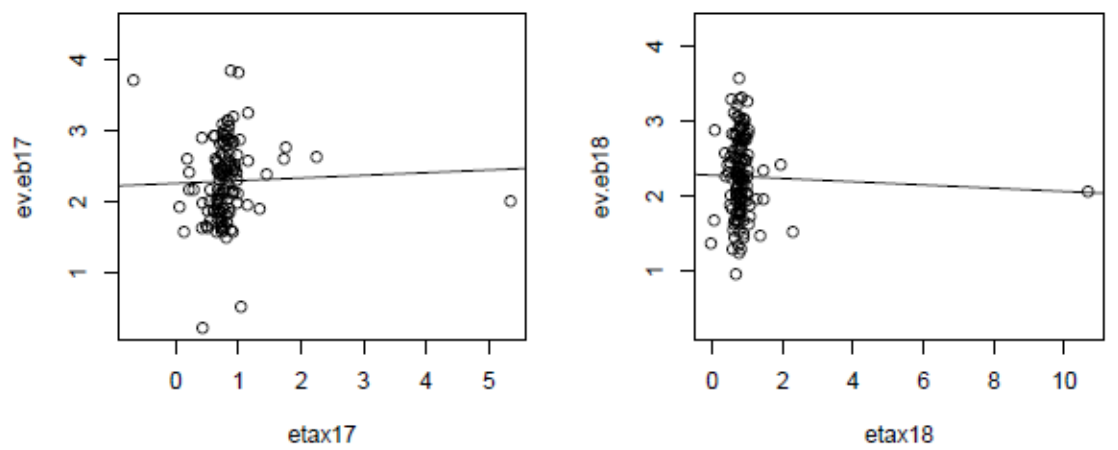

Fonte: Elaboração própria

O etax teve uma relação negativa próxima à neutralidade, era esperado uma relação negativa e, de acordo com a tabela de correlação, não há significância na correlação destas variáveis.

Nas figuras de 14 a 17 são apresentadas a relação do múltiplo EV/IC e as variáveis explicativas para os 2015 a 2018.

Figura 14 - EV/IC x wacc
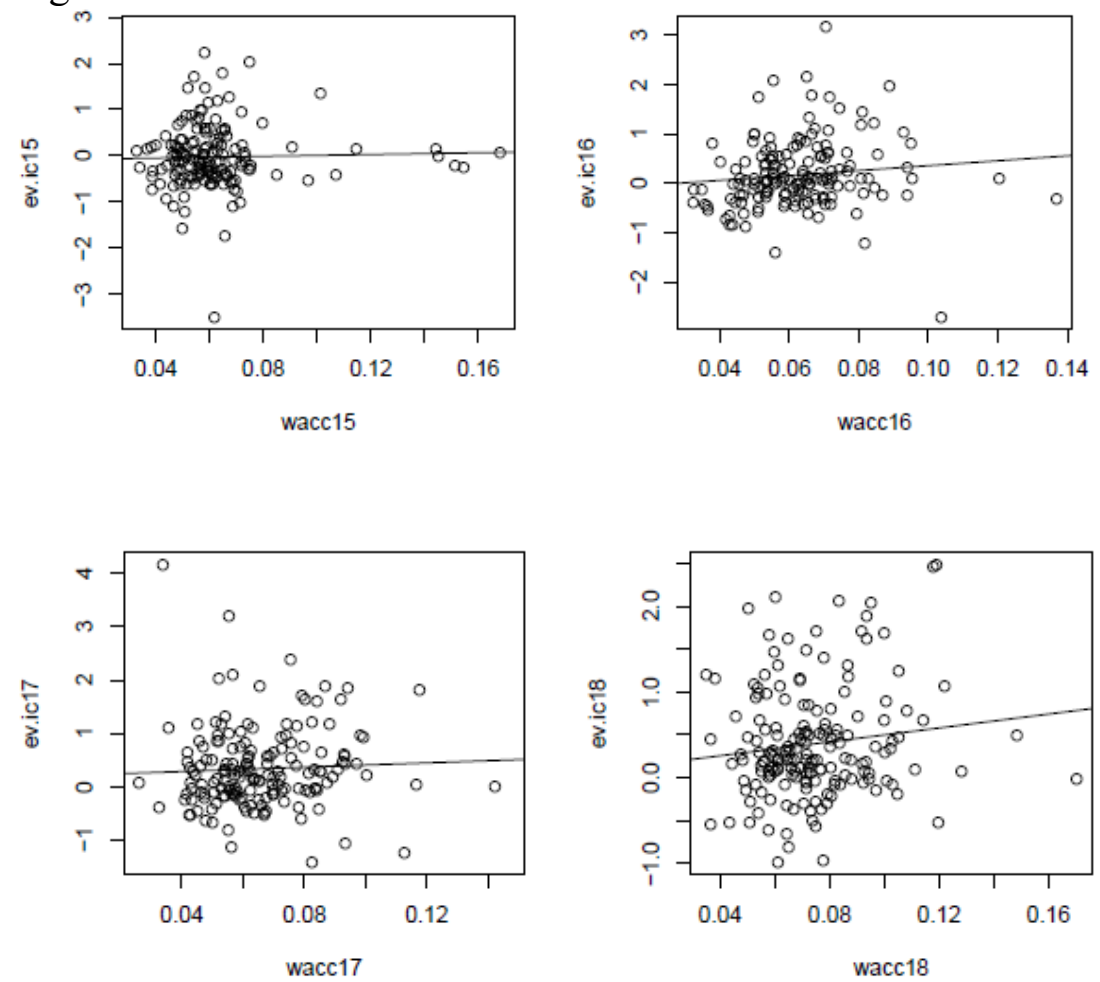

Fonte: Elaboração própria

A linha de tendência é levemente positiva, se aproximando de uma relação neutra; era esperada uma relação negativa e, de acordo com a tabela de correlação, apresenta significância somente para dois dos quatros anos da análise. 
Figura 15 - EV/IC x rir
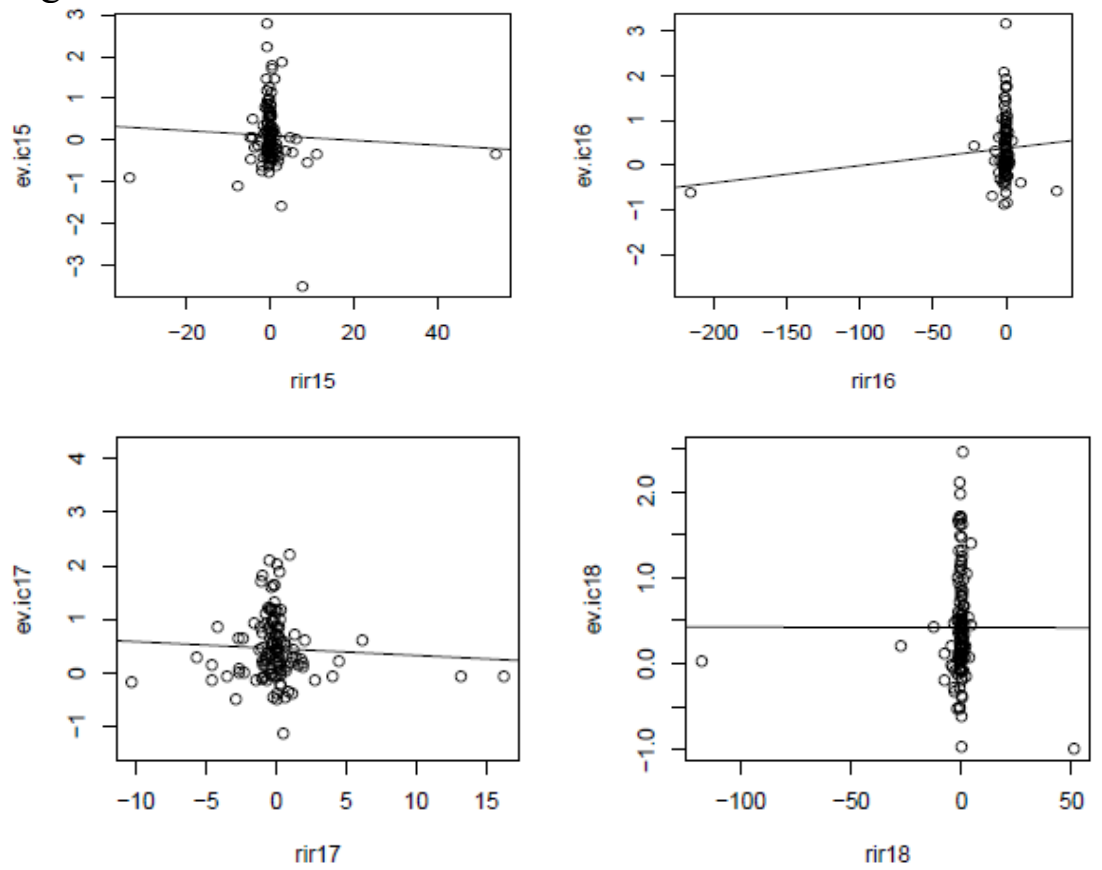

Fonte: Elaboração própria

A rir apresenta uma relação que se altera durante os anos, a relação esperada é que seja positivamente relacionada. Nota-se a presença de outliers. A correlação foi significativa para um dos quatro anos.

Figura 16 - EV/IC x roic
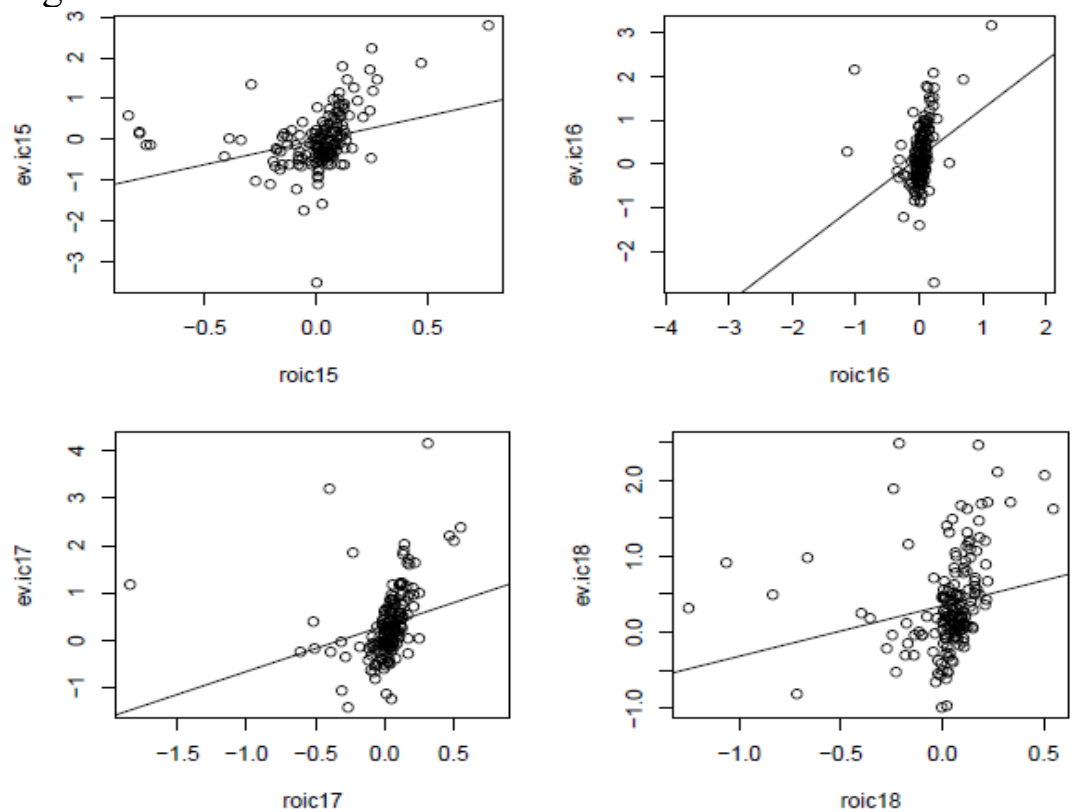

Fonte: Elaboração própria

O roic, variável com maior correlação com o múltiplo, apresentou tendência positiva, conforme o esperado pelo referencial teórico. 
Figura 17 - EV/IC x gr
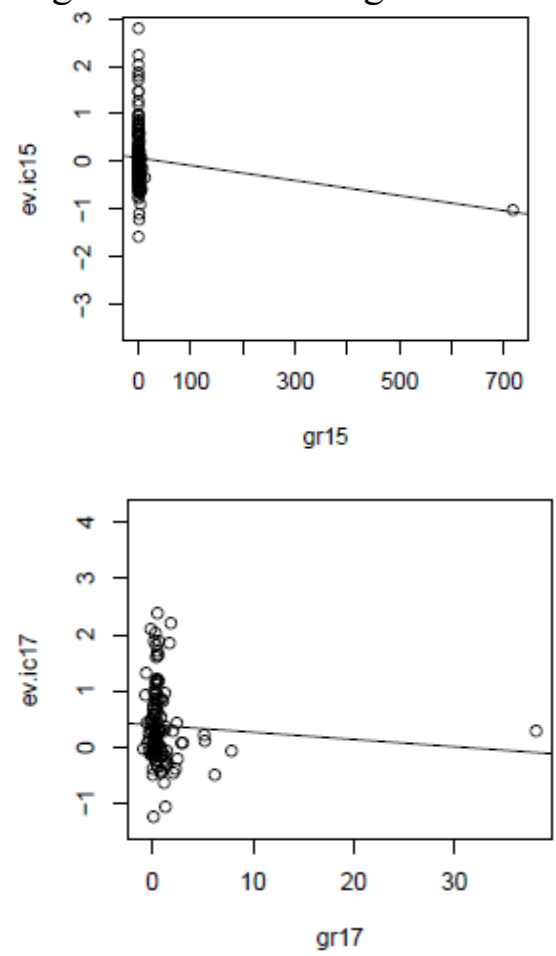

Fonte: Elaboração própria
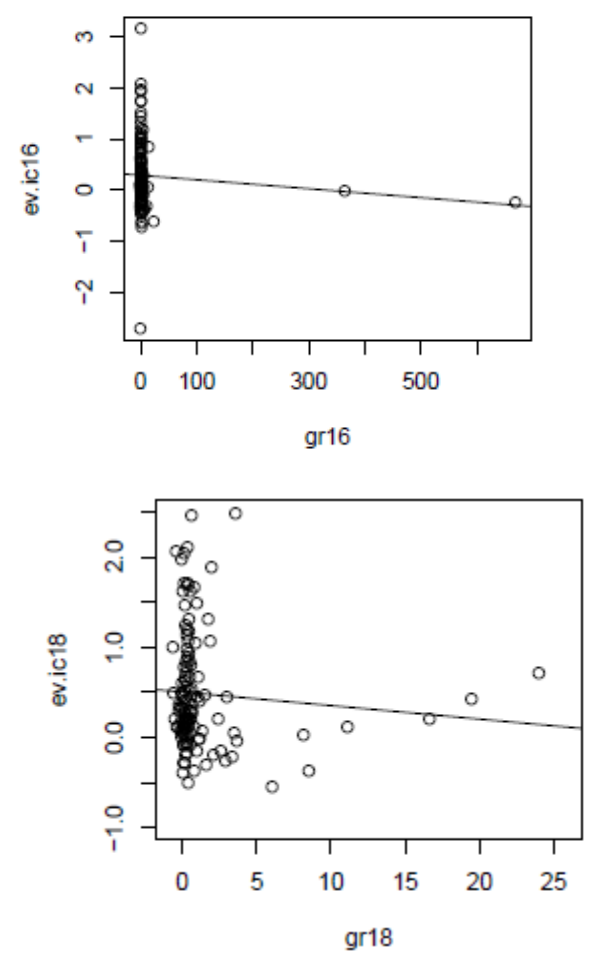

O gr tem relação negativa, ao contrário do apontado pelo referencial teórico e na correlação não houve significância.

Nas figuras de 18 a 22 são apresentadas a relação do múltiplo EV/RECEITA e as variáveis explicativas para os 2015 a 2018.

Figura 18 - EV/RECEITA x wacc
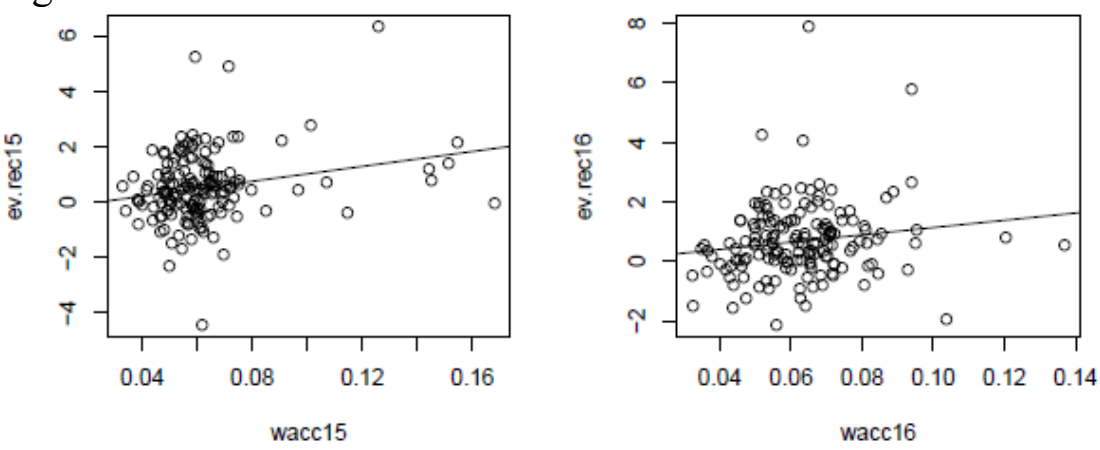

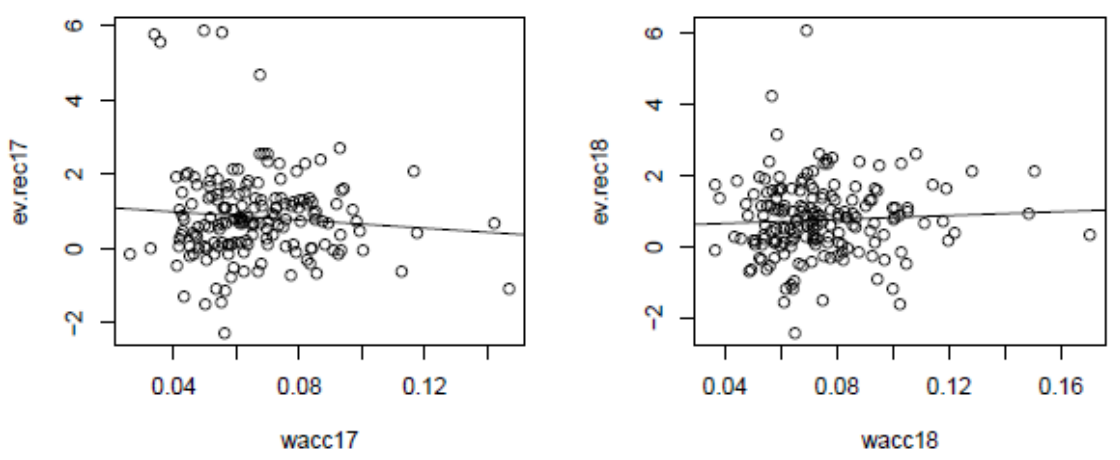

Fonte: Elaboração própria

O wacc não apresentou uma relação definida com o múltiplo EV/Receita, e na tabela de correlação não teve significância em nenhum dos anos analisados.

Figura 19 - EV/RECEITA x rir
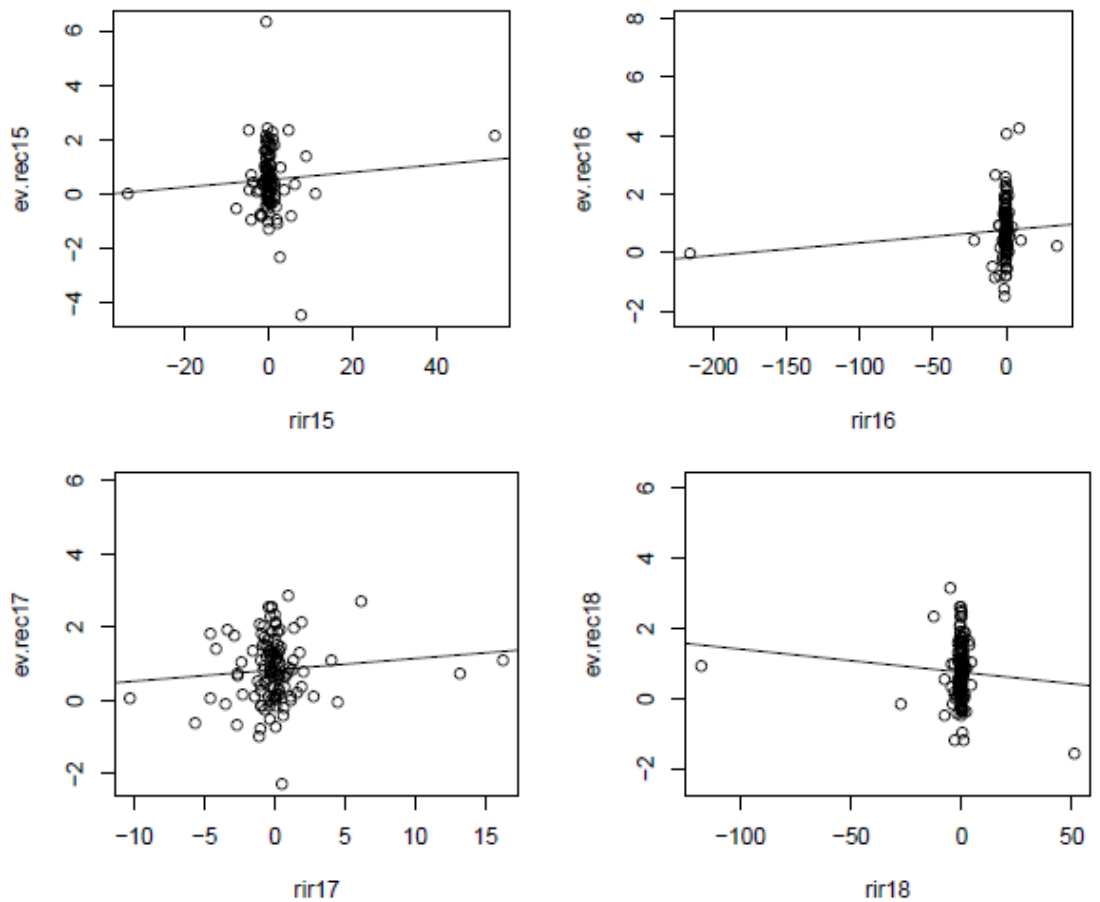

Fonte: Elaboração própria

A relação apresentada foi positiva para maioria dos anos da análise, de acordo com o esperado. Nota-se a presença de outliers. A correlação foi significativa para um dos quatro anos. 
Figura 20 - EV/RECEITA x mo
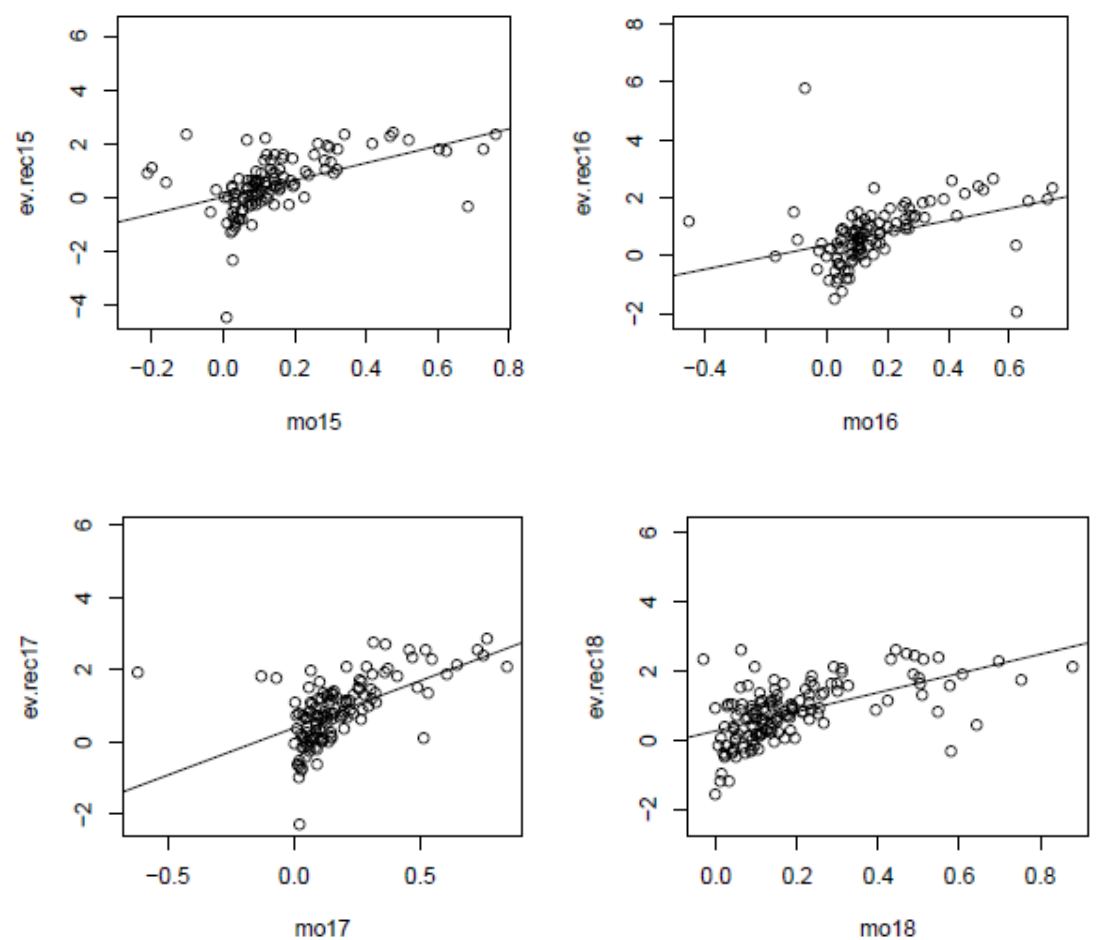

Fonte: Elaboração própria

A mo possui relação positiva, de acordo com o esperado, é a variável com melhor correlação. Nota-se a presença de outliers.

Figura 21 - EV/RECEITA x gr
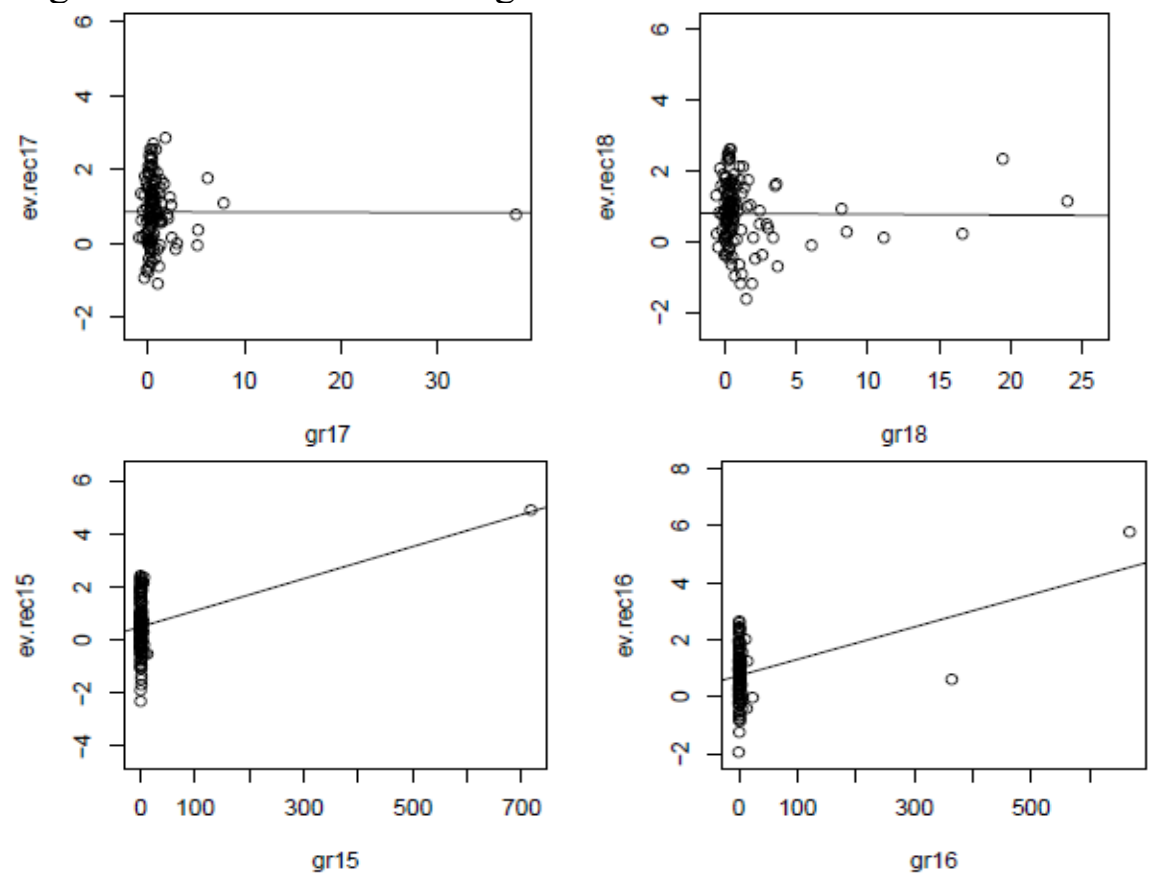

Fonte: Elaboração própria 
A gr possui a tendência positiva para alguns anos, e neutra para outros; era esperada uma relação positiva, a correlação não possui significância e nota-se a presença de outliers.

Figura 22 - EV/RECEITA $x$ etax
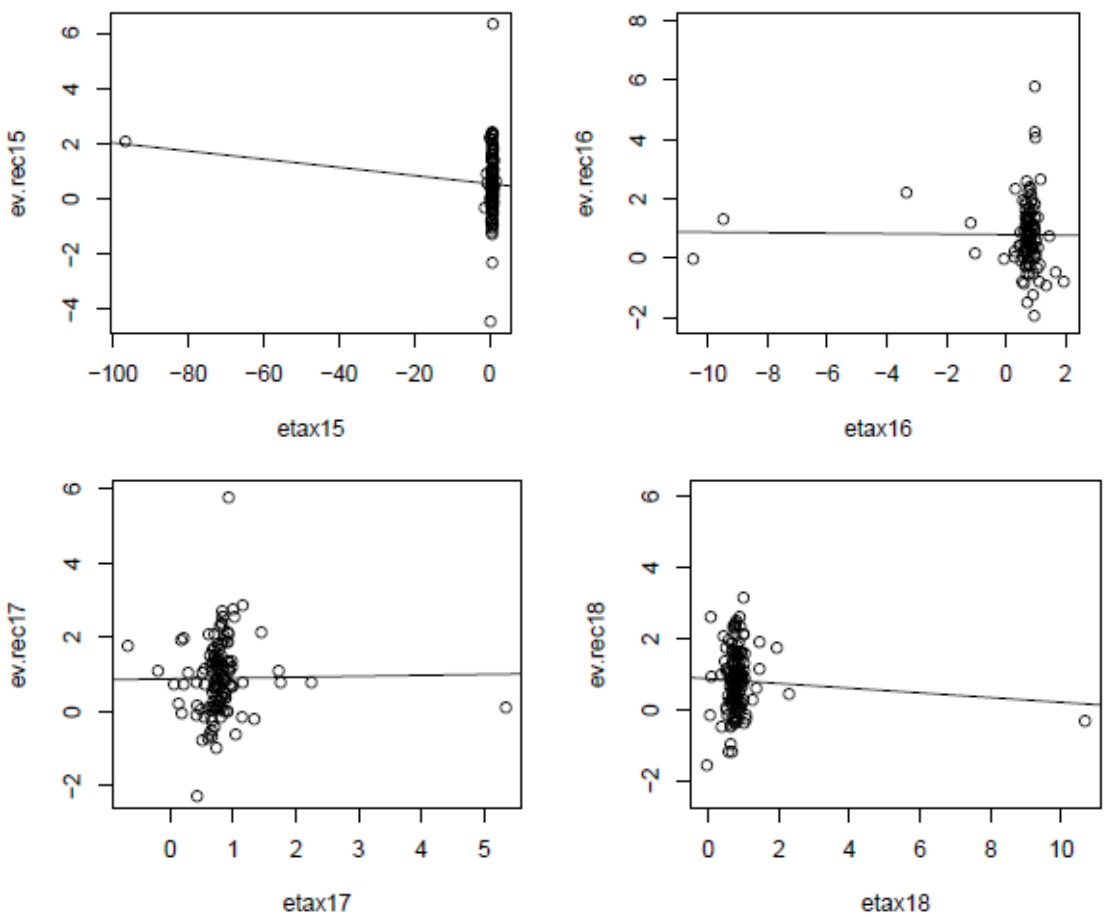

Fonte: Elaboração própria

A tendência varia de negativa para neutra durante os anos; era esperada uma relação negativa, a correlação foi significativa para um dos quatro anos, e nota-se a presença de outliers.

\subsection{Apresentação dos modelos estimados}

Nas tabelas a seguir, são apresentados os resultados dos modelos, calculados pelo software R. Na primeira coluna, é informado a que ano se refere o modelo estimado, nas colunas seguintes são apresentadas as variáveis explicativas de cada múltiplo, e os valores dos coeficientes $b_{0}$ e $b_{j}$ são apresentados somente quando o p-valor dos parâmetros estimados são menores que 0,10. Nas últimas quatro colunas, após as variáveis explicativas, são apresentadas informações para análise dos modelos estimados:

$\mathrm{R}^{2}$ : coeficiente de determinação;

$\mathrm{N}$ : quantidade de empresas para o modelo gerado; 
Shapiro teste: valor do teste de Shapiro-Wilk para análise da normalidade dos resíduos;

BP teste: valor do teste de Breusch-Pagan para análise da variância dos resíduos.

No anexo do trabalho são apresentados os outputs de todos os modelos estimados, assim como a estatística VIF dos respectivos modelos.

Tabela 25 - Modelos estimados para o múltiplo $\ln (\mathrm{P} / \mathrm{L})$

\begin{tabular}{|c|c|c|c|c|c|c|c|c|c|}
\hline $\ln (\mathbf{P} / \mathbf{L})$ & b0 & ewacc & po & roe & gl & $\mathbf{R}^{2}$ & $\mathbf{N}$ & $\begin{array}{c}\text { shapiro } \\
\text { teste }\end{array}$ & $\begin{array}{r}\text { BP } \\
\text { teste }\end{array}$ \\
\hline 2015 & $2.39^{* * *}$ & & $0.72^{* *}$ & & $0.06^{* * *}$ & 0.42 & 90 & 0.77 & 0.39 \\
\hline 2016 & $2.78^{* * *}$ & & & & $0.14^{* * *}$ & 0.54 & 77 & 0.01 & 0.22 \\
\hline 2017 & $2.83^{* * *}$ & & $0.20^{\prime}$ & & $0.12^{* * *}$ & 0.54 & 90 & 0.07 & 0.80 \\
\hline 2018 & $3.21^{* * *}$ & $-3.80^{*}$ & & & $0.07^{* * *}$ & 0.49 & 119 & 0.00 & 0.00 \\
\hline
\end{tabular}

Fonte: Elaboração própria

Em relação às variáveis explicativas dos modelos do múltiplo $\ln (\mathrm{P} / \mathrm{L})$, a variável gl foi incluída em todos os anos, a po foi incluída em dois dos quatro anos da análise e o ewacc em somente um ano.

O nível mais baixo do $\mathrm{R}^{2}$ foi de 0,42 e o nível mais alto foi de 0,54 . Os modelos gerados tiveram de 77 a 119 empresas $(\mathrm{N})$. Em relação ao teste de normalidade (teste de Shapiro-wilk), para dois dos quatro anos, há indícios de que a distribuição dos resíduos possui distribuição normal. Em relação à variância dos resíduos (teste de Breusch-Pagan), para três dos quatro anos da análise, há indícios de que não apresentam problemas de heterocedasticidade.

Os modelos finais do múltiplo $\ln (\mathrm{P} / \mathrm{L})$ que atendem às suposições da regressão linear múltipla, foram os de 2015 e 2017.

Modelo 2015: $\ln (\mathrm{P} / \mathrm{L})=2,39+0,72(\mathrm{po})+0,06(\mathrm{gl})$

Modelo 2017: $\ln (\mathrm{P} / \mathrm{L})=2,83+0,20$ (po) $+0,12(\mathrm{gl})$ 
Tabela 26 - Modelos estimados para o múltiplo $\ln (\mathrm{P} / \mathrm{PLC})$

\begin{tabular}{|c|c|c|c|c|c|c|c|}
\hline $\ln (\mathrm{P} / \mathrm{PLC})$ & b0 & ewacc & roe & $\mathbf{R}^{2}$ & $\mathbf{N}$ & $\begin{array}{c}\text { shapiro } \\
\text { teste }\end{array}$ & $\begin{array}{r}\text { BP } \\
\text { teste }\end{array}$ \\
\hline 2015 & & & $1.37^{* * *}$ & 0.16 & 153 & 0.03 & 0.00 \\
\hline 2016 & $0.98^{* * *}$ & $-7.72^{* *}$ & $1.46^{* * * *}$ & 0.12 & 149 & 0.20 & 0.34 \\
\hline 2017 & $1.06^{* * *}$ & $-7.29^{* *}$ & $1.46^{* * *}$ & 0.24 & 157 & 0.00 & 0.00 \\
\hline 2018 & $1.36^{* * *}$ & $-7.37^{* * *}$ & $0.31^{*}$ & 0.11 & 162 & 0.40 & 0.15 \\
\hline
\end{tabular}

Fonte: Elaboração própria

Em relação às variáveis explicativas do múltiplo $\ln (\mathrm{P} / \mathrm{PLC})$, a variável roe foi incluída em todos os anos e o ewacc foi incluso em três dos quatro anos da análise.

O grau de explicação dos modelos $\left(\mathrm{R}^{2}\right)$ foi de 0,11 , menor grau de explicação, e o nível mais alto foi de 0,24. Os modelos estimados tiveram de 126 a 162 empresas (N). Em relação ao teste de normalidade (teste de Shapiro-wilk), para dois dos quatro anos, há indícios de que a distribuição dos resíduos possui distribuição normal. Em relação à variância dos resíduos (teste de Breusch-Pagan) para dois anos, os mesmos apresentaram indícios de que a distribuição dos resíduos possui distribuição normal (2016 e 2018), há indícios de que os resíduos não apresentam problemas de heterocedasticidade.

Os modelos finais do múltiplo $\ln (\mathrm{P} / \mathrm{PLC})$ que atendem as suposições da regressão linear múltipla, foram os de 2016 e 2018 :

$$
\begin{aligned}
& \text { Modelo 2016: } \ln (\mathrm{P} / \mathrm{PLC})=0,98-7,72(\text { ewacc })+1,46(\text { roe }) \\
& \text { Modelo 2018: } \ln (\mathrm{P} / \mathrm{PLC})=1,36-7,37(\text { ewacc })+0,31(\text { roe })
\end{aligned}
$$

\begin{tabular}{|c|c|c|c|c|c|c|c|c|c|}
\hline $\ln ($ EV/EBITDA) & b0 & wacc & rir & roic & etax & $\mathbf{R}^{2}$ & $\mathbf{N}$ & $\begin{array}{c}\text { shapiro } \\
\text { teste }\end{array}$ & $\begin{array}{c}\text { BP } \\
\text { teste }\end{array}$ \\
\hline 2015 & $2,16 * * *$ & & & & $0,09 * * *$ & 0,07 & 121 & 0,00 & 0,53 \\
\hline 2016 & $2,08^{* * *}$ & & $0,05 * * *$ & & $0,56^{* * *}$ & 0,30 & 72 & 0,33 & 0,42 \\
\hline 2017 & $2,21 * * *$ & & & $0,77^{`}$ & $0,06^{* * *}$ & 0,15 & 114 & 0,18 & 0,45 \\
\hline 2018 & $2,28 * * *$ & & & & $0,06^{* * *}$ & 0,12 & 120 & 0,69 & 0,69 \\
\hline
\end{tabular}

Tabela 27 - Modelos estimados para o múltiplo $\ln ($ EV/EBITDA)

Fonte: Elaboração própria

Em relação às variáveis explicativas do múltiplo $\ln (\mathrm{EV} /$ Ebitda), a variável gr foi inclusa em todos os anos, a rir e a roic foram inclusas em um dos anos da análise.

O grau de explicação dos modelos $\left(\mathrm{R}^{2}\right)$ foi de 0,12 , menor grau de explicação, e o nível mais alto foi de 0,37 . Os modelos estimados tiveram de 72 a 121 empresas (N). Em 
relação ao teste de normalidade (teste de Shapiro-wilk), somente para um dos anos há indícios de que a distribuição dos resíduos não possui distribuição normal. Em relação à variância dos resíduos (teste de Breusch-Pagan), para todos os anos há indícios de que os mesmos não apresentam problemas de heterocedasticidade.

Os modelos finais do múltiplo $\ln ($ EV/EBITDA) que atendem as suposições da regressão linear múltipla, foram os de 2016, 2017 e 2018.

$$
\begin{aligned}
& \text { Modelo 2016: } \ln (\mathrm{EV} / \mathrm{EBITDA})=2,08+0,05(\text { rir })+0,56(\mathrm{gr}) \\
& \text { Modelo 2017: } \ln (\mathrm{EV} / \mathrm{EBITDA})=2,21+0,77(\text { roic })+0,06(\mathrm{gr}) \\
& \text { Modelo 2018: } \ln (\mathrm{EV} / \mathrm{EBITDA})=2,28+0,06(\mathrm{gr})
\end{aligned}
$$

\begin{tabular}{|c|c|c|c|c|c|c|c|c|c|c|c|}
\hline $\ln (\mathrm{EV} / \mathrm{IC})$ & b0 & wacc & rir & roic & gr & etax & $\mathbf{R}^{2}$ & $\mathbf{N}$ & F teste & $\begin{array}{c}\text { shapiro } \\
\text { teste }\end{array}$ & BP teste \\
\hline 2015 & -0.02 & & & $1.19^{* * *}$ & & & 0.10 & 155 & 0,00 & 0,00 & 0.78 \\
\hline 2016 & $0.16^{* *}$ & & & $1.11^{* * *}$ & & & 0.09 & 157 & 0,00 & 0,00 & 0.11 \\
\hline 2017 & $0.30^{* * *}$ & & & $0.97^{* * *}$ & & & 0.07 & 164 & 0,00 & 0,00 & 0.004 \\
\hline 2018 & 0.11 & & & $4.28^{* * *}$ & & $-0.10^{*}$ & 0.37 & 132 & 0,00 & 0,00 & 0.43 \\
\hline
\end{tabular}

Tabela 28 - Modelos estimados para o múltiplo $\ln (\mathrm{EV} / \mathrm{IC})$

Fonte: Elaboração própria

Em relação às variáveis explicativas do múltiplo $\ln (\mathrm{EV} / \mathrm{IC})$, a variável roic foi inclusa em todos os anos e o etax foi incluso em somente um ano.

O grau de explicação dos modelos $\left(\mathrm{R}^{2}\right)$ foi de 0,07 , menor grau de explicação, e o nível mais alto foi de 0,37. Os modelos estimados tiveram de 132 a 164 empresas (N). Em relação ao teste de normalidade (teste de Shapiro-wilk), para todos os anos, há indícios de que a distribuição dos resíduos não possui distribuição normal. Em relação à variância dos resíduos (teste de Breusch-Pagan) para três anos da análise, há indícios de que os resíduos não apresentam problemas de heterocedasticidade.

Nos modelos finais do múltiplo $\ln (\mathrm{EV} / \mathrm{IC})$, nenhum atendeu as suposições da regressão linear múltipla. 
Tabela 29 - Modelos estimados para o múltiplo $\ln (\mathrm{EV} / \mathrm{REC})$

\begin{tabular}{|c|c|c|c|c|c|c|c|c|c|c|}
\hline $\ln (\mathrm{EV} / \mathrm{REC})$ & b0 & wacc & rir & mo & gr & etax & $\mathbf{R}^{2}$ & $\mathbf{N}$ & $\begin{array}{c}\text { shapiro } \\
\text { teste }\end{array}$ & $\begin{array}{r}\text { BP } \\
\text { teste }\end{array}$ \\
\hline 2015 & $0,76^{* * *}$ & & & $4,10 * * *$ & $0,31 * * *$ & $-1,26^{* * *}$ & 0,50 & 97 & 0,58 & 0,08 \\
\hline 2016 & $1,31^{* * *}$ & & $0,04 * *$ & $3,08 * * *$ & $0,24 *$ & $-1,39 * * *$ & 0,42 & 73 & 0,11 & 0,25 \\
\hline 2017 & $0,62 * * *$ & & & $2,92 * * *$ & $0,10^{\prime}$ & $-0,39 * *$ & 0,44 & 104 & 0,00 & 0,00 \\
\hline 2018 & $0,81 * * *$ & & $0,01^{*}$ & $4,27 * * *$ & $0,16^{* * *}$ & $-0,98 * * *$ & 0,53 & 105 & 0,47 & 0,11 \\
\hline
\end{tabular}

Fonte: Elaboração própria

Em relação às variáveis explicativas do múltiplo $\ln (\mathrm{EV} / \mathrm{REC})$, as variáveis mo, gr e etax foram inclusas em todos os anos e a rir em dois anos da análise.

O grau de explicação dos modelos foi de 0,42 , menor grau de explicação, e o nível mais alto foi de 0,53. Os modelos estimados tiveram de 73 a 105 empresas (N). Em relação ao teste de normalidade (teste de Shapiro-wilk), para três anos há indícios de que a distribuição dos resíduos possui distribuição normal, e em relação à variância dos resíduos (teste de Breusch-Pagan), para três anos há indícios de que os resíduos não apresentam problemas de heterocedasticidade.

Os modelos finais do múltiplo $\ln (\mathrm{EV} / \mathrm{REC})$ que atendem as suposições da regressão linear múltipla, foram os de 2015, 2016 e 2018.

$$
\begin{aligned}
& \text { Modelo 2015: } \ln (\mathrm{EV} / \mathrm{REC})=0,76+4,10(\mathrm{mo})+0,31(\mathrm{gr})-1,26(\text { etax }) \\
& \text { Modelo 2016: } \ln (\mathrm{EV} / \mathrm{REC})=1,31+0,04(\mathrm{rir})+3,08(\mathrm{mo})+0,24(\mathrm{gr})-0,39(\text { etax }) \\
& \text { Modelo 2018: } \ln (\mathrm{EV} / \mathrm{REC})=0,81+0,01(\text { rir })+4,27(\mathrm{mo})+0,16(\mathrm{gr})-0,98(\text { etax })
\end{aligned}
$$

\subsubsection{Análise comparativa dos modelos estimados}

Para estimação dos modelos, nota-se que alguns coeficientes das variáveis explicativas utilizadas nos modelos estimados variam de ano para ano na significância e na relação (positiva/negativa) com o respectivo múltiplo, apresentando, em alguns anos da análise, sinais contrários ao esperado pela teoria. O que já era esperado, conforme indicava a análise da relação entre as variáveis dependentes e as independentes, abordado no item 4.3 (Análise da relação entre as variáveis dependentes e as independentes). Esta instabilidade entre as variáveis independentes com a dependente durante o tempo foi relatada por Heveadi (1999), Omran (2003), Damodaran (2007). Contudo, ressalta-se que quando o sinal não correspondia com esperado, a variável era removida no ano em estudo. 
Também os testes para os pressupostos da regressão linear múltipla não eram satisfeitos para alguns modelos estimados nos anos da análise.

Em relação a quais modelos apresentam melhores resultados, constatou-se que os modelos que apresentaram maiores valores para o coeficiente de determinação $\left(\mathrm{R}^{2}\right)$ foram os do múltiplo $\ln (\mathrm{EV} /$ Receita), seguido dos modelos para o múltiplo $\ln (\mathrm{P} / \mathrm{L})$.

No que concerne à análise dos resíduos, teste de Shapiro-wilk e teste de BreuschPagan, os modelos para o múltiplo $\ln (E V / E b i t d a)$ e $\ln (E V / R e c e i t a)$ foram os que apresentaram melhores resultados: ambos estimaram três modelos satisfazendo as suposições da técnica de regressão linear múltipla para o período de análise. Seguidos dos modelos para o múltiplo $\ln (\mathrm{P} / \mathrm{L})$ e $\ln (\mathrm{P} / \mathrm{PLC})$ que estimaram dois modelos satisfazendo as suposições.

Em relação à quantidade de empresas para os modelos gerados $(\mathrm{N})$, os que tiveram maior número de empresas foi o múltiplo $\ln (\mathrm{EV} / \mathrm{IC})$, seguidos do múltiplo de valor de mercado $\ln (\mathrm{P} / \mathrm{PLC})$, pelo fato de terem menos empresas com valores negativos para a variável de padronização. Assim, pode-se considerar que os múltiplos de valor patrimonial contábil são os que mantém maior número de empresas para gerar os modelos.

Contudo, os modelos estimados para esses múltiplos apresentaram piores resultados em termos de $\left(\mathrm{R}^{2}\right)$, em comparação aos demais analisados. $\mathrm{E}$ os modelos estimados para o múltiplo $\ln (\mathrm{EV} / \mathrm{IC})$ não foram válidos para nenhum ano, enquanto os modelos estimados para o do múltiplo $\ln (\mathrm{P} / \mathrm{PLC})$ foram válidos para dois anos. Assim, entre os múltiplos de valor patrimonial contábil, pode-se considerar os modelos estimados para o múltiplo $\ln (\mathrm{P} / \mathrm{PLC})$ superiores.

Entre os múltiplos de lucro, os modelos estimados para o múltiplo $\ln (\mathrm{P} / \mathrm{L})$ apresentaram maiores $\left(\mathrm{R}^{2}\right)$, enquanto os modelos estimados para o múltiplo $\ln (\mathrm{EV} / \mathrm{EBITDA})$ estimaram coeficientes para as variáveis explicativas de forma mais confiável. Nota-se que, quando os modelos estimados para o múltiplo $\ln (\mathrm{P} / \mathrm{L})$ são válidos, estes apresentam $\mathrm{R}^{2}$ superiores aos modelos estimados para o múltiplo $\ln ($ EV/EBITDA).

Desta forma, de acordo com os resultados encontrados na pesquisa, os modelos estimados para o múltiplo $\ln (\mathrm{EV} /$ Receita) são superiores em relação aos demais analisados, sendo, desta forma, considerado o múltiplo que apresentou melhores modelos. 


\subsubsection{Análise comparativa entre as pesquisas realizadas em países emergentes}

Como já comentado anteriormente, a análise comparativa entre as pesquisas realizadas em contexto de países emergentes é limitada, devido a diferentes metodologias e diferentes anos de análise, o que impacta no grau de explicação das variáveis explicativas.

Contudo, na análise comparativa em termos do coeficiente de determinação apresentados na Tabela (1), o estudo de Heveadi (1999), que analisou o múltiplo P/L, encontrou, para os anos de 1995 a 1997, $\mathrm{R}^{2}$ variando de 0,12 a 0,49 nos anos da análise.

Nos demais estudos analisados, onde os autores fizeram comparações entre modelos de outros múltiplos, Damodaran, ao contrário do encontrado na presente pesquisa, para as regressões dos modelos dos múltiplos P/L, P/PLC, EV/EBITDA EV/IC e EV/Receita, aponta que os modelos estimados para o múltiplo EV/IC são os que apresentam maior $\mathrm{R}^{2}$, variando de 0,46 a 053 , entre os anos de 2015 a 2018.

Entretanto, Maniar (2014) aponta como melhores modelos os estimados para o múltiplo P/L, em que se apresenta coeficiente de determinação de 0,72 e o múltiplo P/Receita com 0,66. Arruda (2015), entre os múltiplos analisados, indica os modelos estimados para o múltiplo P/Receita com coeficiente de determinação de 0,50, e Gupta (2018) designa os modelos estimados para os múltiplos EV/EBITDA e P/Receita como os que apresentam melhores resultados. Assim, esses três estudos, de forma geral, sugerem como melhores modelos os estimados para os múltiplos de receita e lucro, o que corrobora com os resultados encontrados na presente pesquisa. 


\section{CONCLUSÃO}

O objetivo deste trabalho foi identificar quais as características que melhor explicam as diferenças do preço relativo das empresas listadas na bolsa de valores brasileira, e quais modelos estimados para explicar os múltiplos apresentam melhores resultados.

Nesse sentido, a presente pesquisa contribui para uma melhor compreensão da metodologia de avaliação de empresas por múltiplos, agregando maior grau de confiabilidade na utilização da técnica. A forma tradicional de estimação de valor de empresas por múltiplos utiliza uma média dos valores dos múltiplos das empresas consideradas comparáveis, sendo estas selecionadas com base em características semelhantes da empresa em avaliação. $\mathrm{Na}$ presente pesquisa ao aplicar a técnica de regressão linear múltipla é realizada uma forma de controle das diferenças das empresas, uma vez que a natureza das empresas envolve muitas especificidades e que sempre existirá algum grau de diferença entre as mesmas. Assim, com os modelos estimados é possível precificar os múltiplos de forma mais confiável, ao ponderar os impactos das características das empresas.

Em relação a quais características das empresas melhor explicam as diferenças do preço relativo das empresas listadas na bolsa de valores brasileira, foram identificadas, para os múltiplos de valor de mercado $\mathrm{P} / \mathrm{L}$ e $\mathrm{P} / \mathrm{PLC}$, as variáveis explicativas: crescimento; taxa de distribuição de dividendos; risco; e rentabilidade. Para os múltiplos de valor de empresa EV/EBITDA, EV/IC e EV/Receita, foram identificadas as variáveis explicativas: crescimento; taxa de reinvestimento; risco; rentabilidade; taxa de tributação; e margem operacional.

$\mathrm{Na}$ estimação dos modelos, nota-se que os coeficientes das variáveis explicativas utilizadas variam de ano para ano, na significância e na relação (positiva/negativa) com o respectivo múltiplo, apresentando, em alguns anos da análise, sinais contrários ao esperado pela teoria. Esta instabilidade entre as variáveis independentes com a dependente durante o tempo foi relatada por Heveadi (1999), Omran (2003), e Damodaran (2007). Também os testes para os pressupostos da regressão linear múltipla não eram satisfeitos para alguns modelos estimados nos anos da análise.

Em relação a quais modelos apresentam melhores resultados, identificou-se os modelos estimados para o múltiplo $\ln (E V /$ Receita $)$ superiores aos demais. Os modelos estimados para múltiplos de lucro são os segundos melhores - na comparação entre esses o múltiplo $\ln (\mathrm{P} / \mathrm{PL})$ apresentam maiores $\mathrm{R}^{2}$ enquanto que os modelos estimados para o múltiplo 
$\ln ($ EV/EBITDA) estimaram coeficientes para as variáveis explicativas de forma mais confiável.

Nota-se que, quando os modelos estimados para o múltiplo $\ln (\mathrm{P} / \mathrm{PL})$ são válidos (satisfazem as suposições da regressão linear múltipla), estes apresentam $\mathrm{R}^{2}$ superiores aos modelos estimados para o múltiplo $\ln ($ EV/EBITDA). Por outro lado, os modelos estimados para os múltiplos de patrimônio líquido contábil foram os que apresentaram piores resultados, sendo que os modelos estimados para o múltiplo $\ln (\mathrm{EV} / \mathrm{IC})$ não foram válidos para nenhum ano, enquanto os modelos estimados para o do múltiplo $\ln (\mathrm{P} / \mathrm{PLC})$ foram válidos para dois anos. Assim, entre os múltiplos de valor patrimonial contábil, pode-se considerar os modelos estimados para o múltiplo $\ln (\mathrm{P} / \mathrm{PLC})$ relativamente melhores.

Os resultados encontrados convergem com as pesquisas realizadas em contexto de países emergentes por Maniar (2014), Arruda (2015) e Gupta (2018), que sugerem como melhores modelos, os estimados para os múltiplos de receita e lucro.

Contudo, este estudo apresenta contornos: o período considerado para a construção dos modelos foi relativamente pequeno (quatro anos 2015 - 2018), dada a limitação da disponibilidade de algumas variáveis explicativas selecionadas. Além disso, para tratamento de outliers, realizou-se alguns testes, como exclusão de algumas empresas com dados discrepantes, porém, como os outputs dos modelos estimados não apresentavam melhora relevante, optou-se por manter a variabilidade das variáveis, mantendo as observações discrepantes.

Portanto, um estudo mais aprofundado dos outliers e de seu tratamento pode trazer melhora para os modelos estimados. Ressalta-se que não foi utilizada transformação das formas funcionais para as variáveis independentes. Um estudo mais aprofundado dos outliers e das formas funcionais para as variáveis independentes poderia corrigir os problemas dos resíduos dos modelos estimados que não respeitaram as suposições da regressão linear múltipla.

Assim, sugere-se, para futuros trabalhos: expandir os anos da análise; fazer um estudo mais aprofundado de observações discrepantes (outliers) e de como lidar com estas; e testar outras formas funcionais (logarítmica, quadrática, inversa) para as variáveis independentes, o que pode corrigir os problemas dos resíduos dos modelos estimados que não respeitaram as suposições da regressão linear múltipla. 


\section{REFERÊNCIAS}

Alford, A. W. (1992). The effect of the set of comparable firms on the accuracy of the priceearnings valuation method. Journal of Accounting Research, Vol. 30, 94-108.

Arruda Filho, R. P. D. (2015). Múltiplos e seus determinantes: um estudo para o mercado de ações brasileiro (Doctoral dissertation).

Assaf, A. (2017). Valuation Métricas de Valor \& Avaliação de Empresas (2a ed.) São Paulo: Atlas.

Bhojraj, S., \& Lee, C. (2002). Who is my peer? A valuation-based approach to the selection of comparable firms. Journal of Accounting Research, 40(2), 407-439.

Cavallari, A. L. G. (2006). Um estudo da relação entre macrodirecionadores de valor e o preço da ação no mercado de capitais brasileiro (Doctoral dissertation, Universidade de São Paulo).

Costa, L. G. T. A., Costa, L. R. T. A., \& ALVIM, M. A. (2011). Valuation: manual de avaliação e reestruturação econômica de empresas. São Paulo: Atlas.

Cerbasi, G. P. (2003). Metodologias para determinação do valor das empresas: uma aplicação no setor de geração de energia hidrelétrica (Doctoral dissertation, Universidade de São Paulo).

Cheng, C., \& McNamara, R. (2000). The Valuation Accuracy of the Price-Earnings and PriceBook Benchmark Valuation Methods. Review of Quantitative Finance and Accounting Vol. 15, 349-370.

Cohen, J. B., Black, F., \& Scholes, M. (1972). The valuation of option contracts and a test of market efficiency. The journal of finance, 27(2), 399-417.

Copeland, T. E., \& Antikarov, V. (2002). Opções reais: um novo paradigma para reinventar a avaliação de investimentos. Campus.

Couto, J., Brito, P., \& Cerqueira, A. (2016). The Method of Market Multiples on the Valuation of Companies: A Multivariate Approach.

Damodaran, A. (2006). Relative valuation. Foundations and Trends in Finance, 1(8), 753-753.

Damodaram, A. (2007). Avaliação de Empresas, 2 ed. São Paulo, Pearson Prentice Hall.

Damodaran, A. (2010). Avaliação de Investimentos, 2 ed. Rio de Janeiro, Qualitymark Editora Ltda.

Damodaran, A. (2012). Investment valuation: Tools and techniques for determining the value of any asset (Vol. 666). John Wiley \& Sons.

Dittmann, I., \& Weiner, C. (2005). Selecting comparables for the valuation of European firms. 
De Aguiar, A. B., Pimentel, R. C., Rezende, A. J., \& Corrar, L. J. (2011). Análise dos direcionadores de valor em empresas brasileiras. RAM. Revista de Administração Mackenzie, 12(2), 90-112.

Fávero, L. P., \& Belfiore, P. (2017). Manual de análise de dados: estatística e modelagem multivariada com Excel®, SPSS® e Stata®. Elsevier Brasil.

Fernandez, P. (2001). Valuation using multiples. How do analysts reach their conclusions. IESE Business School, 1-13.

Gewehr, D. H. (2007). Avaliação relativa de ações baseada em múltiplos de mercado projetados e passados: um estudo comparativo de performance na Bovespa. (Mestrado em administração-finanças) - UFRGS, Porto Alegre.

Goedhart, M., Koller, T., \& Wessels, D. (2015). Valuation: Measuring and managing the value of companies. JohnWiley \& Sons.

Goh, C. F., Rasli, A., Dziekonski, K., \& Khan, S. U. R. (2015). Market-based Valuation Multiples: Evidence from Agribusiness Sector. Pertanika Journal of Social Sciences \& Humanities, 23.

Gupta, V. (2018). Predicting accuracy of valuation multiples using value drivers: evidence from Indian listed firms. Theoretical Economics Letters, 8(5), 1-18.

Hashemzadeh, N., Davis, E., Wade, E., Prather, L. J., Topuz\&, J. C., \& Uzmanoglu, C. (2008). The Usefulness of Price to Earnings Ratio $(\mathrm{P} / \mathrm{E})$ in Predicting Share Price Behavior: A Review of Recent Evidence. Compiled and Edited by: Vivek Bhargava, Alcorn State University Co-editor: Steve Wells, Western Kentucky University Editorial Assistant, 134.

Heveadi, A. N. (1999). Price earnings ratio (PER) model consistency: evidence from Jakarta Stock Exchange. Gadjah Mada International Journal of Business, 1(2), 85-97.

Junior, R., Saraiva, T., \& Ikeda, R. H. (2004). Mercados eficientes e arbitragem: um estudo sob o enfoque das finanças comportamentais. Revista Contabilidade \& Finanças, 15(34), 97-107.

Kim, M., \& Ritter, J. R. (1999). Valuing IPOs. Journal of Financial Economics, Vol. 53, No. 3, 409-437.

Koller, Tim, Valuation: measuring and managigng the value of companies, Hoboken, N. J. John Wiley \& Sons, Inc. 2005

Lie, E., \& Lie, H. J. (2002). Multiples used to estimate corporate value. Financial Analysts Journal, 58(2), 44-54.

Liu, J., Nissim, D., \& Thomas, J. (2002). Equity valuation using multiples. Journal of Accounting Research, 40(1), 135-172.

Maniar, B. (2014). Factors Influencing Pricing Multiples in India. IUP Journal of Applied Finance, 20(1). 
Markowitz, H. (1952). Portfolio selection. The journal of finance, 7(1), 77-91.

Omran, M. F. (2003). Equity valuation using multiples in the emerging market of the United Arab Emirates. Review of Middle East Economics and Finance, 1(3), 267-283.

Orlovas, A. D., Serra, R. G., \& Carrete, L. S. (2018). A Utilização do múltiplo EV/EBITDA na precificação de IPO's no mercado brasileiro. Revista Contemporânea de Contabilidade, 15(37), 34-51.

Osmundsen, P., Asche, F., Misund, B., \& Mohn, K. (2006). Valuation of international oil companies. The Energy Journal, 49-64.

Pasin, R. M. (2004). Avaliação relativa de empresas por meio da regressão de direcionadores de valor (Doctoral dissertation, Universidade de São Paulo).

Pearl, J., \& Rosenbaum, J. (2013). Investment banking: valuation, leveraged buyouts, and mergers and acquisitions. John Wiley \& Sons.

Serra, R. G. \& Fávero L. P. L. (2017): Multiples' Valuation: The Selection of Cross-Border Comparable Firms, Emerging Markets Finance and Trade.

Sharpe, W. F. (1964). Capital asset prices: A theory of market equilibrium under conditions of risk. The journal of finance, 19(3), 425-442.

Titman, S., \& Martin, J. D. (2009). Avaliação de projetos e investimentos. Bookman Editora.

Whitbeck, V. S., \& Kisor Jr, M. (1963). A new tool in investment decision-making. Financial Analysts Journal, 19(3), 55-62.

Wilcox, J. W. (1984). The P/B-roe valuation model. Financial Analysts Journal, 40(1), 58-66. 


\section{ANEXOS}

\section{Anexo 1 - Lista de Equações}

$$
\begin{aligned}
& \beta=\frac{\operatorname{cov}(\mathrm{r}, \mathrm{RT})}{\operatorname{var}(\mathrm{RT})}, \\
& \mathrm{Ke}=r_{\mathrm{f}}+\beta\left(\mathrm{Rm}-r_{\mathrm{f}}\right), \\
& \mathrm{WACC}=\mathrm{K}_{\mathrm{e}} \times\left[\frac{\mathrm{E}}{\mathrm{E}+\mathrm{D}}\right]+\mathrm{K}_{\mathrm{d}} \times(1-\mathrm{T}) \mathrm{x}\left[\frac{\mathrm{E}}{\mathrm{E}+\mathrm{D}}\right], \\
& \mathrm{V}=\sum_{t=1}^{n} \frac{F C D F_{t}}{(1+w a c c)^{\mathrm{I}}}+\frac{F C D F_{\mathrm{t}+1}}{(w a c c-g)(1+w a c c) t+1}, \\
& \frac{P_{a}}{L_{a}}=\frac{P_{\varepsilon}}{L_{\varepsilon}}, \\
& P_{a}=\frac{P_{G}}{L_{\varepsilon}} \times L_{a}
\end{aligned}
$$

Valor de mercado agregado $=$ preço da ação $x$ quantidade de ações

Valor empresarial $=$ Valor de mercado agregado + endividamento oneroso caixa e equivalente de caixa

$$
\begin{aligned}
& \mathrm{P}=\frac{\mathrm{D}}{\text { ewacc }-\mathrm{g}} \text {, } \\
& \frac{\mathrm{P}}{\mathrm{LPA}}=\mathrm{PL}=\frac{\text { pox }(1+\mathrm{g})}{\text { ewace }-\mathrm{g}} . \\
& g=\operatorname{roe} x(1-p o), \\
& \text { po }=1-\frac{\mathrm{g}}{\mathrm{ROE}}, \\
& \frac{P}{\mathrm{LPA}}=\frac{1-\frac{\mathrm{g}}{\mathrm{ROE}} \mathrm{x}(1+\mathrm{g})}{\text { ewace }-\mathrm{g}} . \\
& \mathrm{EV}=\frac{\mathrm{FCDF}}{\text { wace }-\mathrm{g}}, \\
& \mathrm{EV}=\frac{E B I T D A_{1}(1-t)-D A(1-t)-\text { reinvestimento }}{\text { wace }-g},
\end{aligned}
$$




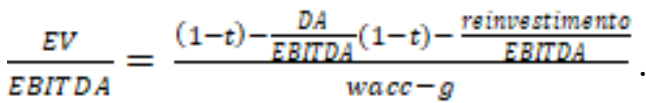

$\mathrm{D}=L_{1} \mathrm{x} p o$,

$\mathrm{P}=\frac{\mathrm{L}_{1} \mathrm{xpo}}{\text { ewace }-\mathrm{g}}$,

roe $=\frac{\mathrm{LL}}{\text { PLC }}$,

$P=\frac{\text { PLC } \mathrm{x} \text { roex } p o}{\text { ewace }-g}$,

$\frac{P}{P L C}=\frac{\text { roe } x \text { po }}{\text { ewace }-\mathrm{g}}$.

po $=\frac{-\mathrm{g}}{\text { roe }}+1$.

$\frac{P}{\mathrm{PLC}}=\frac{\text { roe }-\mathrm{g}}{\text { ewacc }-\mathrm{g}}$

$\mathrm{FCDF}=\mathrm{EBIT}_{1}(1-\mathrm{t}) \mathrm{x}(1-\mathrm{rir})$,

rir $=\frac{\text { reinvestimento }}{\text { NOPAT }}$,

$\mathrm{EV}=\frac{\text { EBIT }(1-\mathrm{t}) \mathrm{x}(1-\mathrm{rir})}{\text { wace }-\mathrm{g}}$.

$\frac{\mathrm{EV}}{\mathrm{CI}}=\frac{\text { roie }(1-\mathrm{rir})}{\text { wace }-\mathrm{g}}$,

rir $=\frac{\mathrm{g}}{\text { roie }}$,

$\frac{\mathrm{EV}}{\mathrm{CI}}=\frac{\text { roic }-\mathrm{g}}{\text { wacc }-\mathrm{g}}$

$\frac{\text { EV }}{\text { Receita }}=\frac{\frac{\text { EBIT(1-D) }}{\text { Receita }} \mathrm{x}(1-\text { rir })}{\text { wacc-g }}$,

$\mathrm{Y} i=b_{0}+b_{1}\left(X_{1 i}\right)+b_{2}\left(X_{2 i}\right)+\ldots+b_{k}\left(X_{k i \bar{i}}\right)+u_{i}$ 


\section{Anexo 2 - Output dos modelos}

\section{Output modelo P/L 2015:}

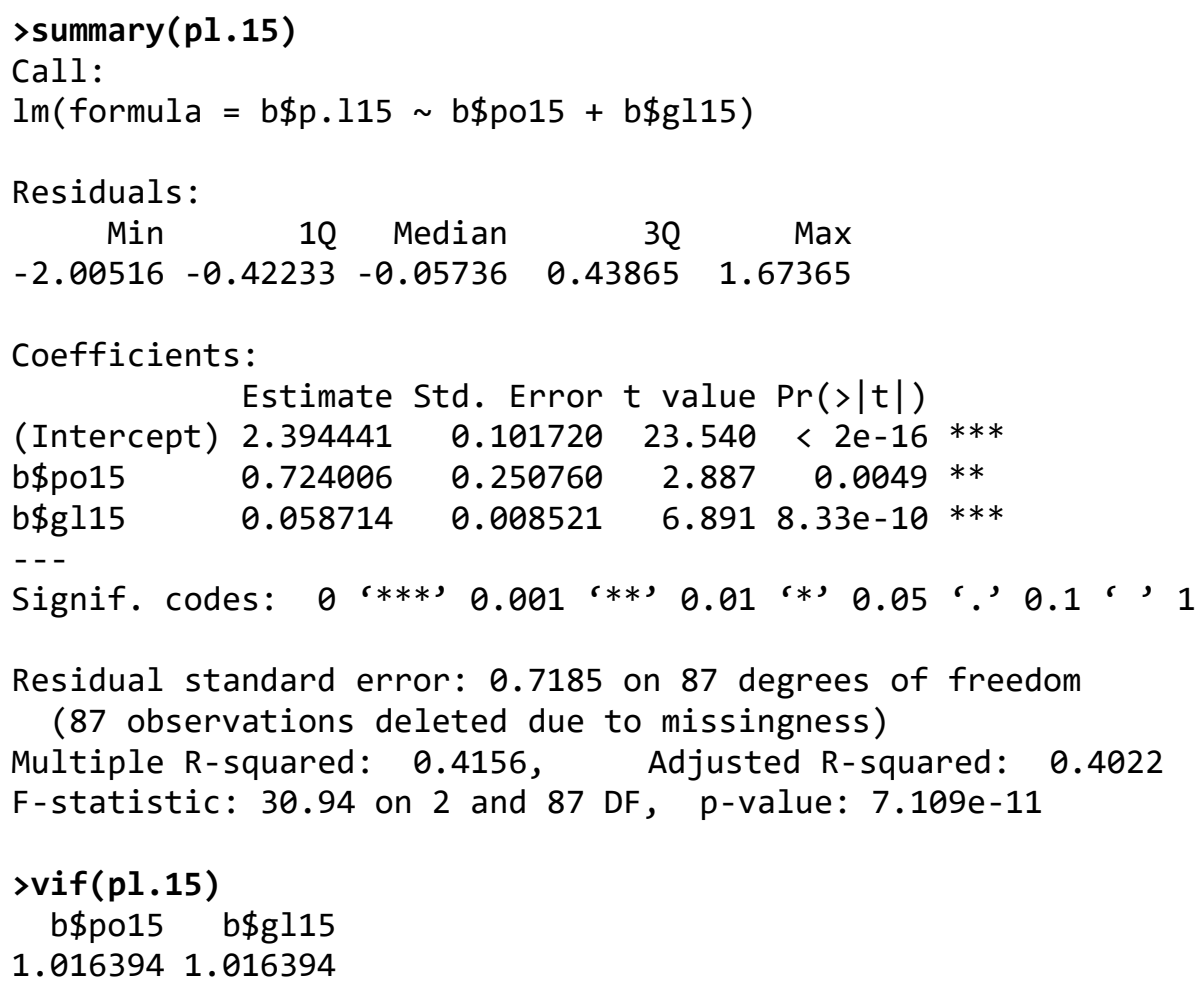

\section{Output modelo P/L 2016:}

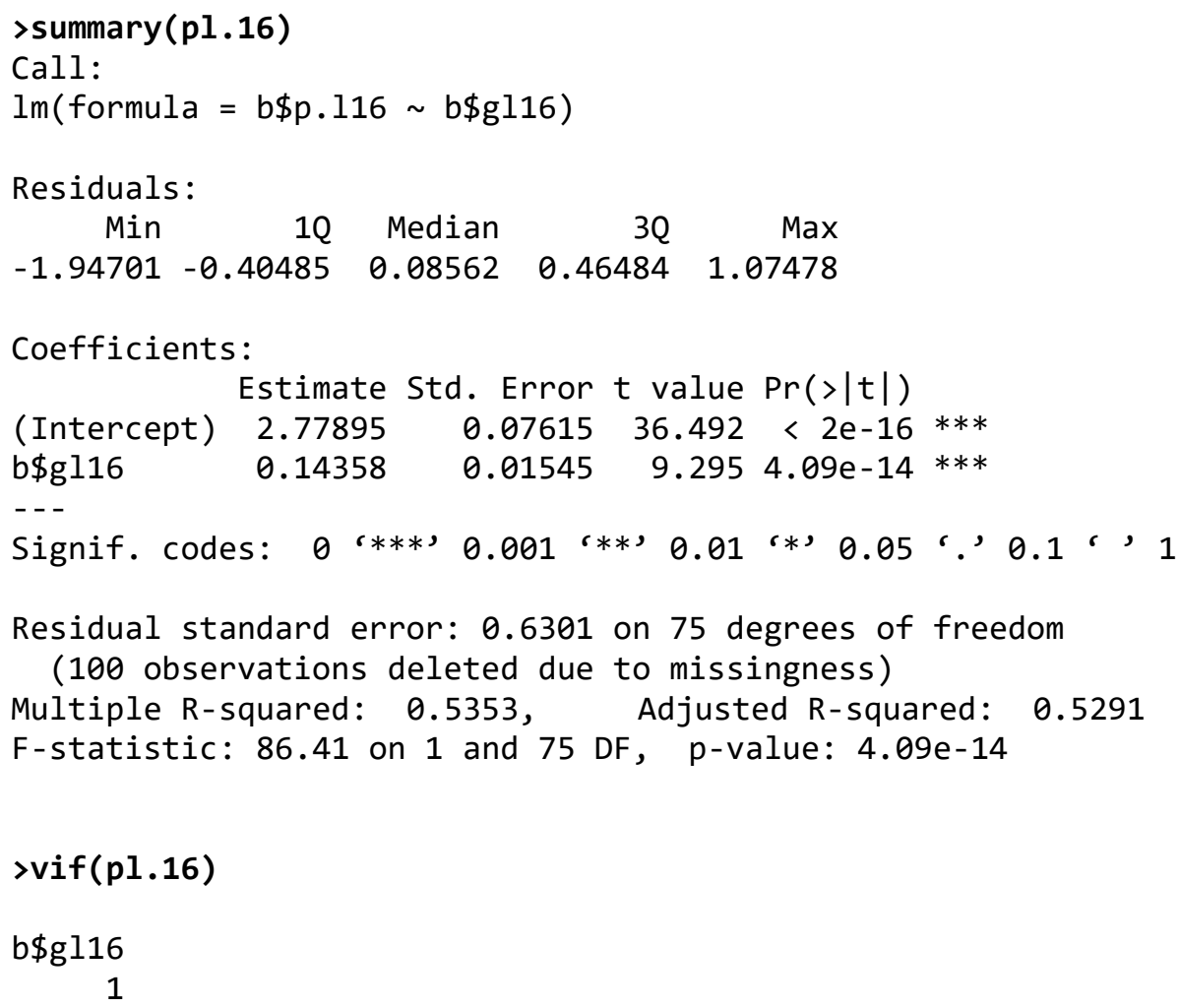


Output modelo P/L 2017:

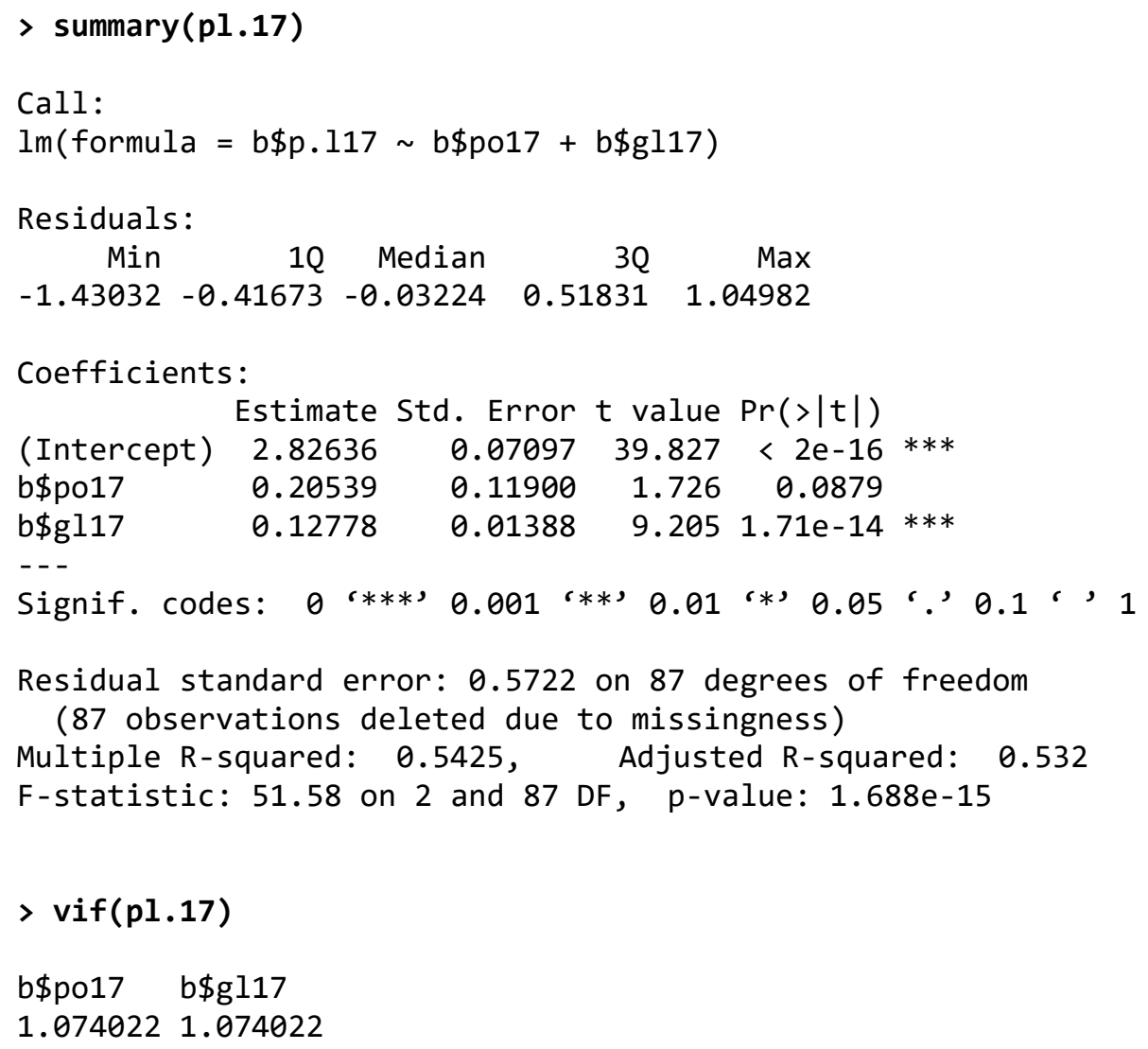

\section{Output modelo P/L 2018:}

$>\operatorname{summary}(\mathrm{pl} .18)$

Call:

$\operatorname{lm}($ formula $=b \$ p .118 \sim b \$$ ewacc18 $+b \$ g 118)$

Residuals:

Min 1Q Median 3Q Max

$\begin{array}{lllll}-1.4364 & -0.5578 & -0.1454 & 0.4894 & 1.8173\end{array}$

Coefficients :

$$
\text { Estimate Std. Error } t \text { value } \operatorname{Pr}(>|t|)
$$

(Intercept) $3.2195640 .228079 \quad 14.12<2 \mathrm{e}-16 * * *$

$\begin{array}{lllll}\text { b\$ewacc18 } & -3.803192 & 2.290882 & -1.66 & 0.0996 .\end{array}$

$\begin{array}{llll}\mathrm{b} \$ \mathrm{gl18} & 0.069114 & 0.006633 & 10.42<2 \mathrm{e}-16 * * *\end{array}$

- -

Signif. codes: 0 '***' 0.001 '**, 0.01 '*' 0.05 '.' 0.1 ' 1

Residual standard error: 0.7478 on 116 degrees of freedom (58 observations deleted due to missingness)

Multiple R-squared: 0.49 , Adjusted R-squared: 0.4812

F-statistic: 55.73 on 2 and 116 DF, p-value: < 2.2e-16

$>\operatorname{vif}(\mathrm{pl} .18)$ 
b\$ewacc18 b\$gl18

$1.000013 \quad 1.000013$

\section{Output modelo P/PLC 2015:}

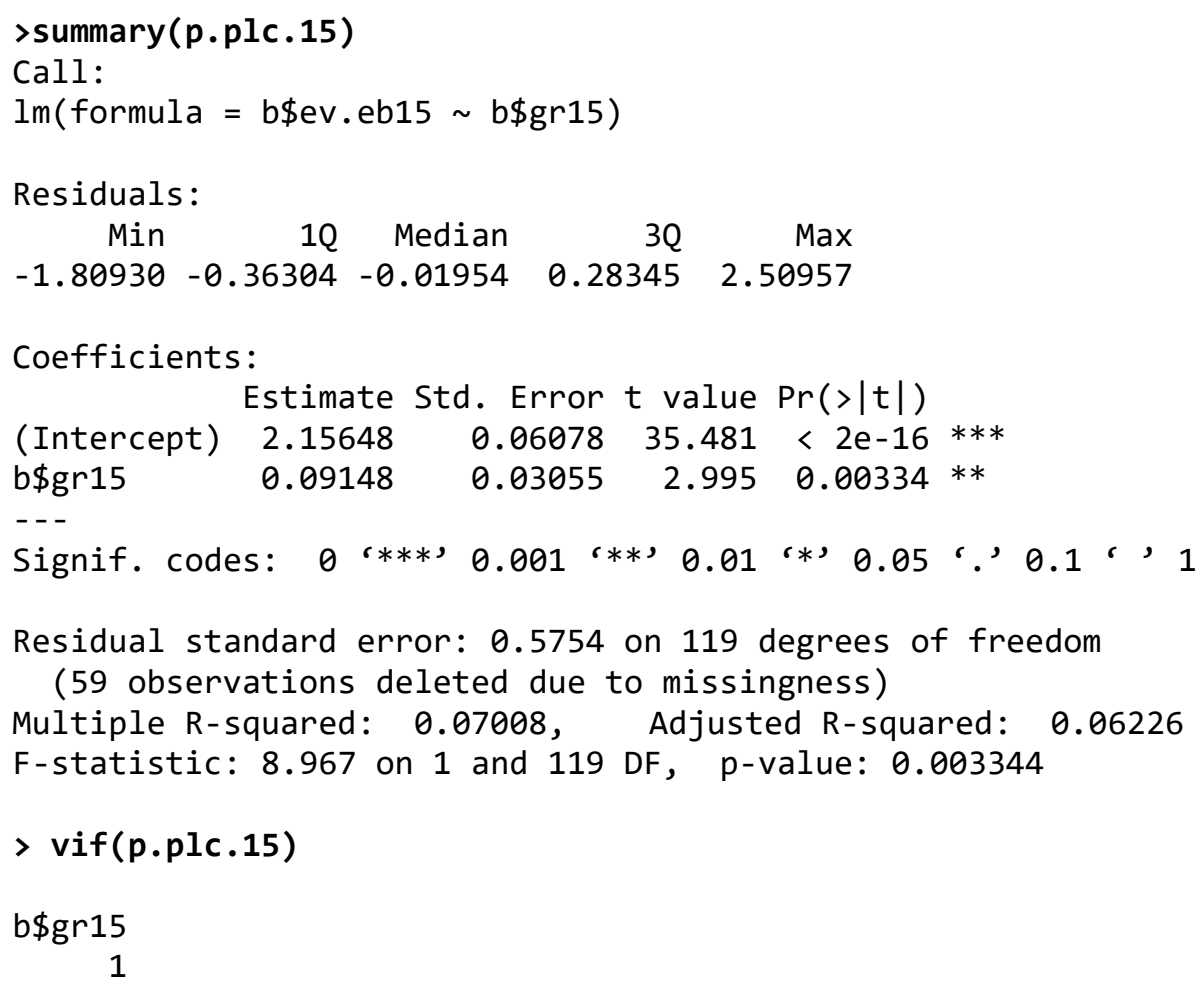

\section{Output modelo P/PLC 2016:}

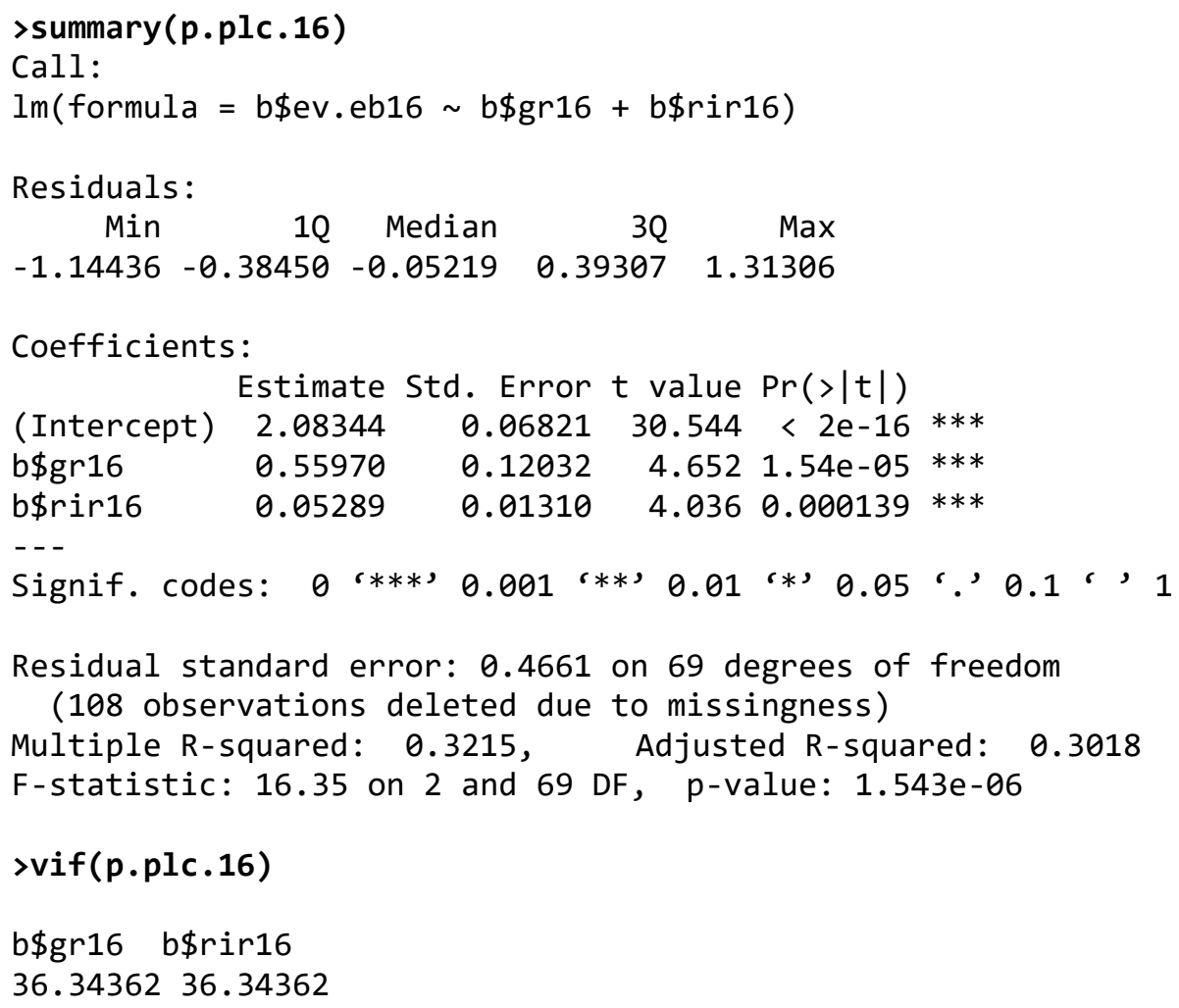




\section{Output modelo P/PLC 2017:}

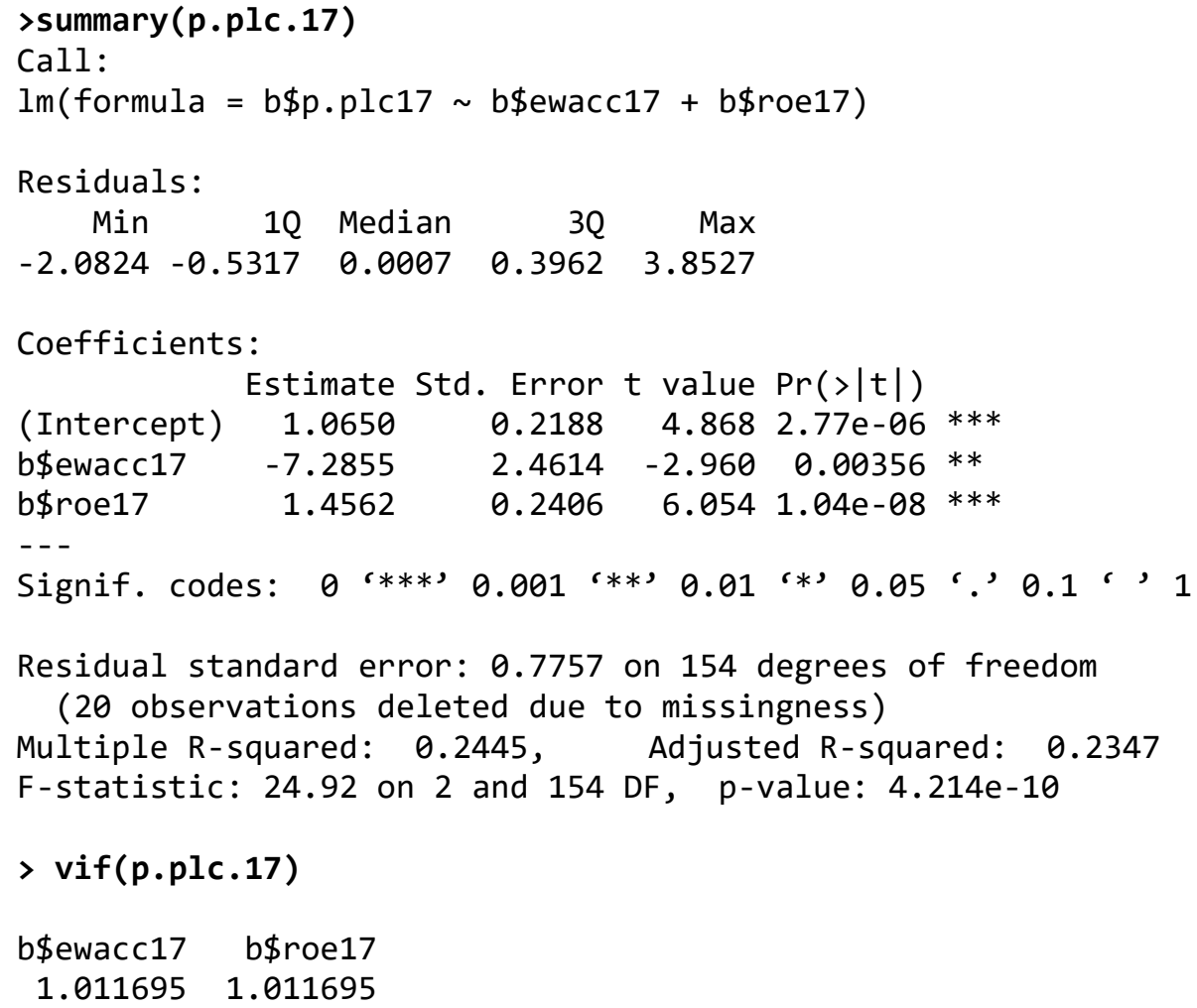

\section{Output modelo P/PLC 2018:}

$>\operatorname{summary}(p \cdot p l c .18)$

Call:

$\operatorname{lm}($ formula $=b \$ p \cdot p l c 18 \sim b \$$ ewacc18 $+b \$$ roe18 $)$

Residuals :

Min $1 Q$ Median $3 Q \quad$ Max

$\begin{array}{lllll}-2.17915 & -0.51928 & -0.06704 & 0.46485 & 2.29101\end{array}$

Coefficients :

\begin{tabular}{|c|c|c|c|c|c|}
\hline & Estimate & Std. Error & t value & $\operatorname{Pr}(>|t|)$ & \\
\hline (Intercept) & 1.3560 & 0.1985 & 6.831 & $1.69 \mathrm{e}-10$ & $* * *$ \\
\hline b\$ewacc18 & -7.3668 & 1.9885 & -3.705 & 0.000292 & $* * *$ \\
\hline b\$roe18 & 0.3132 & 0.1529 & 2.049 & 0.042134 & $*$ \\
\hline
\end{tabular}

Residual standard error: 0.7736 on 159 degrees of freedom (15 observations deleted due to missingness)

Multiple R-squared: $0.1097, \quad$ Adjusted R-squared: 0.09854 F-statistic: 9.8 on 2 and 159 DF, p-value: $9.695 \mathrm{e}-05$ 
b\$ewacc18 b\$roe18

$1.009721 \quad 1.009721$

\section{Output modelo EV/Ebitda 2015:}

$>\operatorname{summary}(\mathrm{ev} \cdot \mathrm{eb} 15)$

Call:

$\operatorname{lm}($ formula $=b \$ e v . e b 15 \sim b \$ g r 15)$

Residuals:

Min $1 Q$ Median $3 Q \quad$ Max

$\begin{array}{lllll}-1.80930 & -0.36304 & -0.01954 & 0.28345 & 2.50957\end{array}$

Coefficients:

Estimate std. Error $t$ value $\operatorname{Pr}(>|t|)$

(Intercept) $2.15648 \quad 0.0607835 .481<2 \mathrm{e}-16$

$\begin{array}{lllll}\text { b\$gr15 } & 0.09148 & 0.03055 & 2.995 & 0.00334\end{array}$

(Intercept) $* * *$

b\$gr15

- - -

Signif. codes:

0 '***, 0.001 '**, 0.01 '*, 0.05 ' 0.1 ' 1

Residual standard error: 0.5754 on 119 degrees of freedom (59 observations deleted due to missingness)

Multiple R-squared: 0.07008, Adjusted R-squared: 0.06226

F-statistic: 8.967 on 1 and 119 DF, p-value: 0.003344

$>\operatorname{vif}(e v \cdot e b 15)$

b\$gr15

1

\section{Output modelo EV/Ebitda 2016:}

> summary (ev.eb16)

Call:

$\operatorname{lm}($ formula $=b \$$ ev.eb16 $\sim$ b\$gr16 $+b \$ r i r 16)$

Residuals :

Min $1 Q$ Median 3Q Max

$\begin{array}{lllll}-1.14436 & -0.38450 & -0.05219 & 0.39307 & 1.31306\end{array}$

Coefficients:

Estimate Std. Error $t$ value $\operatorname{Pr}(>|t|)$

(Intercept) $2.08344 \quad 0.06821 \quad 30.544<2 \mathrm{e}-16$

$\begin{array}{lllll}\text { b\$gr16 } & 0.55970 & 0.12032 & 4.652 & 1.54 \mathrm{e}-05\end{array}$

$\begin{array}{lllll}\text { b\$rir16 } & 0.05289 & 0.01310 & 4.036 & 0.000139\end{array}$

(Intercept)

b\$gr16

b\$rir16

-- -

Signif. codes: 


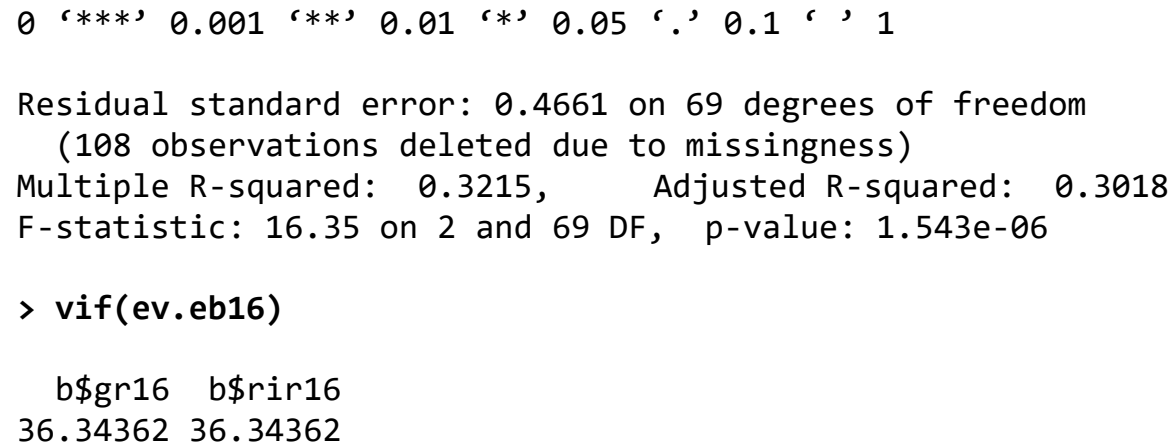

\section{Output modelo EV/Ebitda 2017:}

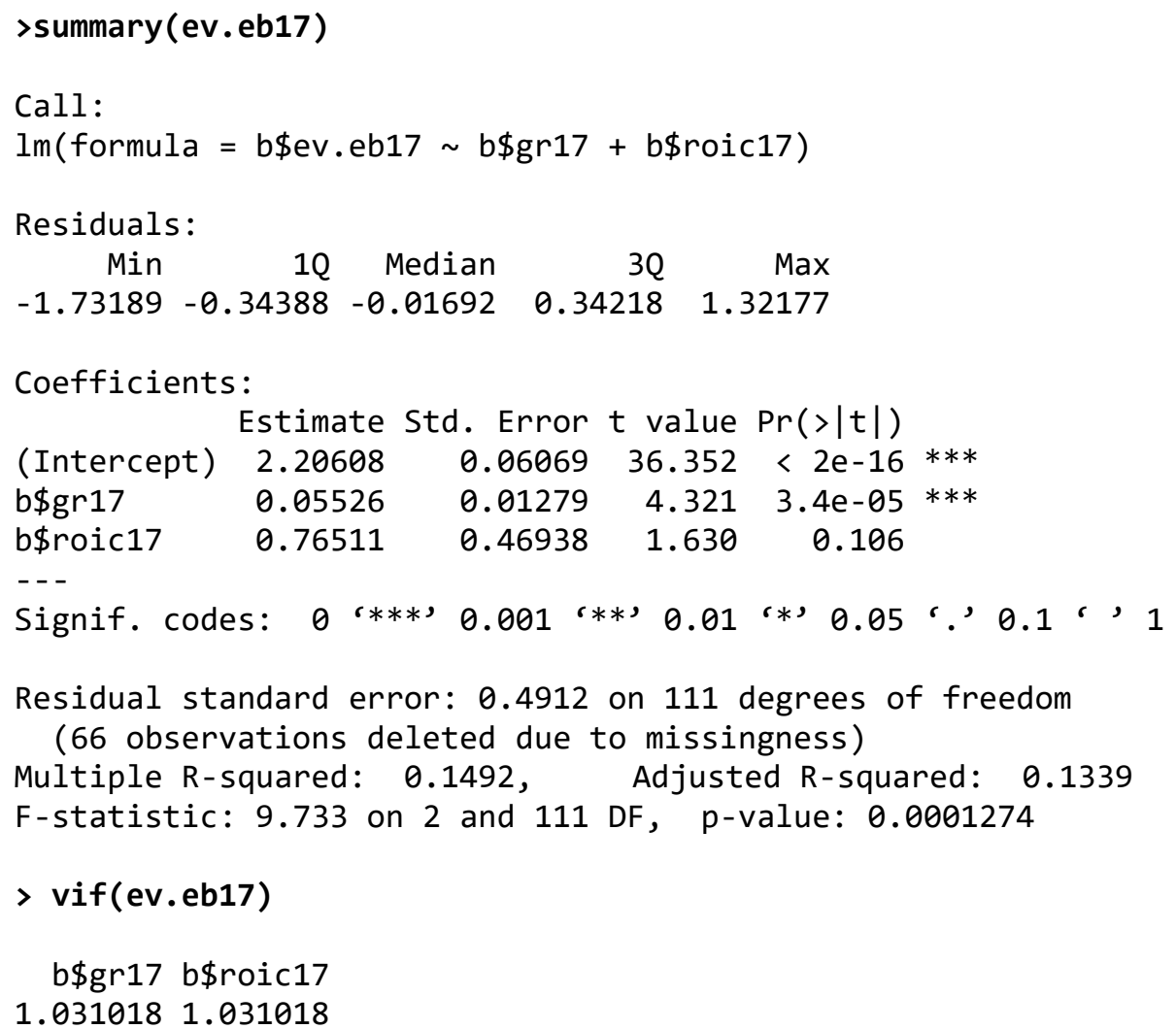

\section{Output modelo EV/Ebitda 2018:}

>summary (ev.eb18)

Call:

$\operatorname{lm}($ formula $=$ b\$ev.eb18 b\$gr18)

Residuals:

Min $1 Q$ Median 3Q Max

$\begin{array}{lllll}-1.30230 & -0.32621 & -0.01984 & 0.37982 & 1.23577\end{array}$

Coefficients : Estimate Std. Error $t$ value $\operatorname{Pr}(>|t|)$

(Intercept) $2.27661 \quad 0.0468348 .614<2 \mathrm{e}-16 * * *$

$\begin{array}{lllll}\text { b\$gr18 } & 0.06161 & 0.01544 & 3.991 & 0.000115 * * *\end{array}$


Signif. codes: 0 '***, 0.001 '**, 0.01 '*' 0.05 '.' 0.1 ', 1

Residual standard error: 0.4866 on 118 degrees of freedom

(60 observations deleted due to missingness)

Multiple R-squared: $0.1189, \quad$ Adjusted R-squared: 0.1115

F-statistic: 15.93 on 1 and 118 DF, p-value: 0.0001145

$>\operatorname{vif}(\mathrm{ev} \cdot \mathrm{eb} 18)$

b\$gr18

1

Output modelo EV/IC 2015:

summary(ev.ic15)

Call:

$\operatorname{lm}($ formula $=b \$$ ev $\cdot r e c 15 \sim b \$ g r 15+b \$$ etax15 $+b \$$ mo15 $)$

Residuals:

$\begin{array}{rrrrr}\text { Min } & 1 Q & \text { Median } & 3 Q & \text { Max } \\ -2.13828 & -0.39768 & 0.04047 & 0.42565 & 1.56845\end{array}$

Coefficients:

Estimate Std. Error $t$ value $\operatorname{Pr}(>|t|)$

$\begin{array}{lllll}\text { (Intercept) } 0.76396 & 0.08033 & 9.510 & 2.22 \mathrm{e}-15\end{array}$

$\begin{array}{lllll}\mathrm{b} \$ g r 15 & 0.31349 & 0.06488 & 4.832 & 5.31 \mathrm{e}-06\end{array}$

b\$etax15 $-1.26960 \quad 0.13402 \quad-9.473 \quad 2.67 e-15$

$\begin{array}{lllll}b \$ m o 15 & 4.09898 & 0.43711 & 9.378 & 4.24 \mathrm{e}-15\end{array}$

Signif. codes: 0 '***, 0.001 '**, 0.01 '*, 0.05 ', 0.1 ', 1

Residual standard error: 0.652 on 93 degrees of freedom

(83 observations deleted due to missingness)

Multiple R-squared: $0.5077, \quad$ Adjusted R-squared: 0.4918

F-statistic: 31.96 on 3 and 93 DF, p-value: $2.738 \mathrm{e}-14$

$>\operatorname{vif}(\mathrm{ev} . \mathrm{ic15})$

b\$gr15 b\$etax15 b\$mo15

$1.12744397 .10420 \quad 397.55724$

\section{Output modelo EV/IC 2016:}

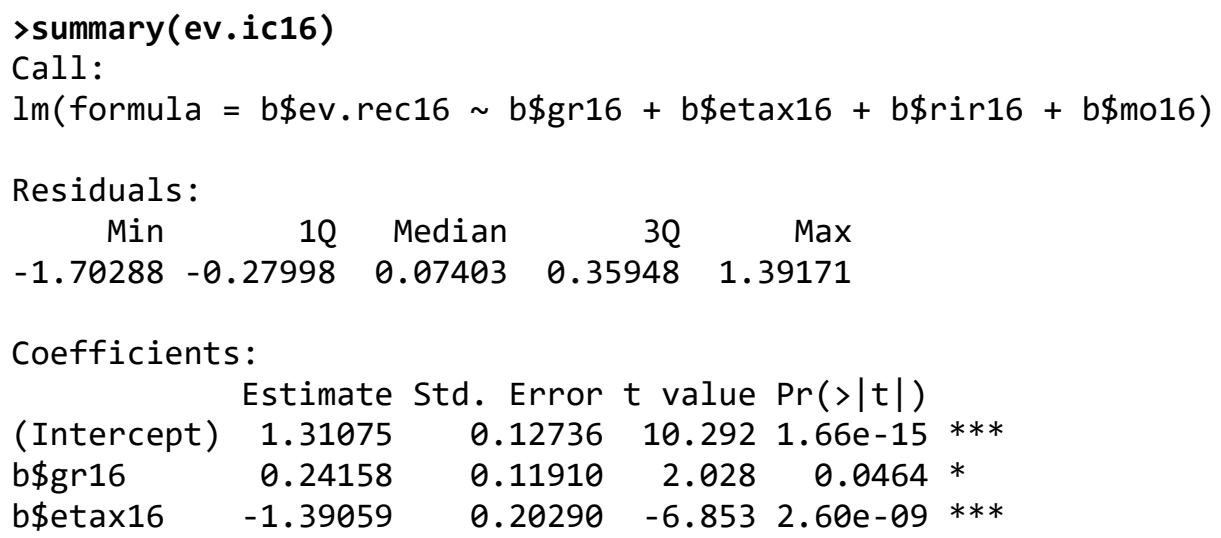




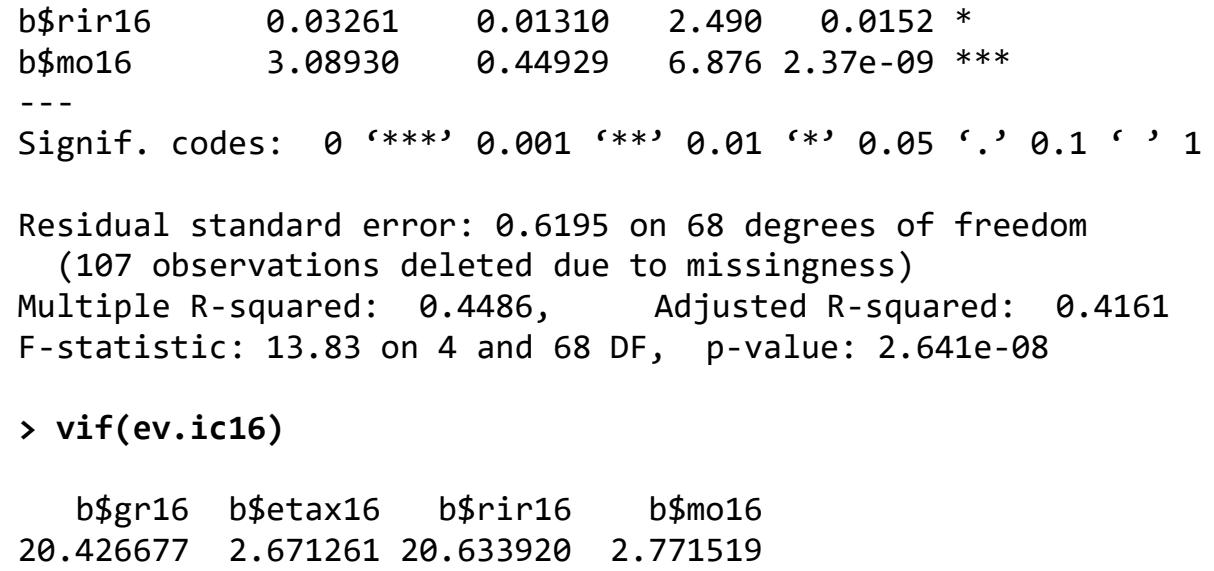

\section{Output modelo EV/IC 2017:}

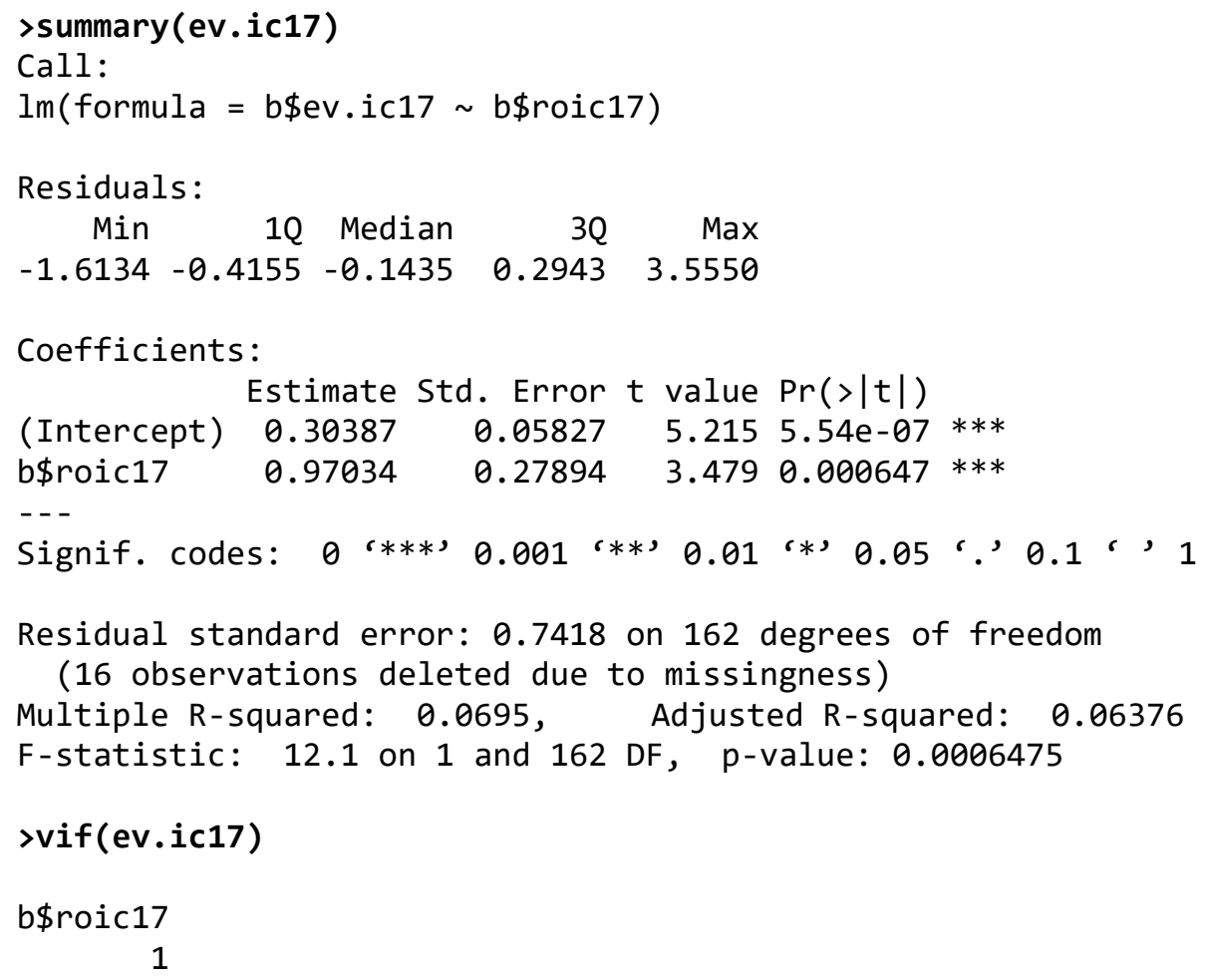

\section{Output modelo EV/IC 2018:}

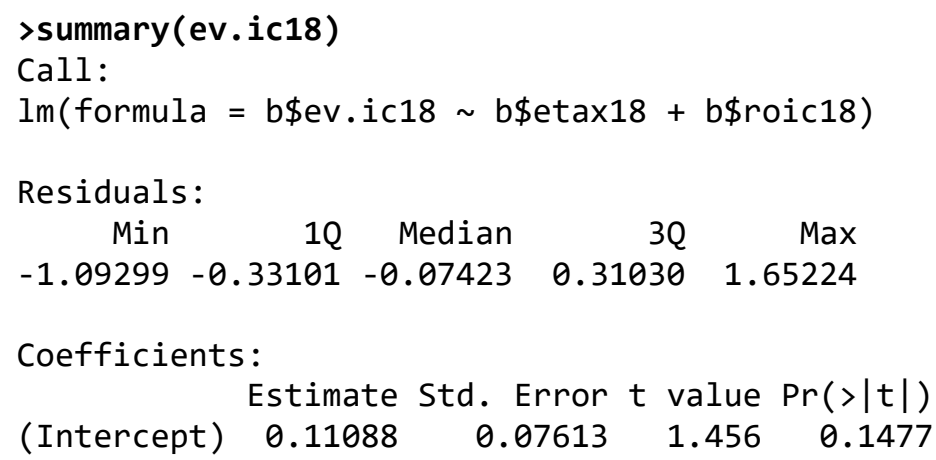




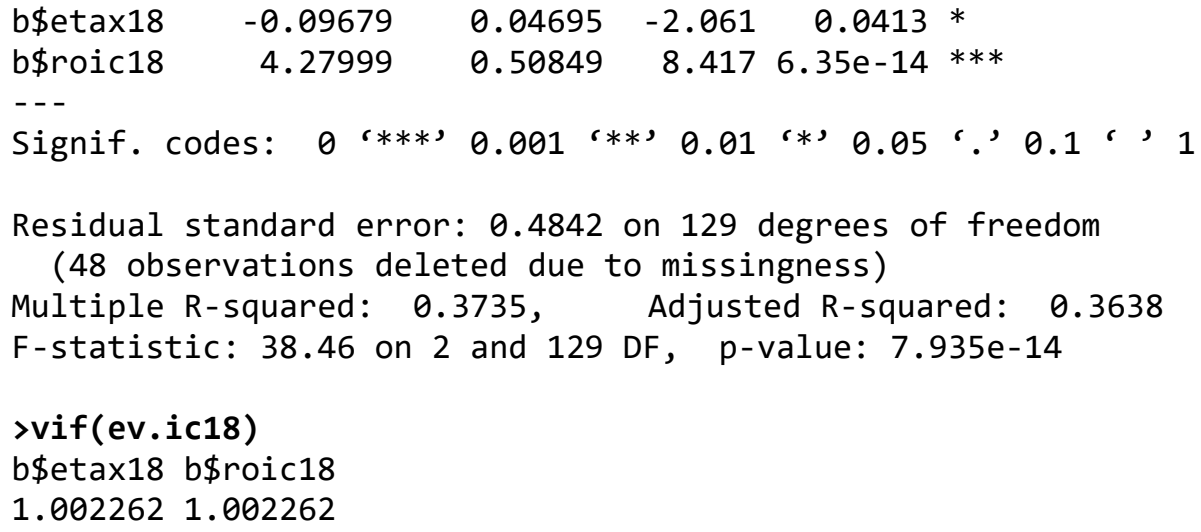

\section{Output modelo EV/Receita 2015:}

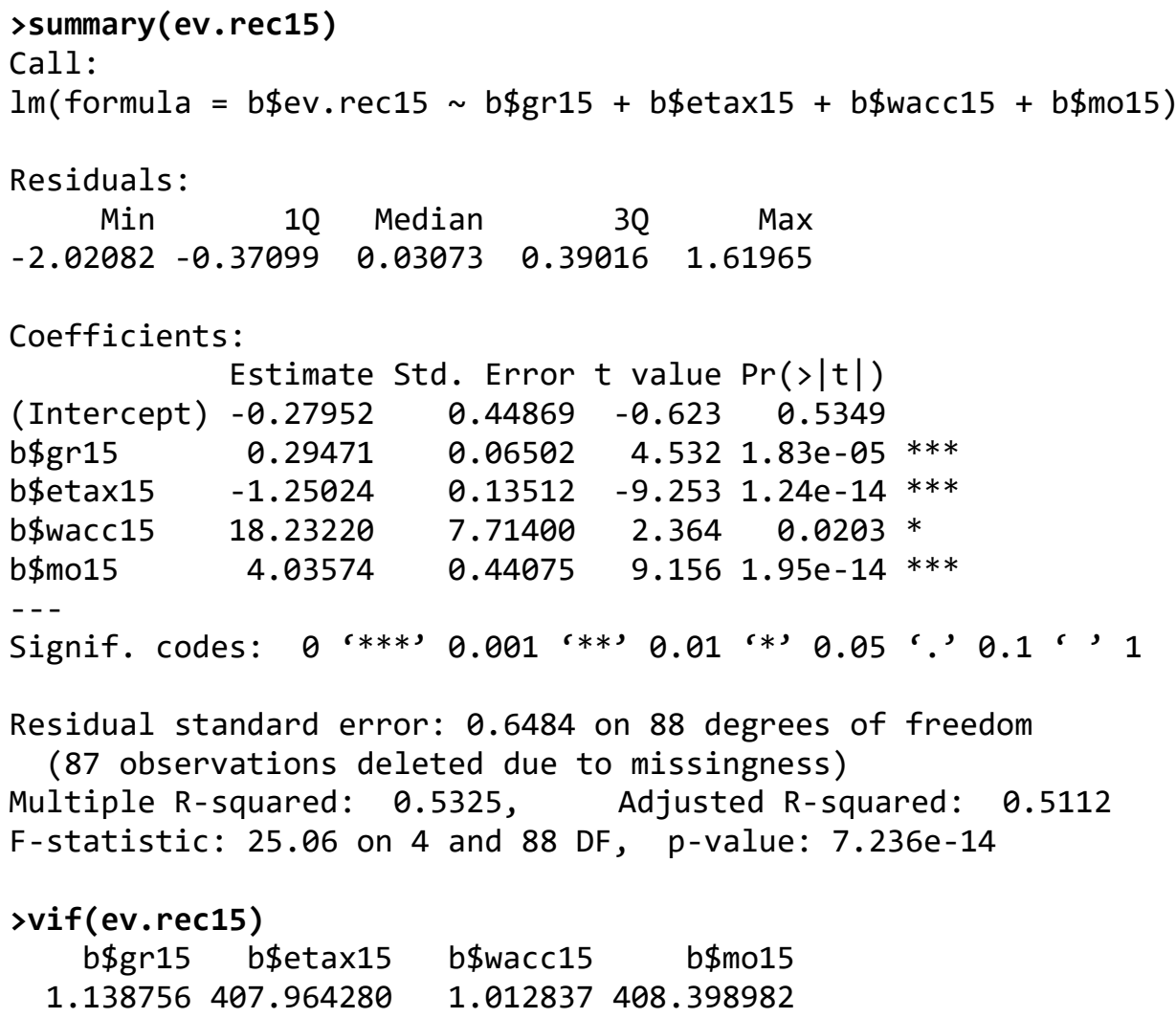

\section{Output modelo EV/Receita 2016:}

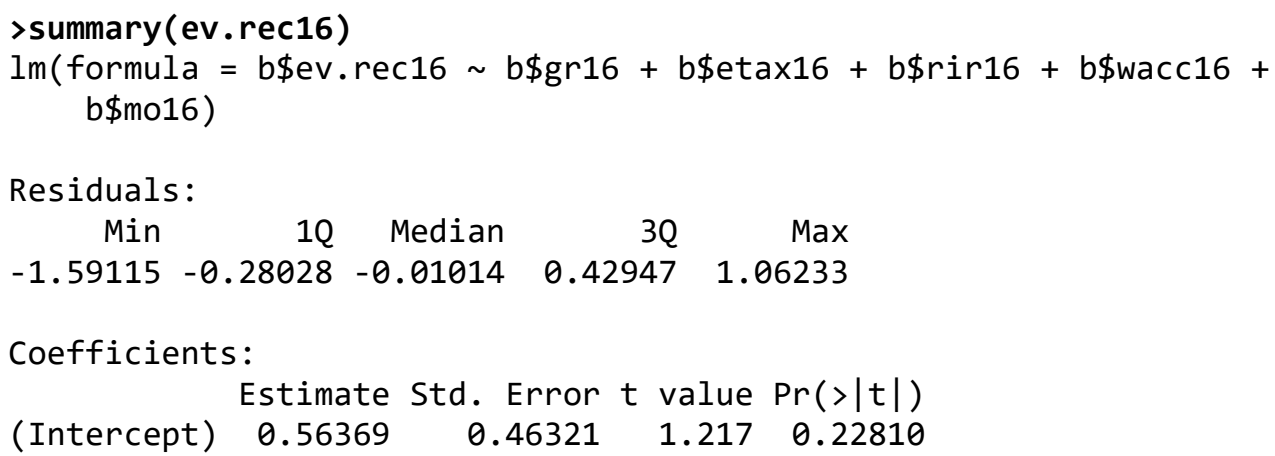




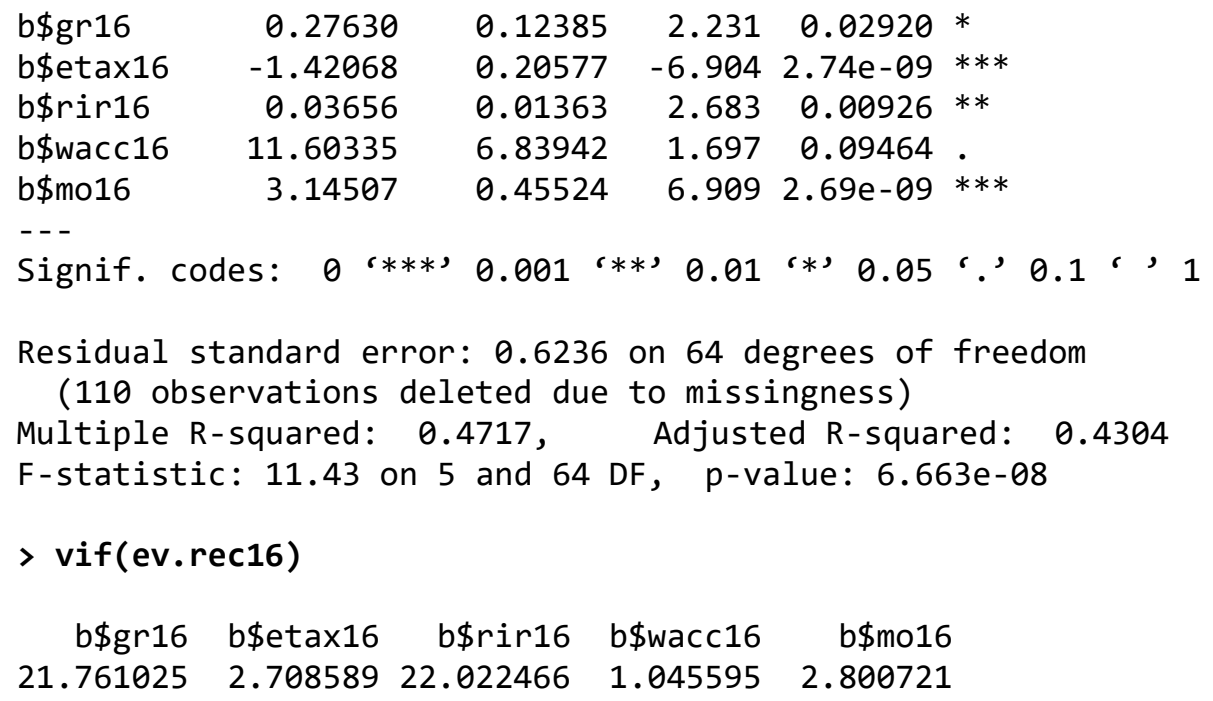

Output modelo EV/Receita 2017:

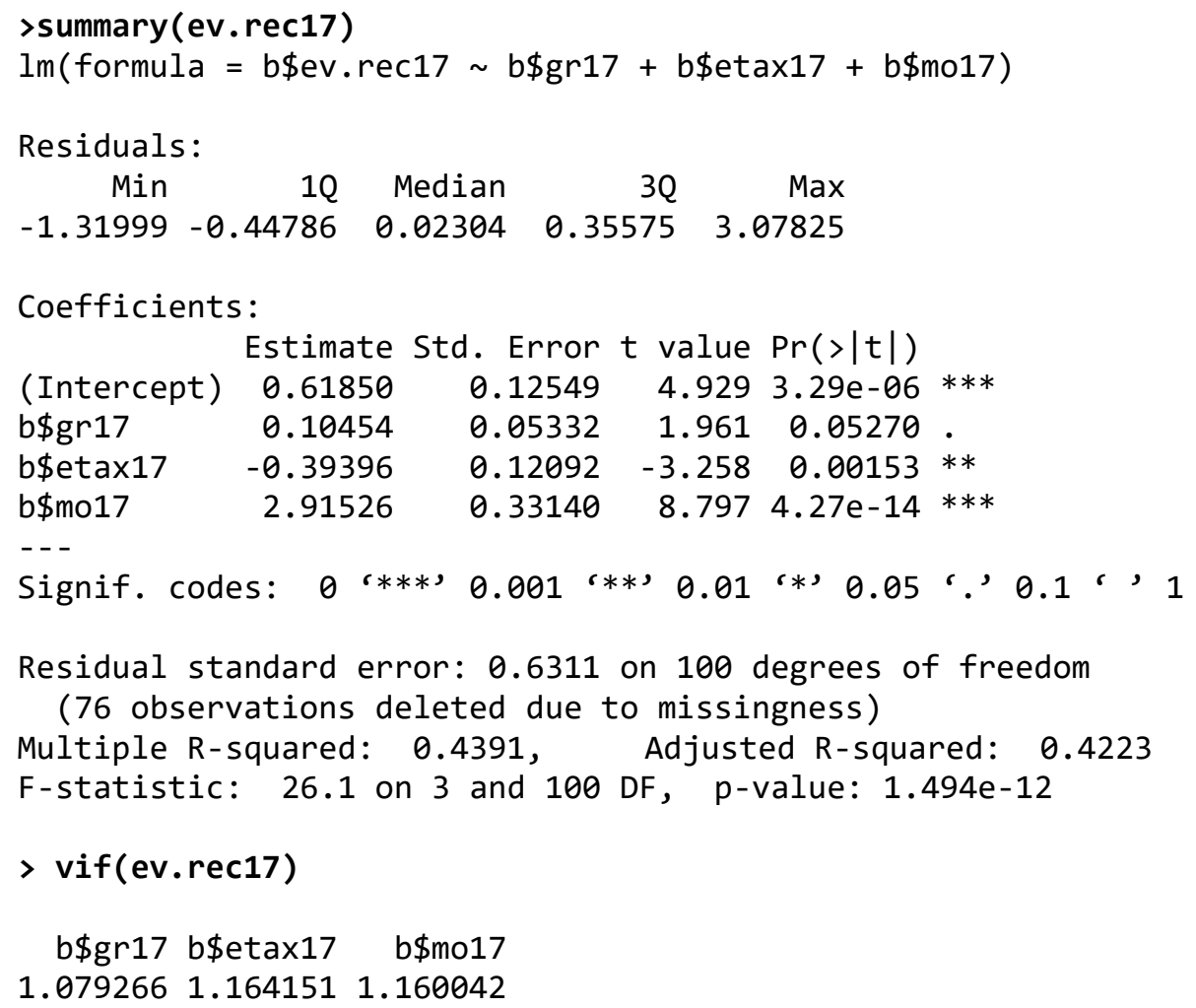

\section{Output modelo EV/Receita 2018:}

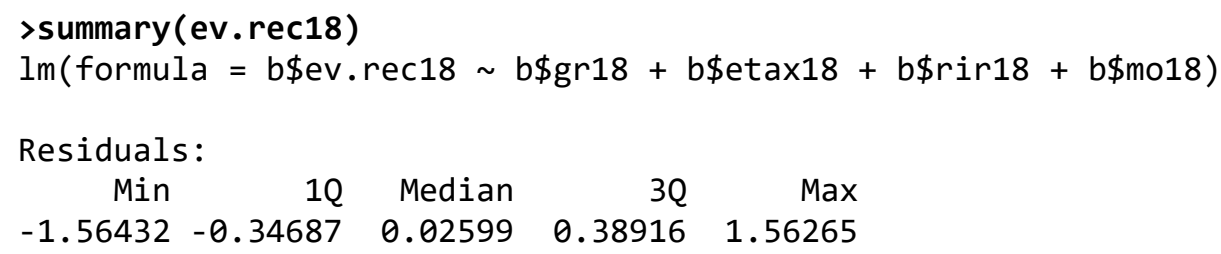


Coefficients:

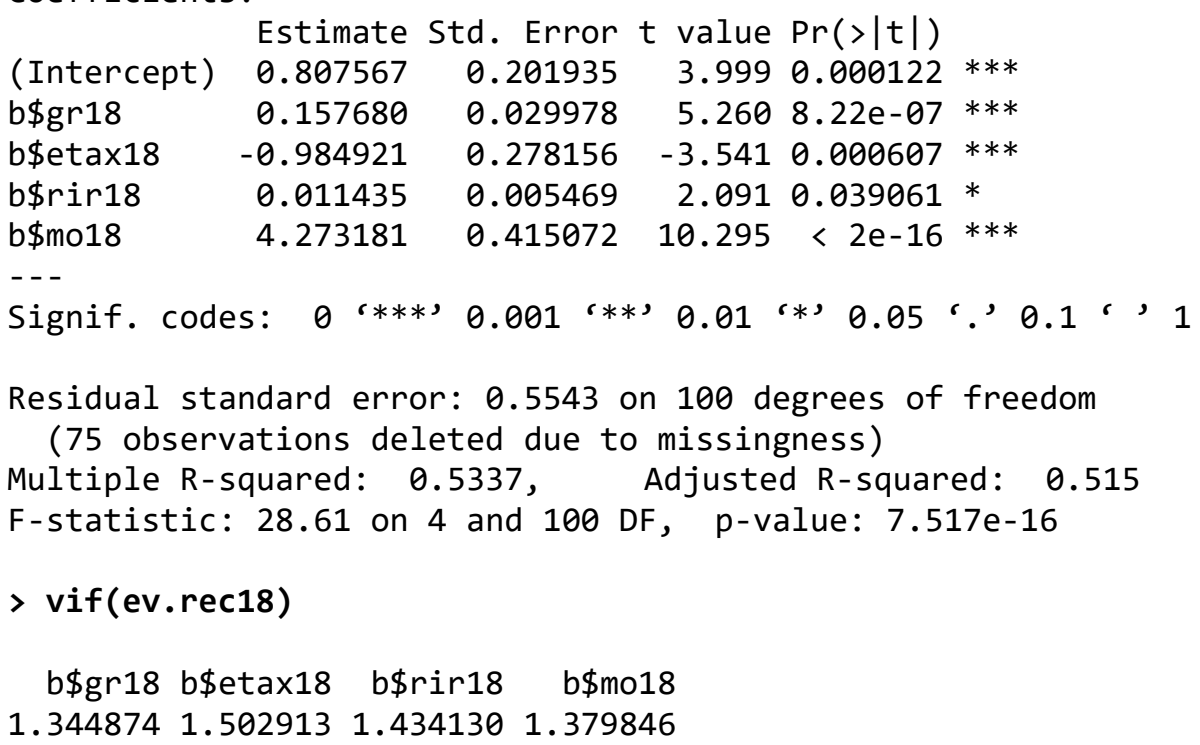




\section{Anexo 3 - Box plot das variáveis dependentes e explicativas}

Figura 23 - Box plot P/L 2015 a 2018

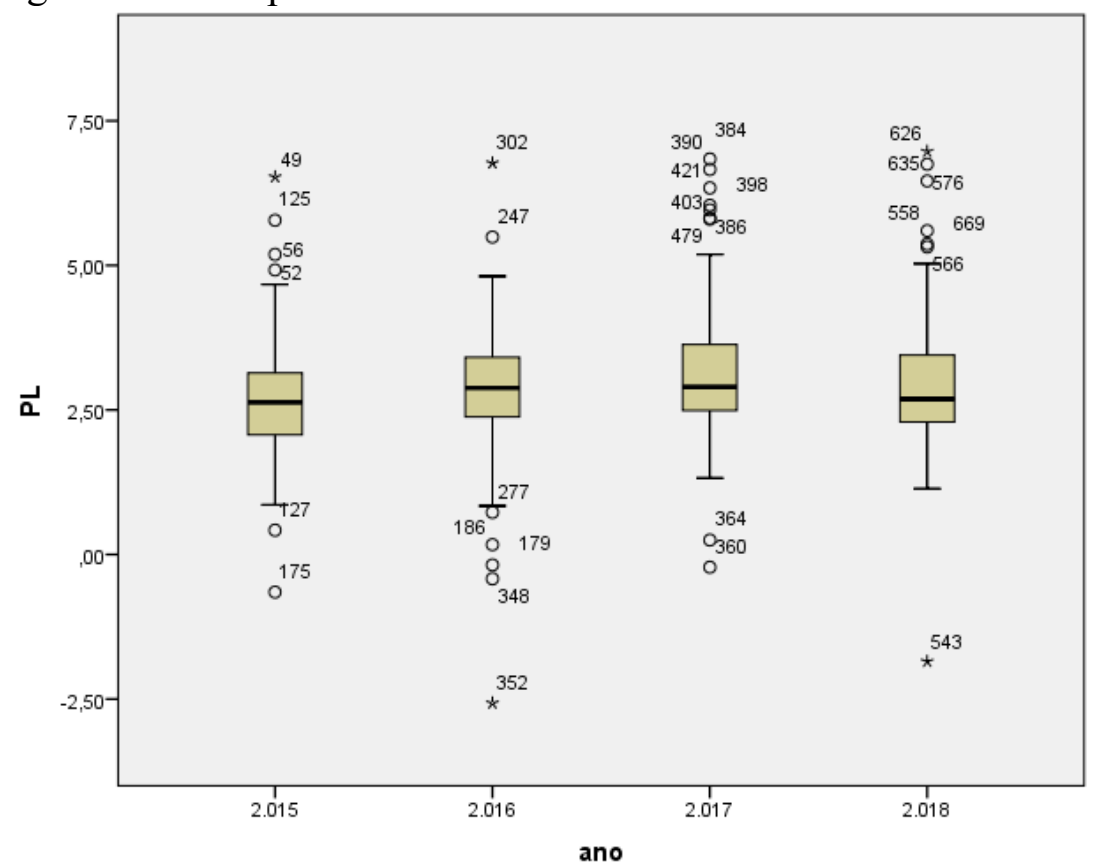

Figura 24 - Box plot P/PLC 2015 a 2018

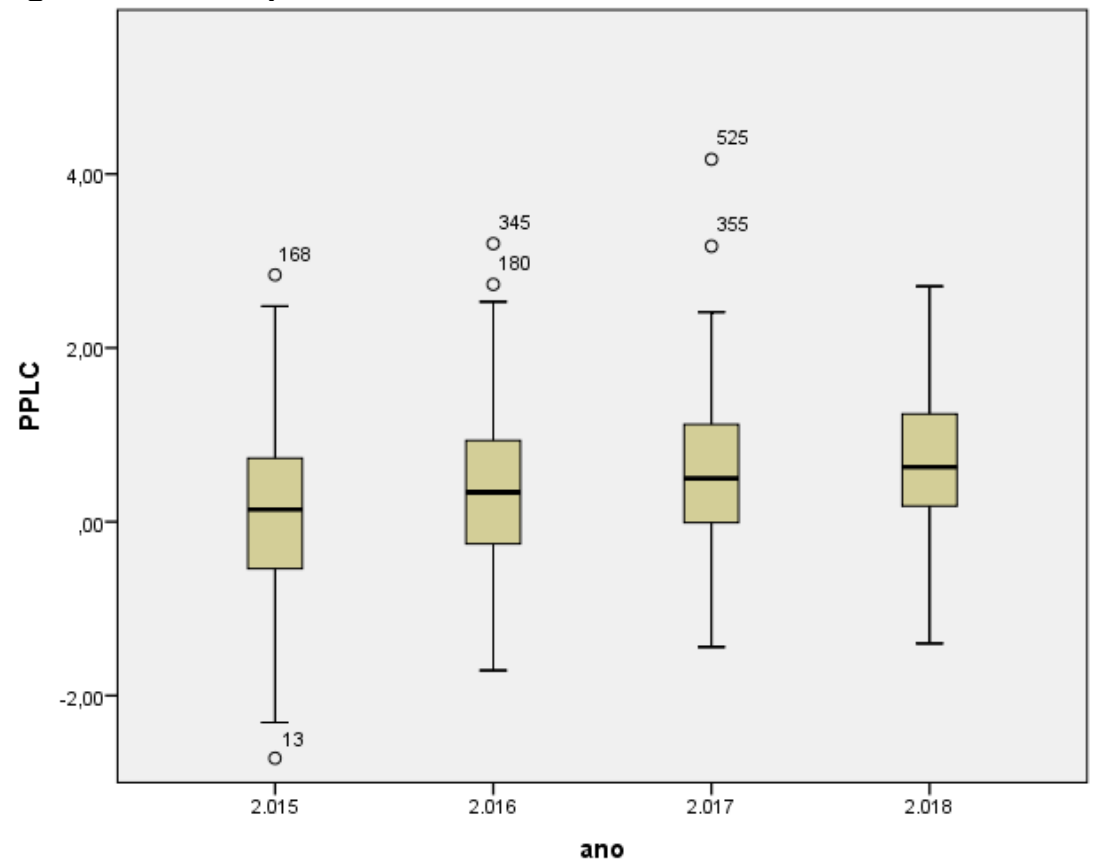


Figura 25 - Box plot g1 2015 a 2018

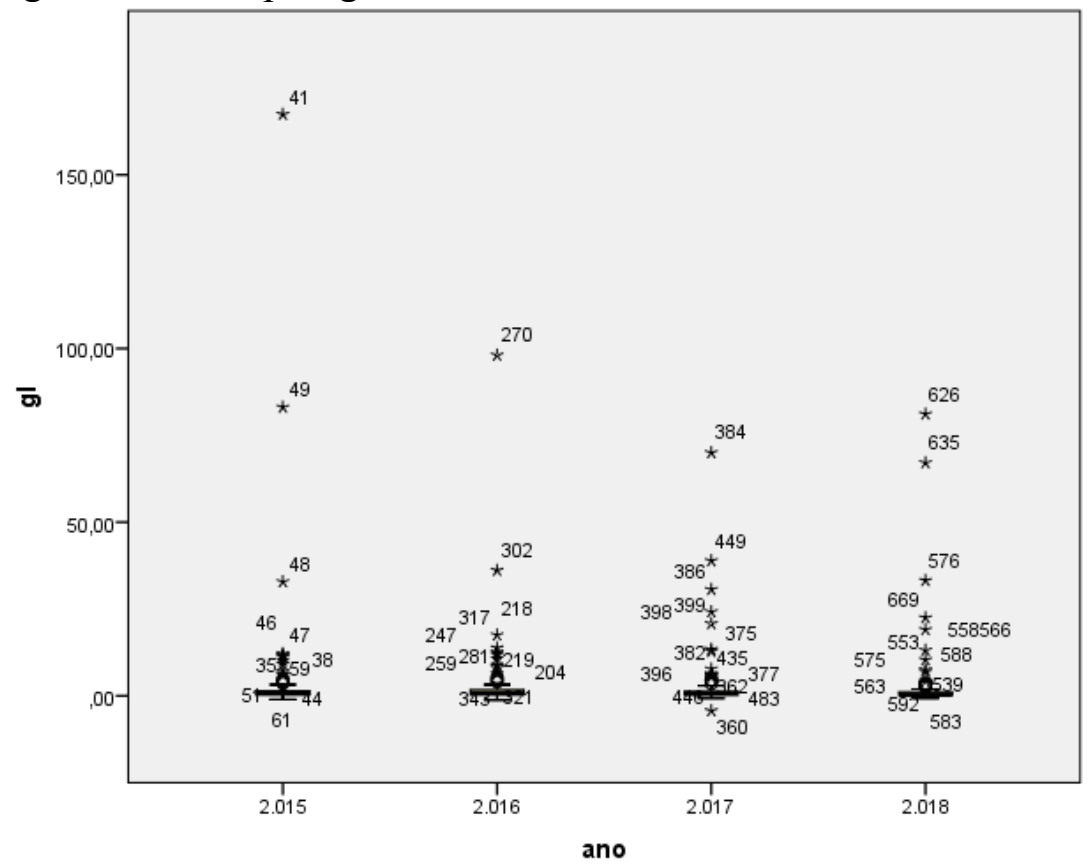

Figura 26 - Box plot ewacc 2015 a 2018

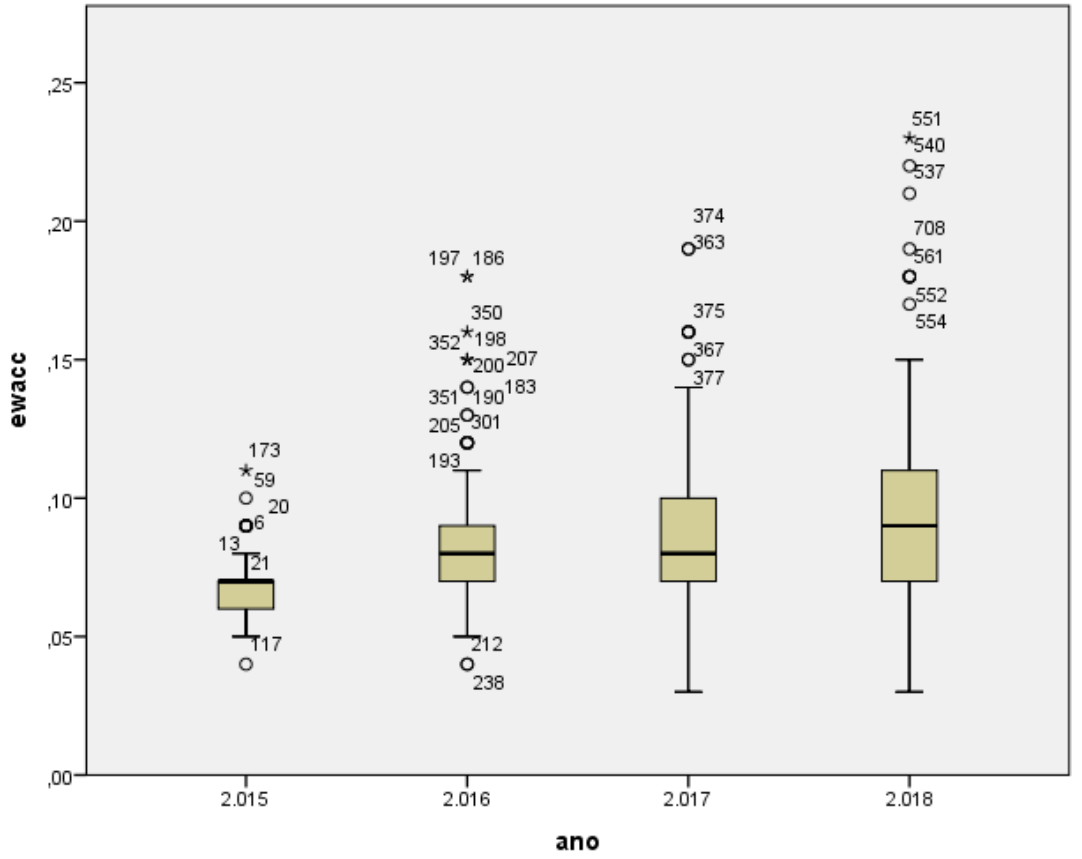


Figura 27 - Box plot po 2015 a 2018

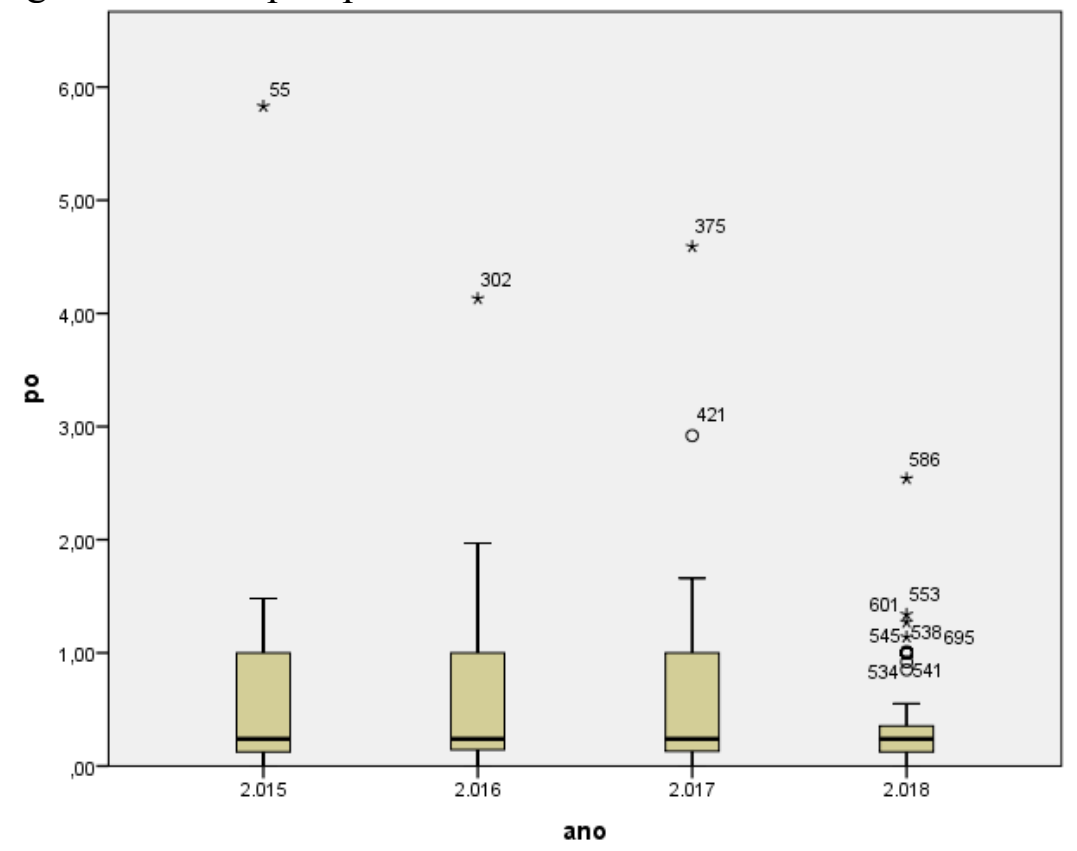

Figura 28 - Box plot roe 2015 a 2018

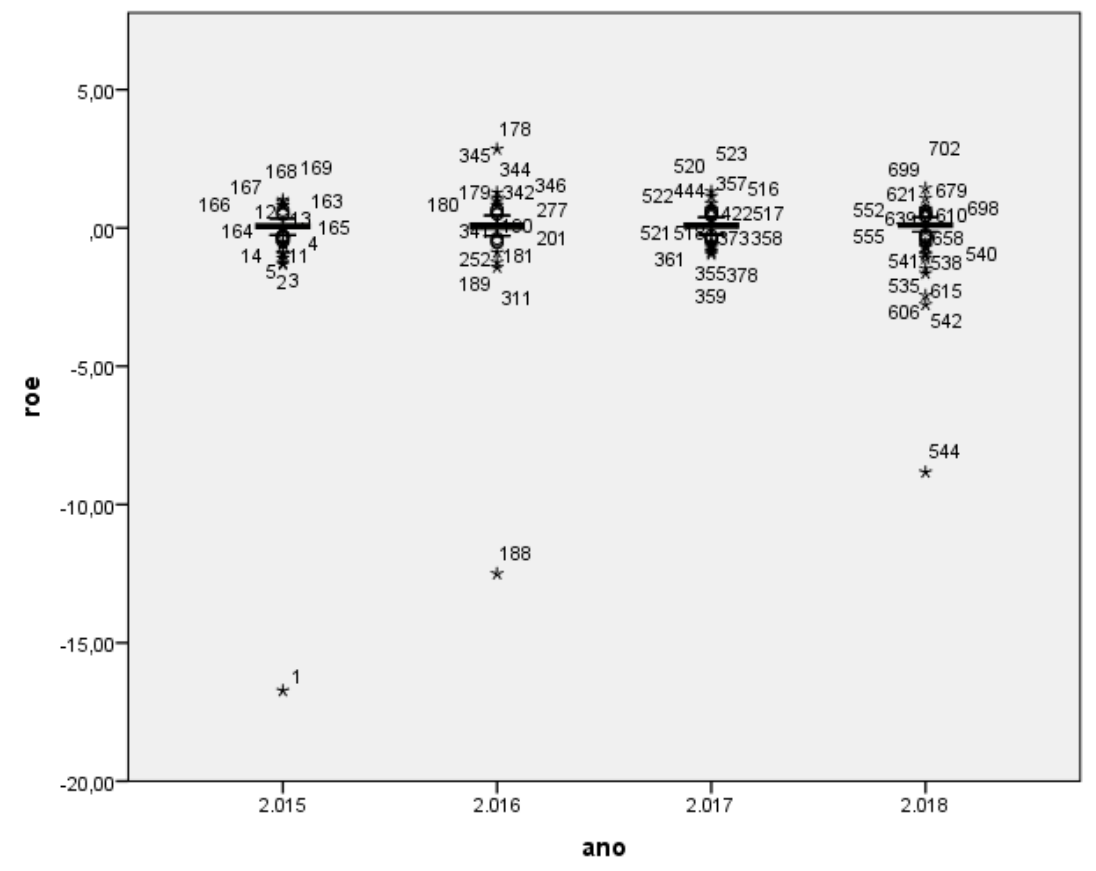


Figura 29 - Box plot EV/EBITDA 2015 a 2018

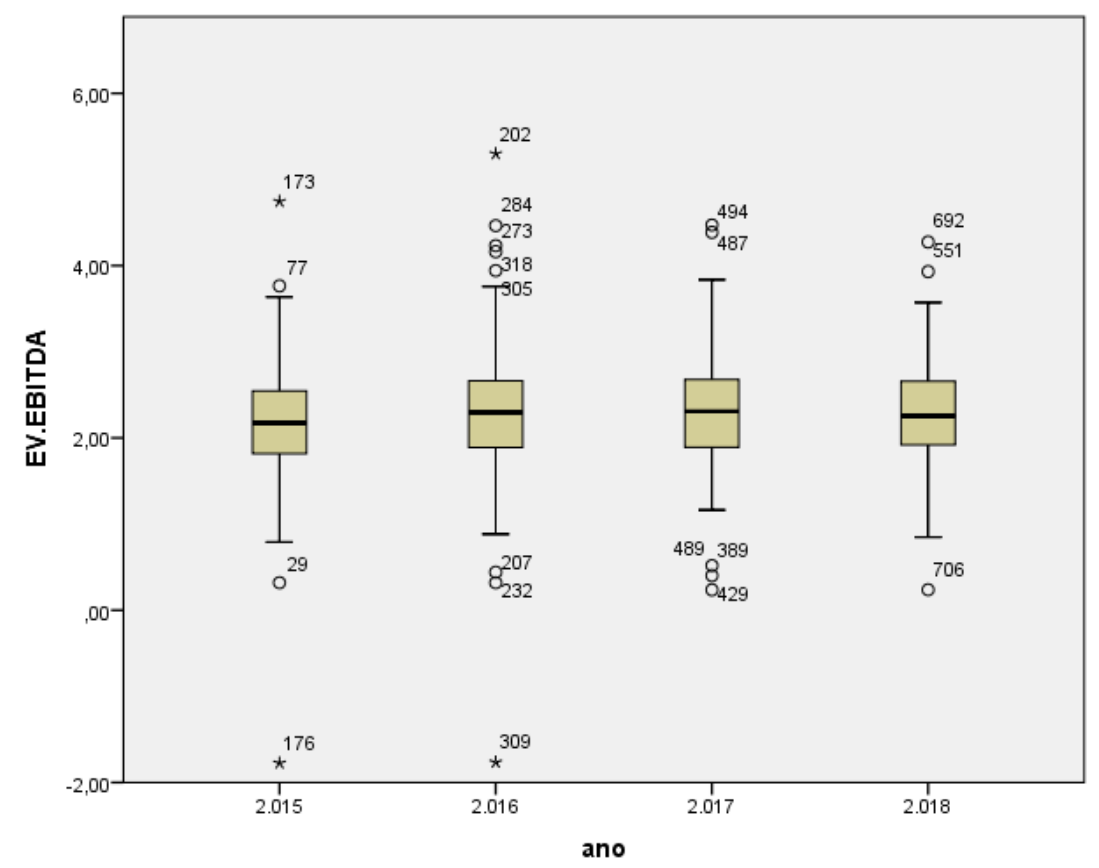

Figura 30 - Box plot EV/IC 2015 a 2018

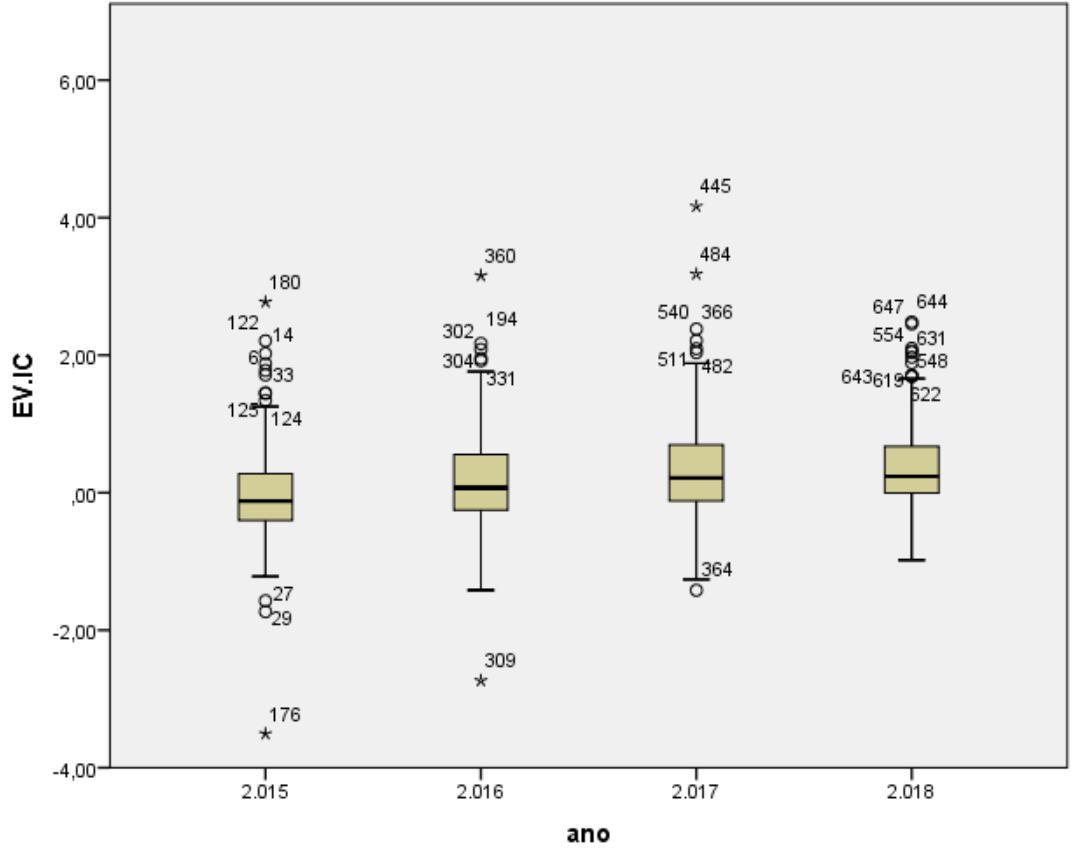


Figura 31 - Box plot EV/Receita 2015 a 2018

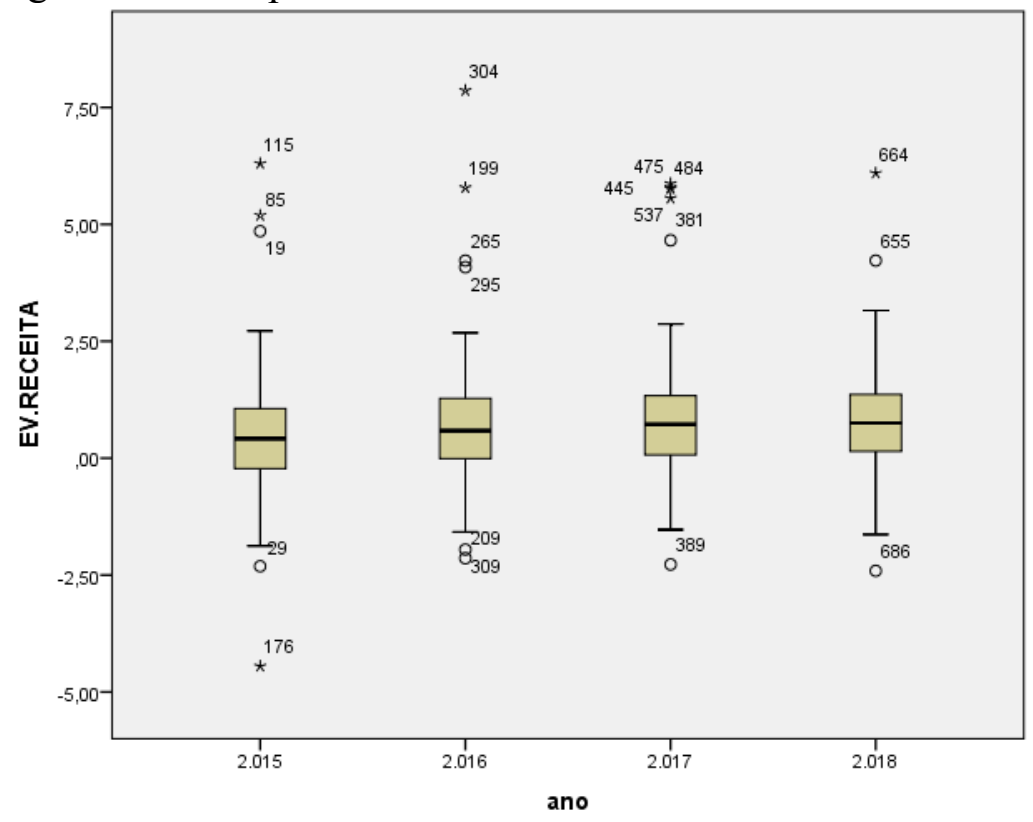

Figura 32 - Box plot gr 2015 a 2018

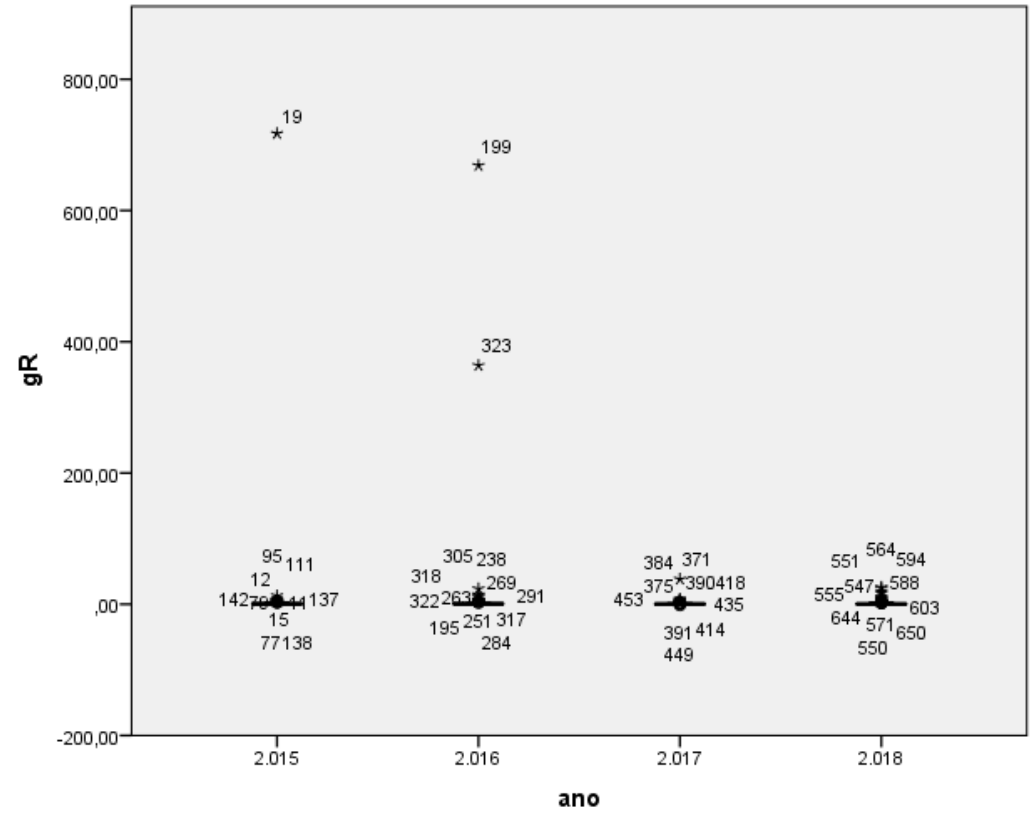


Figura 33 - Box plot wacc 2015 a 2018

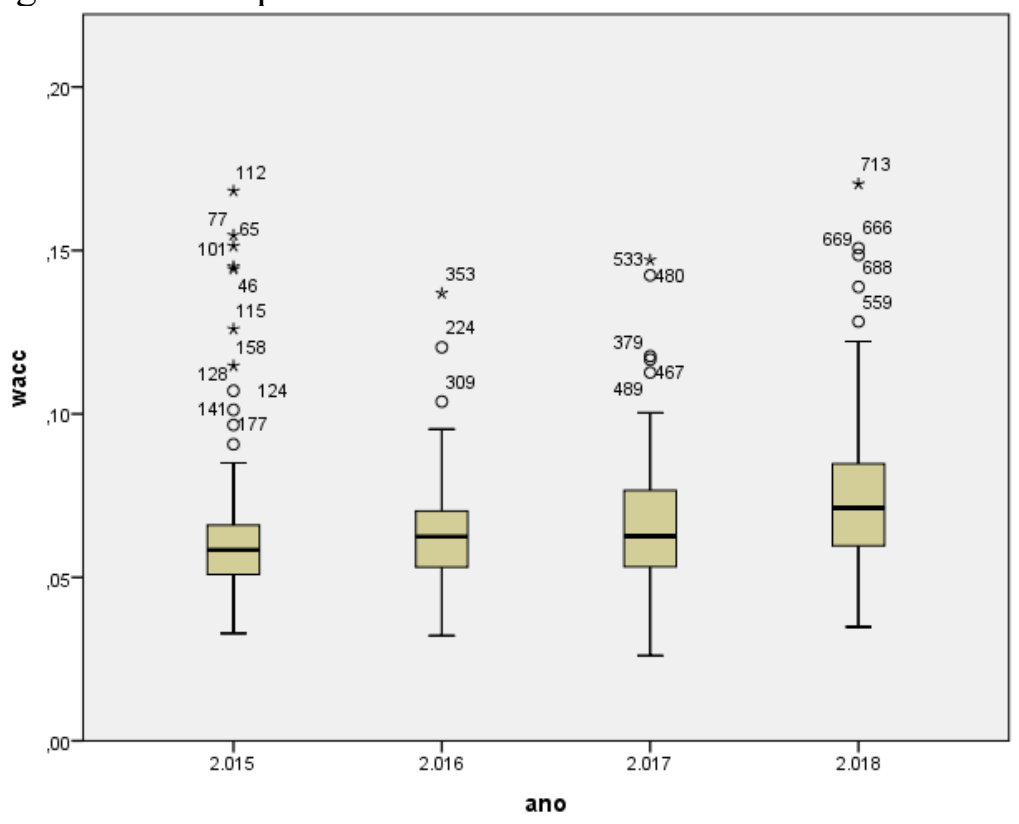

Figura 34 - Box plot roic 2015 a 2018

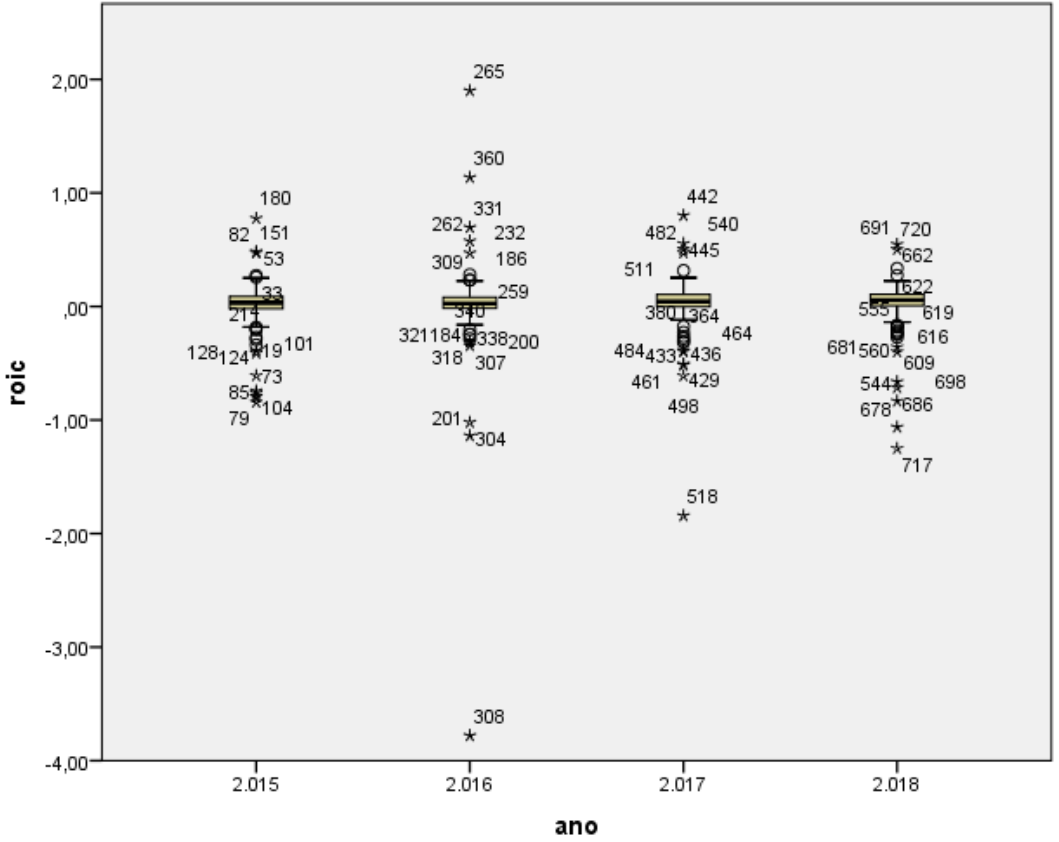


Figura 35 - Box plot rir 2015 a 2018

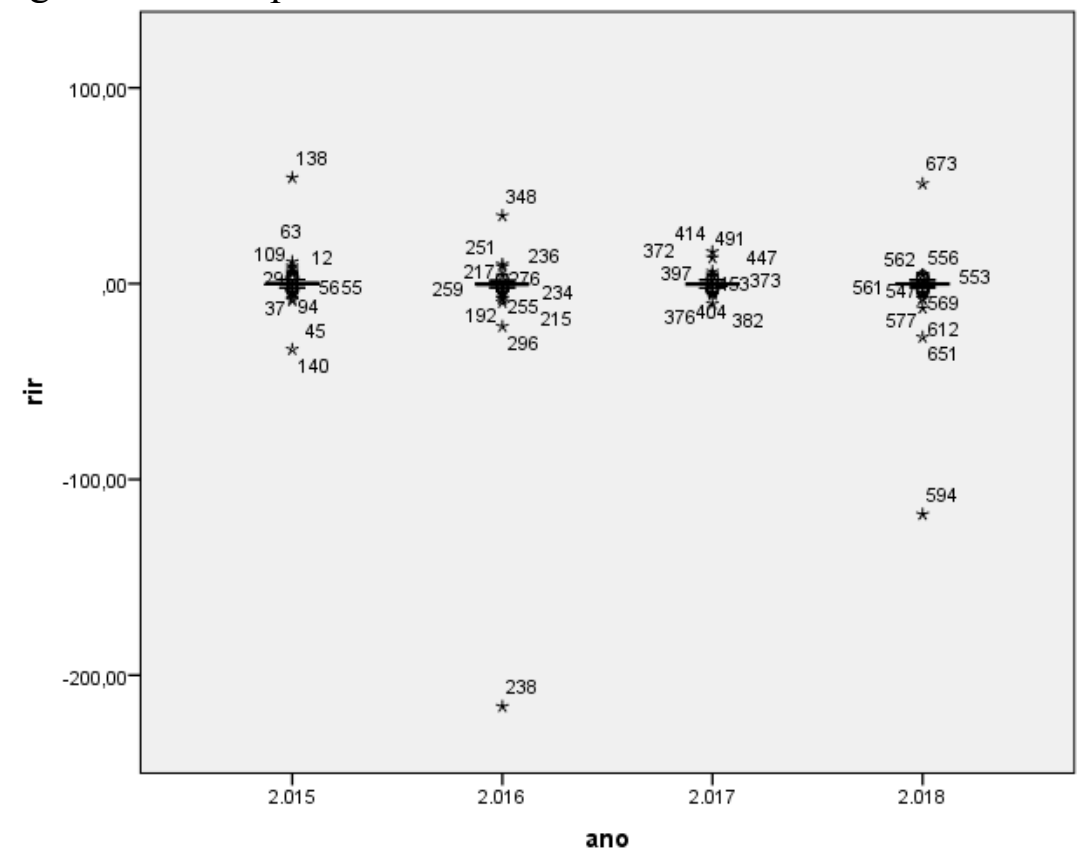

Figura 36 - Box plot etax 2015 a 2018

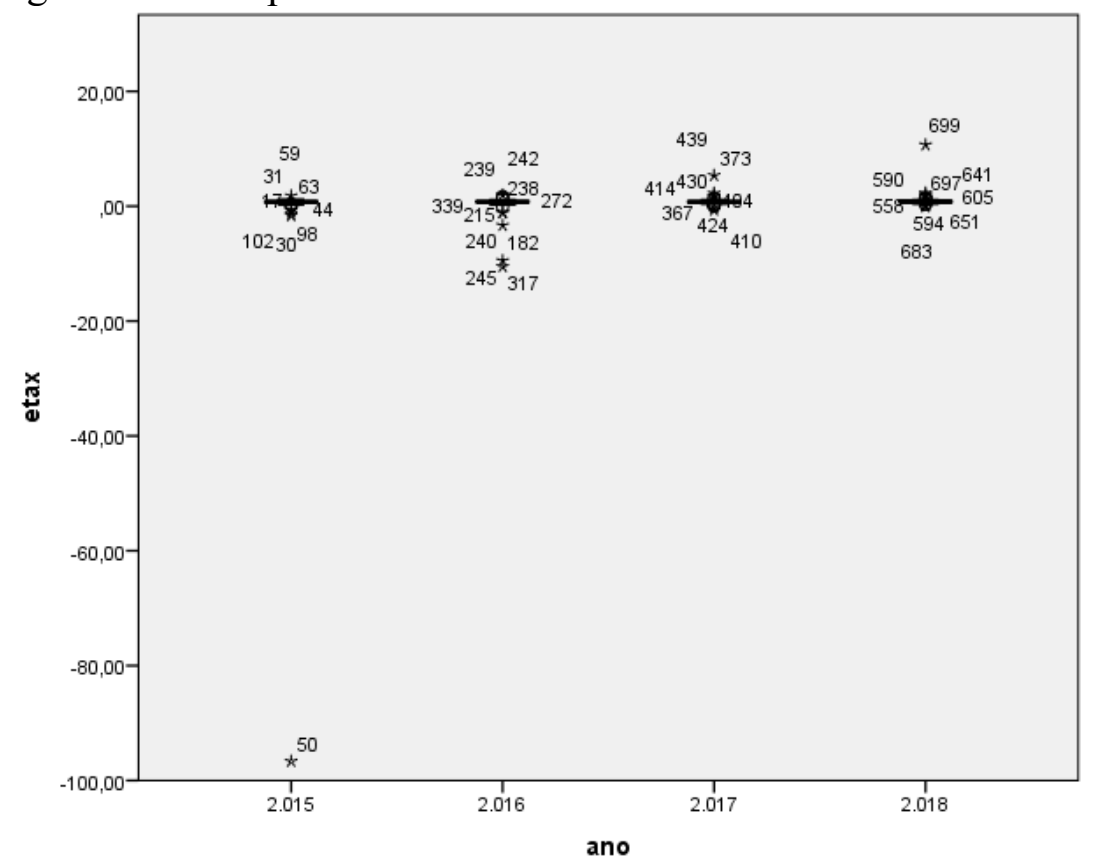


Figura 37 - Box plot mo 2015 a 2018

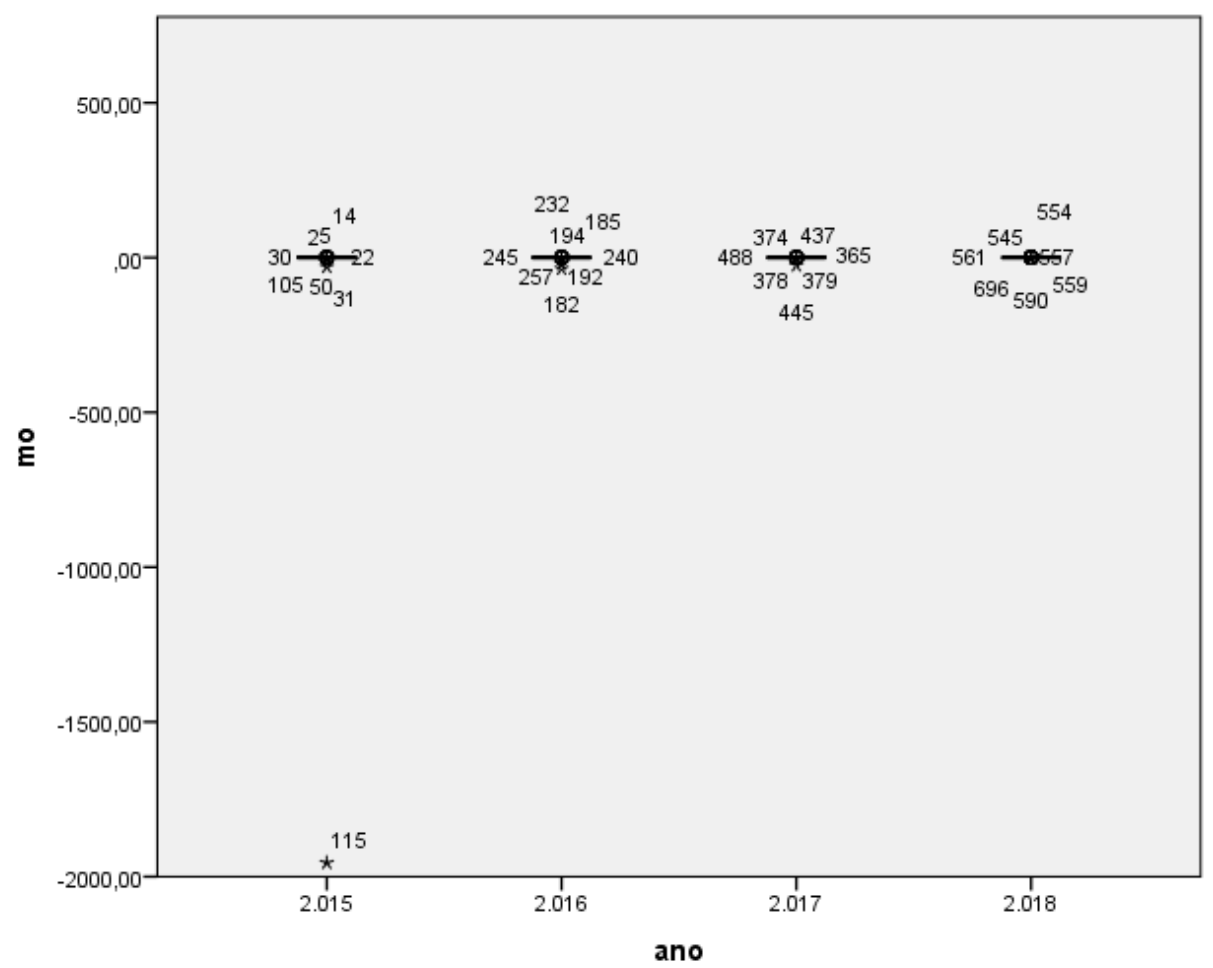

